\title{
3D Seismic, Mechanical Stratigraphy, and Petrophysical Analysis of the Marcellus Shale in Taylor County, West Virginia
}

\author{
Derek Weicht
}

Follow this and additional works at: https://researchrepository.wvu.edu/etd

\section{Recommended Citation}

Weicht, Derek, "3D Seismic, Mechanical Stratigraphy, and Petrophysical Analysis of the Marcellus Shale in Taylor County, West Virginia" (2015). Graduate Theses, Dissertations, and Problem Reports. 6930.

https://researchrepository.wvu.edu/etd/6930

This Thesis is protected by copyright and/or related rights. It has been brought to you by the The Research Repository @ WVU with permission from the rights-holder(s). You are free to use this Thesis in any way that is permitted by the copyright and related rights legislation that applies to your use. For other uses you must obtain permission from the rights-holder(s) directly, unless additional rights are indicated by a Creative Commons license in the record and/ or on the work itself. This Thesis has been accepted for inclusion in WVU Graduate Theses, Dissertations, and Problem Reports collection by an authorized administrator of The Research Repository @ WVU. For more information, please contact researchrepository@mail.wvu.edu. 
3D Seismic, Mechanical Stratigraphy, and Petrophysical Analysis of the Marcellus Shale in Taylor County, West Virginia

\author{
Derek Weicht \\ Thesis submitted to the \\ Eberly College of Arts and Sciences \\ at West Virginia University \\ in partial fulfillment of the requirements \\ for the degree of \\ Master of Science \\ in \\ Geology
}

Thomas H. Wilson, Ph.D., Chair

John Ryan Shackleton, Ph.D.

Timothy R. Carr, Ph.D.

Department of Geology and Geography

Morgantown, West Virginia

2015

Keywords: Marcellus Shale, Appalachian Basin, 3D Seismic, Spectral Blueing, Lambdarho, Mu-rho, Mechanical Stratigraphy, Petrophysics

Copyright $\odot 2015$ Derek Weicht 


\section{Abstract \\ 3D Seismic, Mechanical Stratigraphy, and Petrophysical Analysis of the Marcellus Shale in Taylor County, West Virginia \\ Derek Weicht}

The Marcellus Shale is a Devonian age black shale formed during the Acadian Orogeny along the eastern margin of North America. The Middle Devonian Marcellus Shale is an unconventional shale-gas reservoir that has been a major target of seismic exploration and gas extraction using hydraulic fracturing and horizontal drilling. This study focuses on analyses of seismic response, mechanical, and petrophysical properties of the Marcellus Shale and surrounding strata in Taylor County, West Virginia.

Spectral blueing was performed on the post stack migration seismic volume to enhance the resolution. The resolution of the volume was increased from 61 feet to 47 feet, which improved the detail observed in the seismic response and provided additional insights in the interpretation of the Marcellus and bounding intervals. The isochore map created from the modified Marcellus picks shows greater variability in the thickness of the Marcellus, with an overall trend of thickening to the east. Within the thicker part of the Marcellus, a second negative reflection event appeared that was not obvious in the post stack migration. This event was interpreted to be part of the Lower Marcellus Shale.

Lambda-rho and Mu-rho parameters were calculated using compressional and shear wave vibrations and density obtained from the well logs. When combined with the Young's modulus and Poisson's ratio, these cross-plots are indicative of favorable brittle and total organic carbon (TOC) rich zones that highlight potential drilling targets in the Marcellus. TOC was estimated using the Schmoker and Passey methods, and provide very similar estimates within the Marcellus Shale. Specifically note that the Middle and Lower Marcellus are generally the more TOC rich and productive Marcellus zones. 


\section{Acknowledgements}

A huge thank you to my advisor, Dr. Wilson, for all the guidance and mentoring you have done throughout my thesis. Also, thank you to my committee, Dr. Shackleton and Dr. Carr for all the suggestions and ideas during my time at WVU.

Special thanks to PDC Mountaineer, LLC and Mountaineer Keystone, LLC for providing all the essential seismic and well data, without which I could not have done this project. Also, many thanks to Schlumberger, SMT, IHS, and dGB for use of their Petrel, Kingdom, Petra, and Opendtect software. These were invaluable tools throughout the entirety of my thesis.

Thanks to Payam Kavousi for his knowledge and assistance using the Opendtect software.

Thank you to my parents for all your support. I would not have had all the opportunities without your love and guidance thus far in my life.

Lastly, thank you to my fiancé, Kendi Waltemyer, who always helped to keep me driven even while you had all the responsibilities of graduate school yourself. Your love and support helped immensely. 


\section{Table of Contents}

$\begin{array}{ll}\text { Abstract } & \text { ii }\end{array}$

$\begin{array}{ll}\text { Acknowledgements } & \text { iii }\end{array}$

Table of Contents $\quad$ iv

List of Figures $\quad$ vi

$\begin{array}{ll}\text { Chapter 1, Introduction } & 1\end{array}$

Chapter 2, Geologic Setting 5

2.1 Physiographic Setting 5

$\begin{array}{ll}2.2 \text { Stratigraphy } & 7\end{array}$

2.3 Tectonic Events 12

2.4 Deposition 13

$\begin{array}{ll}\text { Chapter 3, Seismic Interpretation } & 15\end{array}$

3.1 Synthetic Generation, Tie to Well, and Vertical Resolution Limits 15

3.2 Spectral Blueing 20

3.3 Structural Analysis 31

Chapter 4, Mechanical Stratigraphy 36

4.1 Mechanical Properties 36

4.2 Brittleness 36

4.3 Lambda-rho/Mu-rho 39

$\begin{array}{lr}\text { Chapter 5, Petrophysics } & 59\end{array}$

5.1 Total Organic Carbon $\quad 59$

$\begin{array}{ll}\text { 5.2 Mineralogy } & 64\end{array}$ 
Chapter 7, References 


\section{List of Figures}

Figure 1-1. West Virginia Geologic Map with seismic and well location (WVGS).............2

Figure 1-2. General stratigraphic column of the Devonian stratigraphy in West Virginia (Milici

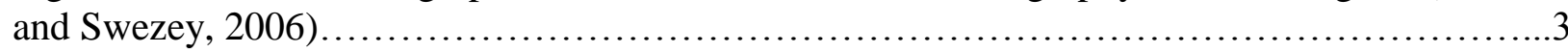

Figure 1-3. Type log showing the Middle Devonian stratigraphy at the Armstrong \#1 well......4

Figure 2-1. Appalachian Plateau physiographic province. Study area outlined in red square. Note high plateau in the stippled area (Modified from Shumaker, 2002$) \ldots \ldots \ldots \ldots \ldots \ldots \ldots \ldots \ldots \ldots$

Figure 2-2. Extent of the Marcellus shale and its stratigraphic location. Study area outlined in red. (Penn State Marcellus Center for Outreach and Research, 2010).......................7

Figure 2-3a. Log responses of the Middle Devonian stratigraphic section observed in the

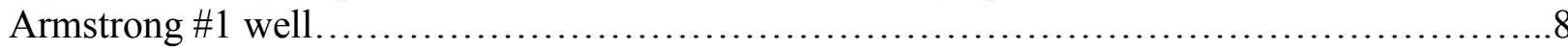

Figure 2-3b. Log response of the Marcellus Shale section observed in the Armstrong \#1 well in Taylor County, WV ...........................................................

Figure 2-4a. Log responses of the Middle Devonian stratigraphic section observed in the Curtis well............................................................................ 10

Figure 2-4b. Log response of the Marcellus Shale section observed in the Curtis well in Taylor

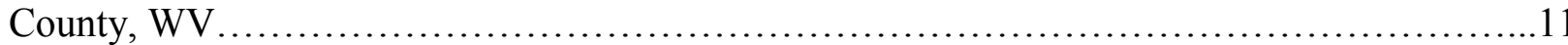

Figure 2-5. Formation of eastern Appalachian Mountains by time period. Modified from Zhu

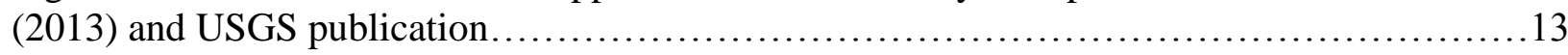

Figure 2-6. Depositional wedge of the Marcellus shale (Boyce, 2010)....................... 14

Figure 3-1. Spectrum of the extracted wavelet of the post stack migration data over the time of

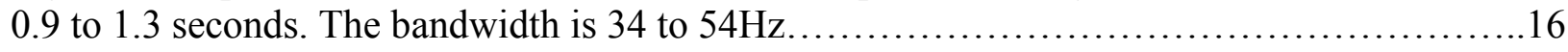

Figure 3-2. View of the extracted wavelet created from parameters in the previous figure. The

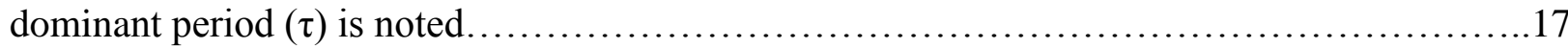

Figure 3-3. A) Seismic wavelet, B) Calibration curves used to identify tuning time, which

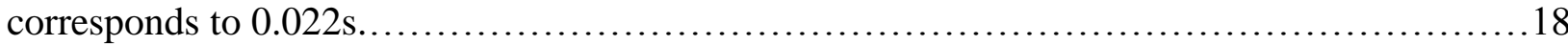

Figure 3-4. Synthetic seismogram computed for the Armstrong \#1 well. Key formation tops are

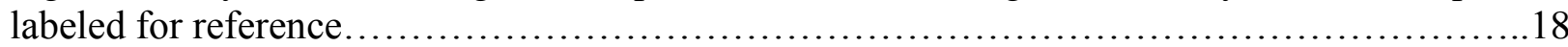

Figure 3-5b. Armstrong \#1 well synthetic shows the correlation of events associated with the Marcellus and bounding strata to the local seismic response. The synthetic is overlain on the seismic at crossline 60 
Figure 3-6. Computed spectrum of the extracted wavelet over the time of 0.9 to 1.3 seconds. The

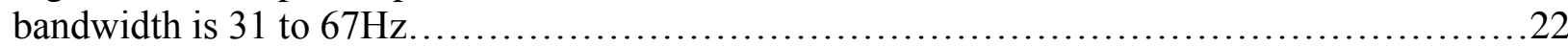

Figure 3-7. Wavelet extracted from the original seismic (blue) with a time from side lobe to side lobe of $22 \mathrm{~ms}$ and spectral blueing (red) with a time from side lobe to side lobe of $17 \mathrm{~ms} . . \ldots \ldots 22$

Figure 3-8. A) Seismic wavelet, B) Calibration curves used to identify tuning time, which

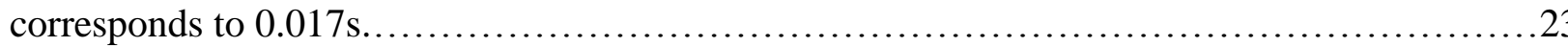

Figure 3-9. New synthetic created based on a wavelet extracted from the spectral blueing volume.

Figure 3-10. Post stack migration - original seismic volume at the Armstrong \#1 well at inline 140.

Figure 3-11. A) Spectral Blueing applied to seismic. B) Zoomed in view of the Marcellus and

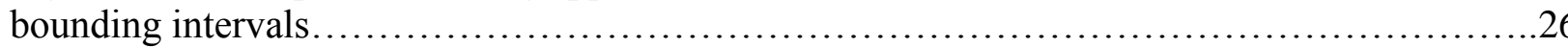

Figure 3-12. Improved pick comparison in the original seismic (A) and spectral blueing (B). Purple line is the pick from Zhu (2013) and the yellow line is the new pick based on the spectral blueing. ... .27

Figure 3-13. Zoomed in view of the picks from the Tully to Onondaga in the original seismic (A)

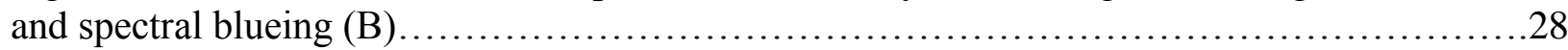

Figure 3-14. View of the post stack migration inline 80 at the Curtis well..................29

Figure 3-15. A) Spectral Blueing applied to seismic. B) Zoomed in view of the Marcellus and

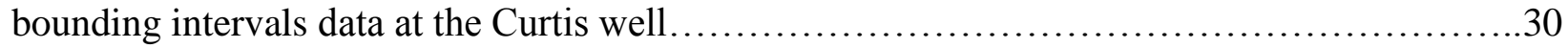

Figure 3-16. Marcellus Shale structure interpreted by Zhu (2013). The direction of $\sigma_{1}$ is interpreted as the direction of the paleo maximum compressive principle stress....

Figure 3-17. Marcellus structure map based on the picks from the spectral blueing. Improved visualization of structural disruption (red lines) in the syncline to the northwest can be seen......32

Figure 3-18. Isochore map of the Marcellus picked on the migrated stack volume showing some thickening toward the east. An estimated increase in thickness moving to the east from $90 \mathrm{ft}$ to $120 \mathrm{ft}$ is occurring

Figure 3-19. Isochore map of the Marcellus from horizons picked in the spectral blueing volume. The Marcellus seems to be generally increasing to the east (as indicated by the red arrow) from $85 \mathrm{ft}$ to about $140 \mathrm{ft}$, a bit more than the isochore interpretation from the post stack migration. The hummocky nature of this isochore map shows improved detail in the changing thickness of the Marcellus. 
Figure 4-1. Cross plot of Young's modulus and Poisson's ratio colored by brittleness at the

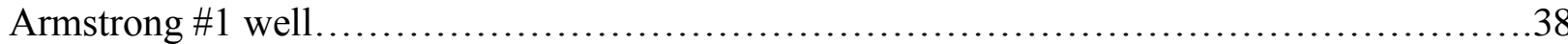

Figure 4-2. Cross plot of Mu-rho and Lambda-rho colored by brittleness at the Armstrong \#1

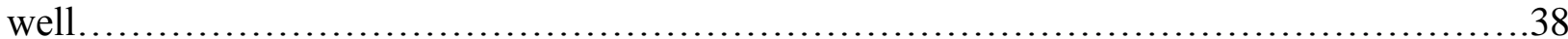

Figure 4-3a. Lower Barnett reservoir quality classification based on seismically inverted rock properties. Four groups are defined: Group 0 or Brittle and TOC rich (black circle), Group 1 or TOC rich and ductile, Group 2 or Brittle and TOC poor, and Group 3 or Ductile and TOC poor. Cut offs selected to make each group as even a possible. Figure from Alzate (2012)...........40

Figure 4-3b. Seismic Lambda-rho/Mu-rho extracted along the wellbores with production logs. The color indicates the gas rate at each individual perforation. Figure from Alzate (2012). The black circle represents the brittle and TOC rich zone..................................40

Figure 4-4a. Cross plot of Mu-rho and Lambda-rho colored by Young's modulus at the Armstrong \#1 well. The brittle and TOC rich zone based on Alzate (2012) is circled in red......42

Figure 4-4b. Cross plot of Mu-rho and Lambda-rho colored by Poisson's ratio at the Armstrong \#1 well. The brittle and TOC rich zone based on Alzate (2012) is circled in red.....

Figure 4-5. Cross plot of Young's modulus and Poisson's ratio colored by TOC at the Armstrong \#1 well. The data points within the purple box are those that fall into the Alzate (2012) classification of brittle and rich. Data points within the purple box are shown stratigraphically in the next figure.

Figure 4-6. Boolean log created based on previous figure of the brittle and rich data points. Areas labeled with green "true" correspond to the purple region selected in previous figure, which is the TOC rich and brittle zone. The upper and lower limits of the producing zone is distinguished

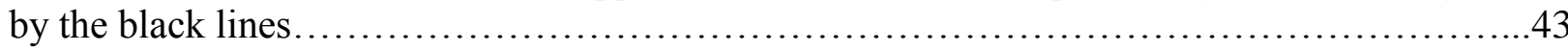

Figure 4-7a. Lambda-rho/Mu-rho cross-plot colored by Young's modulus with Alzate (2012) cut-offs at the Curtis well.................................................................44

Figure 4-7b. Lambda-rho/Mu-rho cross-plot colored by Poisson's ratio with Alzate (2012) cutoffs at the Curtis well. .................................................................44

Figure 4-8. Cross plot of Young's modulus and Poisson's ratio colored by TOC at the Curtis well. The data points within the purple box are those that fall into the Alzate (2012) classification of brittle and rich. Data points within the purple box are shown stratigraphically in the next figure.

Figure 4-9. Boolean log created based on previous figure of the brittle and rich data points. Areas labeled with green "true" correspond to the green region selected in previous figure, which is the TOC rich and brittle zone. The upper and lower limits of the producing zone is distinguished by the black lines... 
Figure 4-10. Cross plot of Mu-rho and Lambda-rho colored by TOC at the Armstrong \#1 well. Data points within the area selected in blue are shown stratigraphically in the next figure.......47

Figure 4-11. Boolean Log created based on previous figure. Areas labeled with green "true" correspond to the blue region selected in previous figure with low lambda-rho/mu-rho.

Figure 4-12. Cross plot of Mu-rho and Lambda-rho colored by TOC at the Curtis. Data points within the area selected in yellow are shown stratigraphically in the next figure....

Figure 4-13. Boolean Log created based on previous figure. Areas labeled with green "true" correspond to the yellow region selected in previous figure with low lambda-rho/mu-rho. ...

Figure 4-14a. Lambda-rho/Mu-rho colored by Young's modulus with modified cut-offs at the

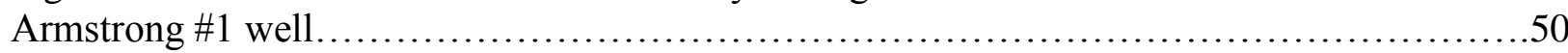

Figure 4-14b. Lambda-rho/Mu-rho colored by Poisson's ratio with modified cut-offs at the

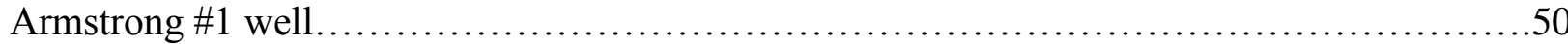

Figure 4-15a. Lambda-rho/Mu-rho cross-plot colored by Young's modulus with modified cutoffs at the Curtis well. .................................................................

Figure 4-15b. Lambda-rho/Mu-rho cross-plot colored by Poisson's ratio with modified cut-offs at the Curtis well.................................................................... 51

Figure 4-16. Modified selection criteria (green square) compared to the Alzate (2012) selection criteria (purple) with data from the Armstrong \#1 well .................................52

Figure 4-17. Modified selection criteria (green square) compared to the Alzate (2012) selection criteria (purple) with data from the Curtis well...........................................52

Figure 4-18. Armstrong \#1 well potential production intervals based on the modified parameters on the left Boolean log with Alzate (2012) parameters on the right log. The upper and lower limits of the producing zone is distinguished by the black lines. Potential new target zones are shown by the black arrows

Figure 4-19. Curtis well potential production intervals based on the modified parameters on the left Boolean log with the Alzate (2012) parameters on the right log. The upper and lower limits of the producing zone is distinguished by the black lines. Potential new target zones are shown

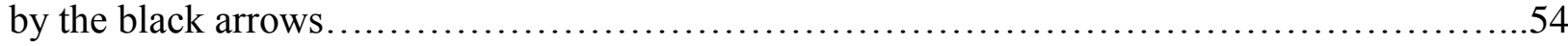

Figure 4-20a. Production comparison of the Armstrong \#1 and Curtis wells each year from 2009 to 2013. Production data was taken from WVGES Pipeline Plus...........................55

Figure 4-20b. Production comparison of the average and total production of the Armstrong \#1 and Curtis wells from 2009 to 2013. Production data taken from WVGES Pipeline Plus........55 
Figure 4-21. Fracability estimate compared to the modified lambda-rho/mu-rho cut-offs at the Armstrong \#1 well. The black lines correspond to the top and base of the current producing interval. Confirmation of new potential targets, based on the fracability and lambda-rho/mu rho, are highlighted by the black arrows....

Figure 4-22. Fracability estimate compared to the modified lambda-rho/mu-rho cut-offs at the Curtis well. The black lines correspond to the top and base of the current producing interval. New potential targets, based on the fracability and lambda-rho/mu rho, are highlighted by the black arrows.

Figure 5-1. Schmoker TOC calculation through the Marcellus Shale at the Armstrong \#1 well plotted with gamma ray....

Figure 5-2. Overlying the sonic and resistivity curves through the Mahantango as a baseline for calculation of the Passey TOC estimate at the Armstrong \#1 well ..........................662

Figure 5-3a. Schmoker and Passey TOC calculations at the Armstrong \#1 well...............63

Figure 5-3b. Cross-plot of Schmoker and Passey TOC estimates colored by gamma ray indicating a mostly linear trend showing the correlations between the two methods.... .64

Figure 5-4. Photoelectric factor, density, and U plotted versus depth......................66

Figure 5-5. RHOmaa-Umaa from the Tully through Onondaga..........................67

Figure 5-6. Ternary mineralogy distribution of the Marble Falls Limestone, Upper Barnett Shale, Forestburg Limestone, and Lower Barnett Shale (Altamar and Marfurt, 2014)................68

Figure 5-7. RHOmaa and Umaa plotted with Passey and Schmoker TOC estimates............69

Figure 6-1. Tully through Huntersville Chert intervals showing how the TOC and brittleness change with RHOmaa and Umaa..................................................... 72

Figure 6-2. TOC comparison to RHOmaa/Umaa and brittleness at the Armstrong \#1 well......73

Figure 6-3. New target zones of the Armstrong \#1 well highlighted by the black boxes........74

Figure 6-4. New target zones of the Curtis well highlighted by the black boxes................75 


\section{Chapter 1}

\section{Introduction}

Shale gas drilling has occurred in the United States for almost two centuries (Rickman et al., 2008). The Marcellus Shale has become one of the most productive shale plays in the United States within the past five years with recent exploration of Marcellus Shale gas reserves relying heavily on hydraulic fracture treatment. Hydraulic fracture treatment produces fracture permeability in an otherwise impermeable rock and allows trapped gas to migrate to the wellbore. Much of the recent technology has facilitated rapid shale gas growth, exploitation, and development of the Marcellus.

The study area is located in northern West Virginia within Taylor County (Figure 1-1). The Marcellus Shale is a primarily dry gas producing formation (with some condensate), shifting to wet gas in the western area around Ohio, along the eastern United States. The Marcellus Shale has been extensively studied through outcrop, seismic, and well logs to understand its lithology, structure, and potential as a gas reservoir (Boyce, 2012, Engelder et al., 2009, Neal, 1979, Kargbo et al., 2010, Soeder and Kappel, 2009, Wang, 2012, and Zhu, 2013). The 3D seismic survey provided by the Petroleum Development Corporation (PDC) includes 197 inlines, 176 crosslines, 32 square miles of 3D seismic, and a well log suite on the Armstrong \#1 (API\# 4709101116) and Curtis (API\# 4709101108) wells.

Integrated log and 3-D seismic interpretation is used to characterize the subsurface geology, including examination of the structural complexity of the area. Mechanical and petrophysical properties help identify optimal zones for lateral placement and increased stimulation, and can tied back to the seismic response. Improvements in horizontal drilling and 
hydraulic fracture treatment technologies have opened the Marcellus Shale gas fairway to expanded exploration and development (Kargbo et al., 2010).

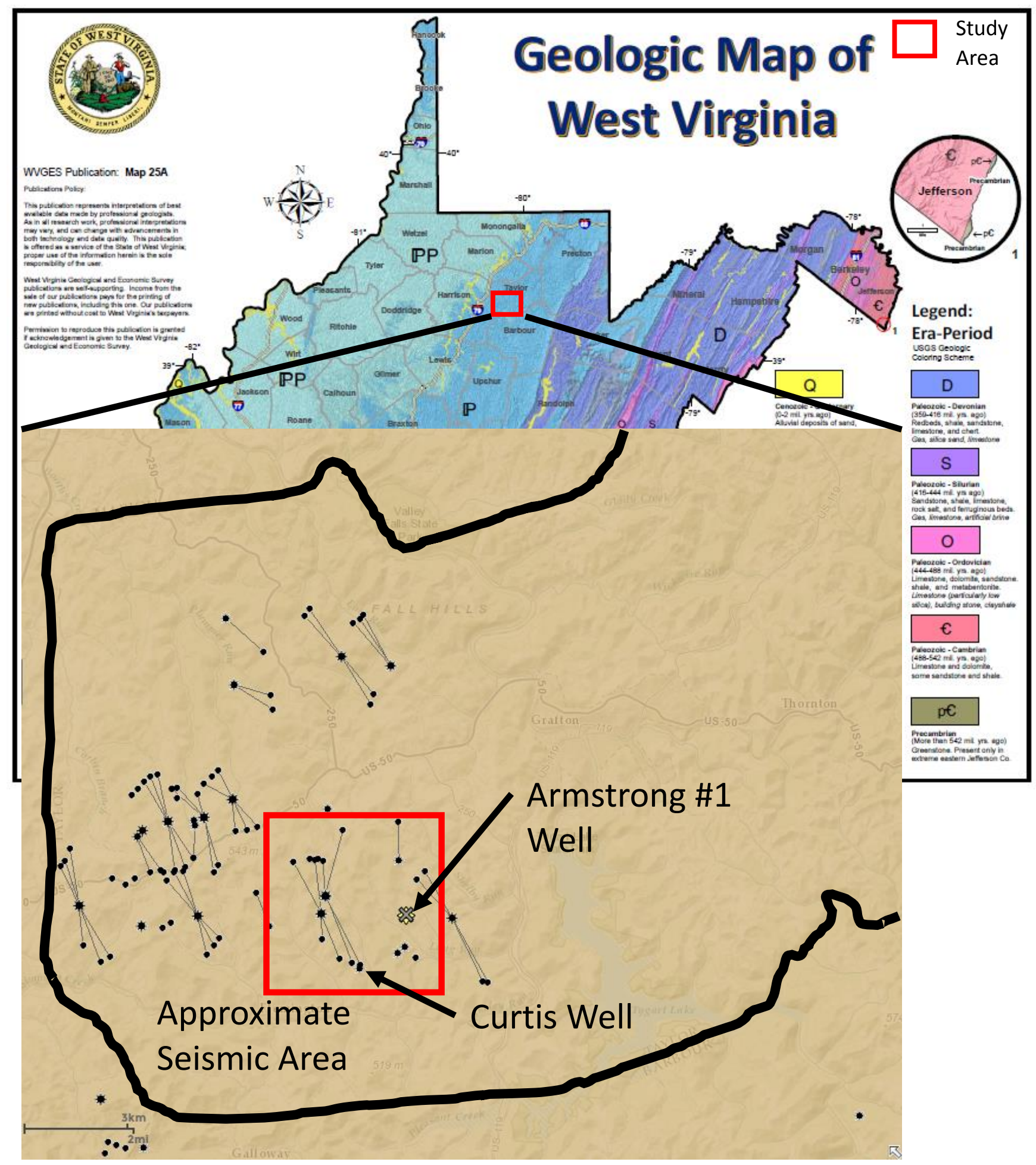

Figure 1-1. West Virginia Geologic Map (WVGS). 
Previously, this area was studied by Zhu (2013). His study consisted of a seismic interpretation and log analysis of the Marcellus Shale. This seismic interpretation focused on analysis of the structure on the Tully, Marcellus, and Onondaga along with a seismic discontinuity analysis using seismic attributes. To perform the log analysis he constructed cross sections through multiple wells in the vicinity of the study area. The cross sections were made for comparison to the seismic interpretation. One of his main goals was to examine the discontinuities present in the seismic data. He interpreted extracted discontinuities in the context of studies by Engelder et al. of the cross cutting $\mathrm{J} 1$ and $\mathrm{J} 2$ joint sets. The $\mathrm{J} 1$ joint set trends eastnortheast and the $\mathrm{J} 2$ joint set trends northwest and cross cuts the $\mathrm{J} 1$ joint set, indicating the $\mathrm{J} 2$ set is younger in formation. Ultimately, he concluded that "horizontal drilling should be N38W and approximately perpendicular to the $\mathrm{J} 1$ set to cross and utilize the joints to guide fracture stimulation" (Zhu, 2013). The Middle Devonian stratigraphy of the area in descending order includes the Harrell Shale, Tully Limestone, Mahantango Shale (alternatively, Hamilton Shale), Marcellus Shale, which includes the thin bedded Purcell Limestone and Cherry Valley Limestone, Onondaga Limestone, and Huntersville Chert (figures 1-2 and 1-3).

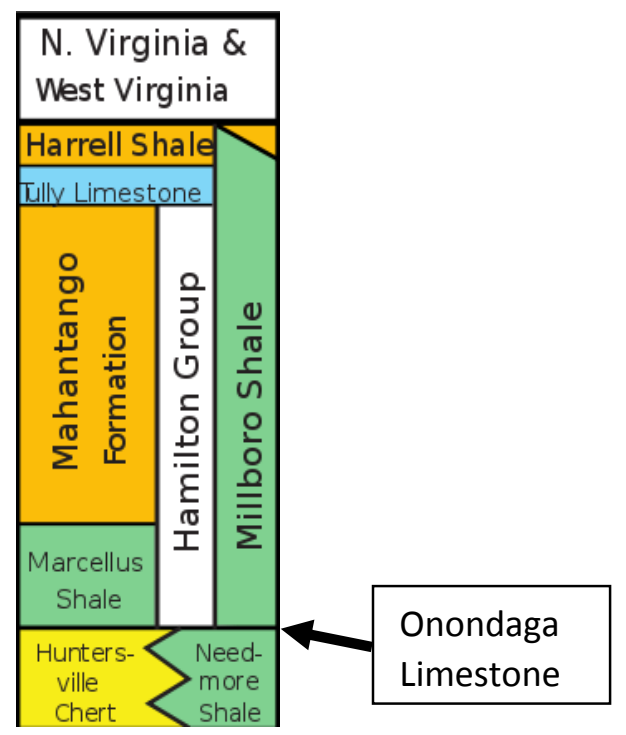

Figure 1-2. General stratigraphic column of the Devonian stratigraphy in West Virginia (Milici and Swezey, 2006). 


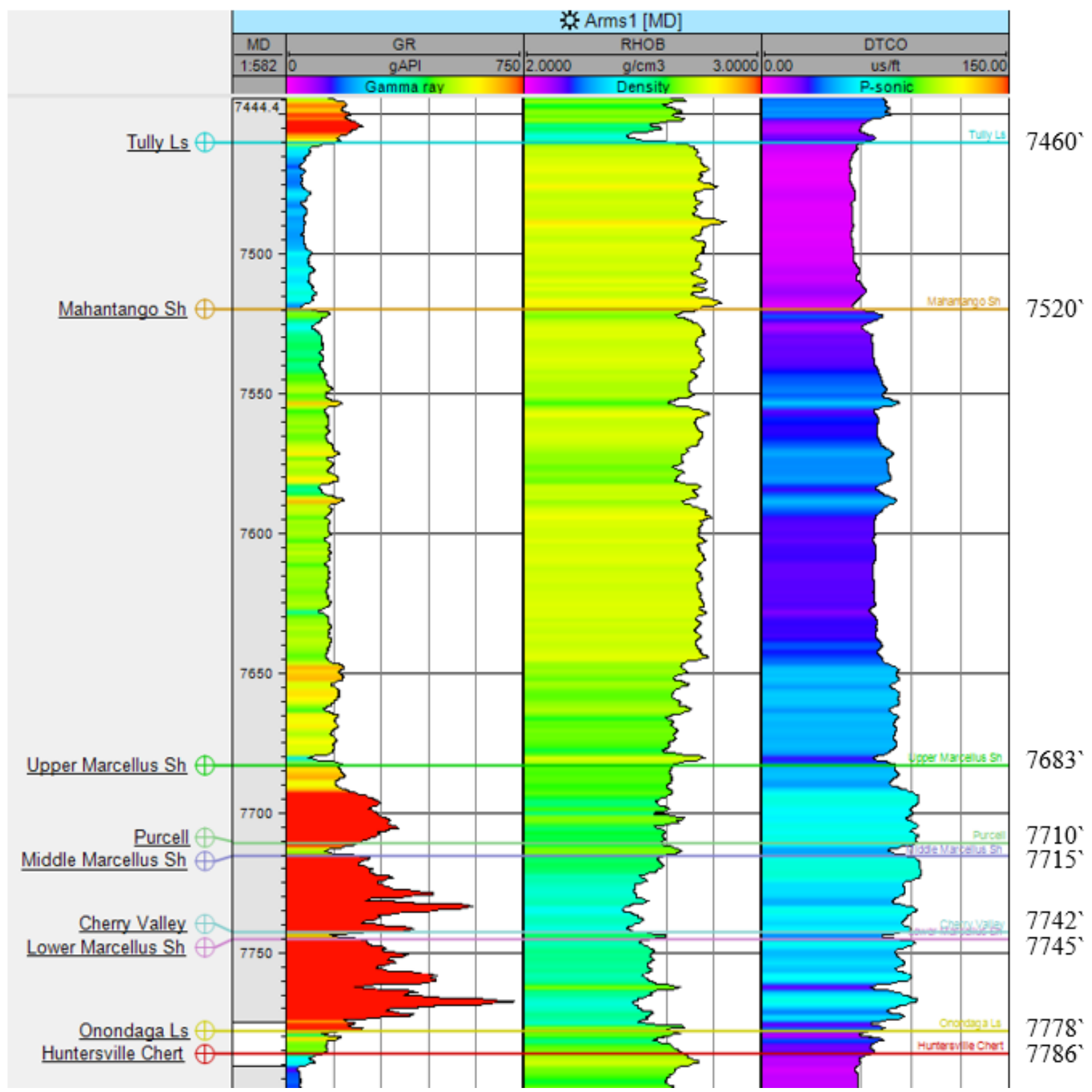

Figure 1-3. Type log showing the Middle Devonian stratigraphy at the Armstrong \#1 well.

This study uses petrophysical and mechanical property logs from the Armstrong \#1 well to describe the geology of the Marcellus Shale interval and relate the rock properties, such as the rock's brittleness, total organic carbon, and mineralogy to the seismic data. 


\section{Chapter 2}

\section{Geologic Setting}

\subsection{Physiographic setting}

Taylor County is located in northern West Virginia, within the central Appalachian basin. The Appalachian basin is a foreland basin containing primarily Paleozoic age (Cambrian Permian) sedimentary rocks. The basin extends over an area of about 185,500 square miles (Ryder, 2000). The area sits in the Appalachian Plateau physiographic province, which is characterized by broad, long wavelength folds. The Appalachian Plateau covers the western twothirds of West Virginia and is separated into two segments, the low plateau and the high plateau provinces (Figure 2-1).

At the surface, the low plateau consists mostly of Pennsylvanian age rocks, which appear almost horizontal with low fold amplitude (dips of 2-3 degrees). The relief is relatively low and the topography is mature. The structures are usually detached in the Salina as well as the Devonian shales. The oldest rocks appear in the eastern high plateau and are Upper Devonian through Mississippian in age. The high plateau consists mostly of Pennsylvanian to Devonian age rocks at the surface. This area appears more rugged, which can be seen by the higher relief and higher fold amplitude. The structures are usually detached in the Martinsburg Shale with some detachment in the overlying Silurian and Devonian units such as the Salina Salt (West Virginia Geologic Survey, 2009). This province sits to the west of the Valley and Ridge province, where fold relief is much higher and fault displacement is much greater. The structures in both of these provinces result from thin skinned tectonics (major detachments above, but not including the basement rock) (Neal, 1979). 


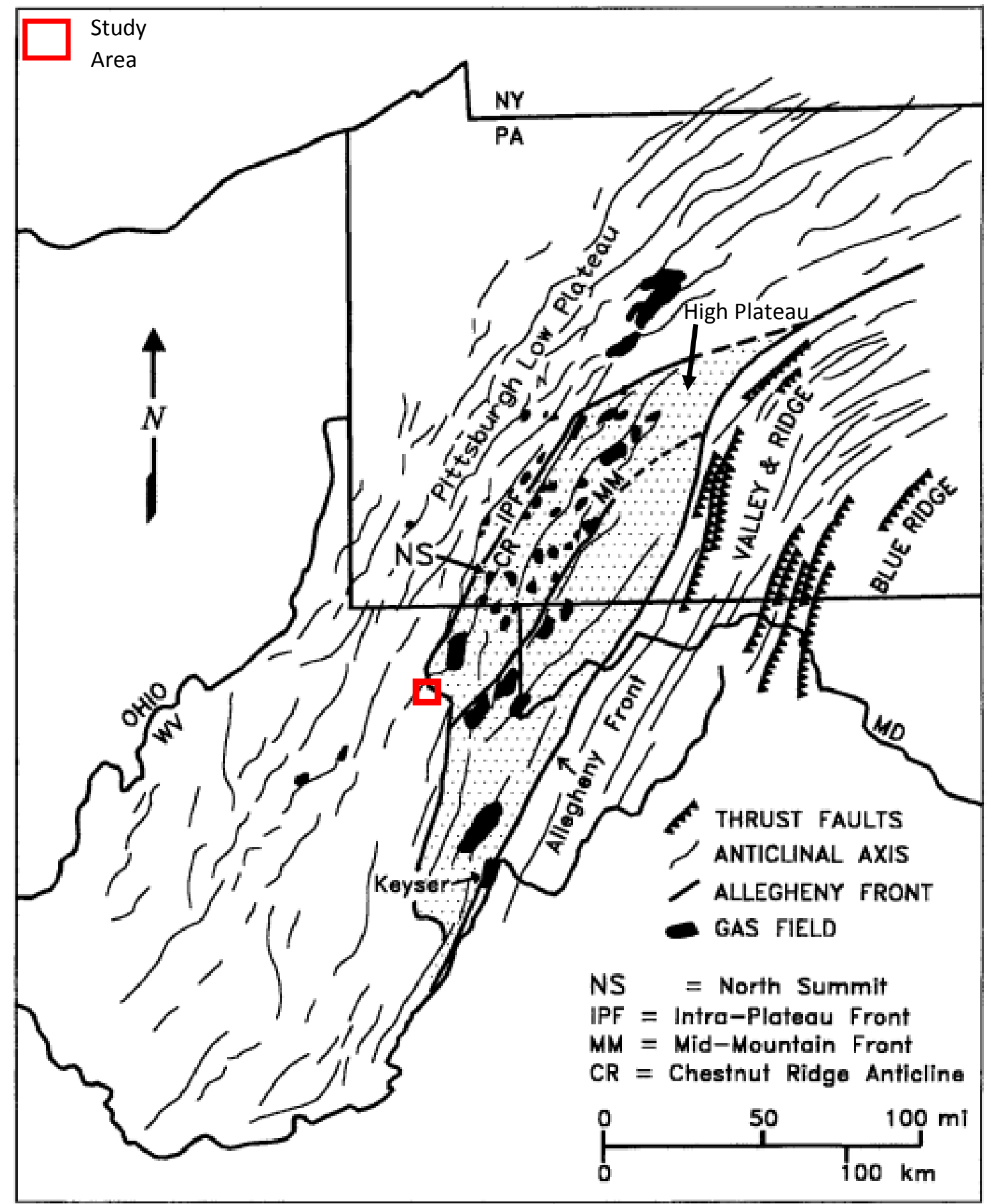

Figure 2-1. Appalachian Plateau physiographic province. Study area outlined in red square. Note high plateau in the stippled area (Modified from Shumaker, 2002). 


\subsection{Stratigraphy}

The Marcellus Shale is an organic rich black shale deposited during the Middle Devonian (383 to 393 million years ago) and is the lowest member of the Hamilton group (Neal, 1979). In this Middle Devonian sequence (figures 2-3 \& 2-4), the Marcellus Shale is overlain by the Mahantango Shale and Tully Limestone and overlays the Onondaga Limestone (Milici and Swezey, 2006). The Marcellus in this area can be split into three sections; the lower, middle and upper Marcellus, which are divided by thin limestone members (figures 2-3b and 2-4b). The Marcellus Shale is primarily composed of very fine silt and clay sized particles. In outcrop it exhibits fissility, meaning it breaks along thin laminae or parallel bedding of the shale. The Marcellus extends through a large part of Pennsylvania and West Virginia and can be found in certain parts of New York, Maryland, and Ohio (Figure 2-2). The Marcellus is named after its type-section in Marcellus, New York (Clark, 1918).

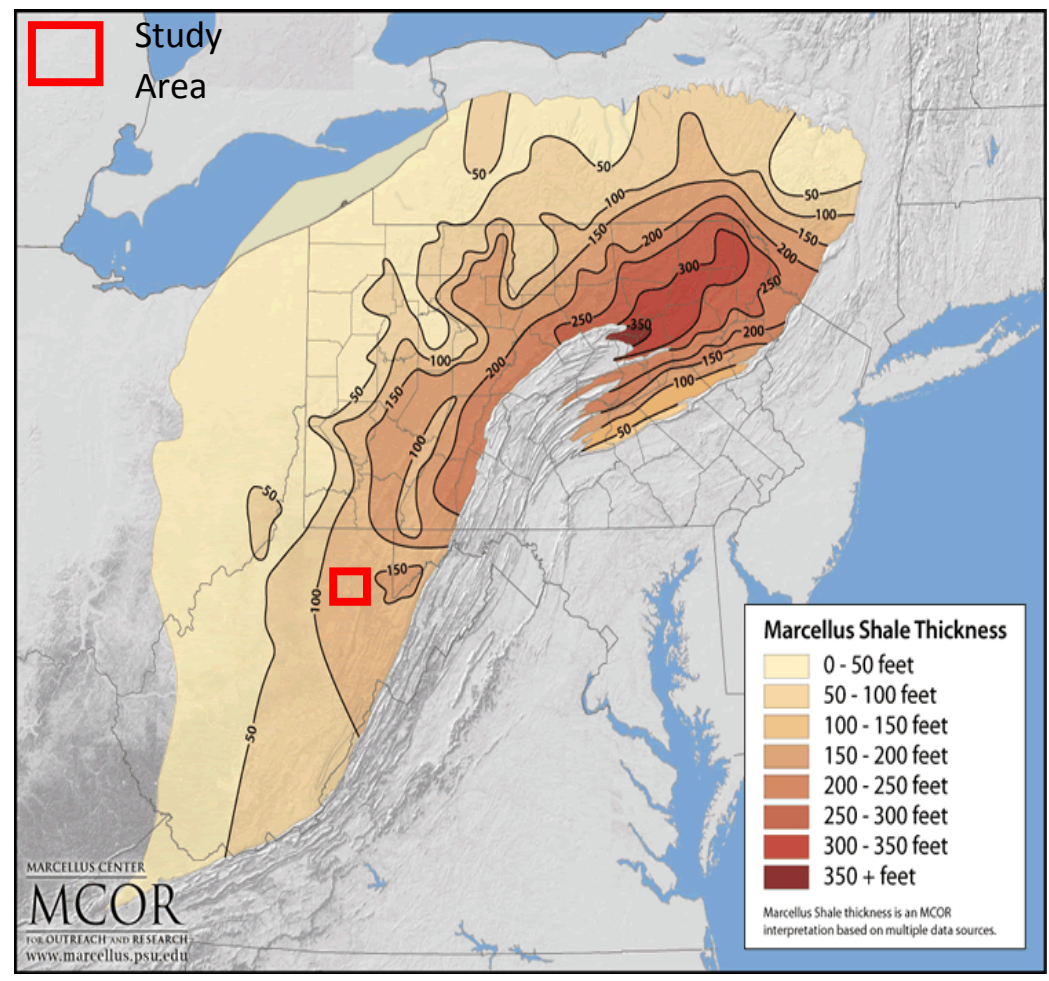

Figure 2-2. Extent of the Marcellus shale and its stratigraphic location. Study area outlined in red. (Penn State Marcellus Center for Outreach and Research, 2010) 


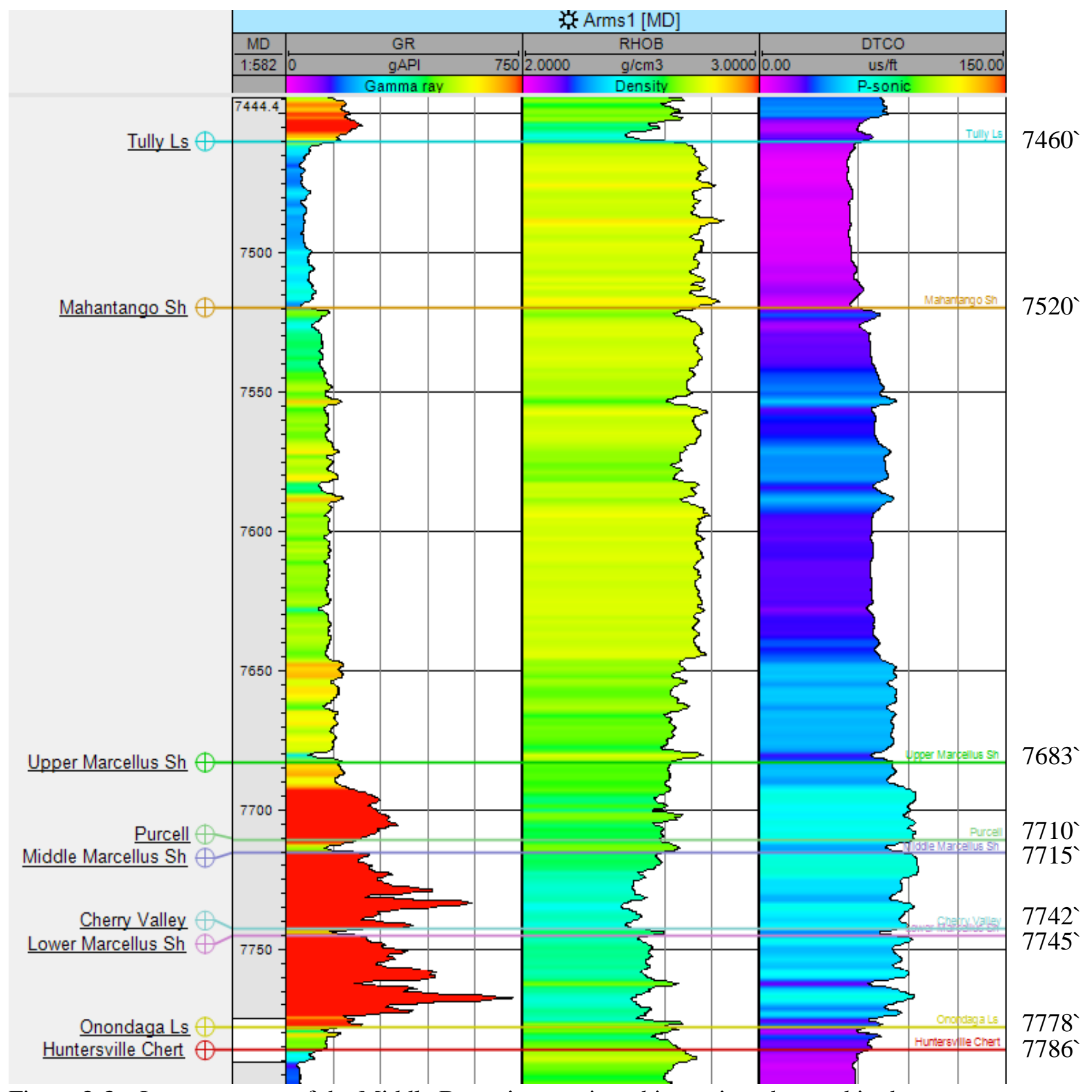

Figure 2-3a. Log responses of the Middle Devonian stratigraphic section observed in the Armstrong \#1 well. 


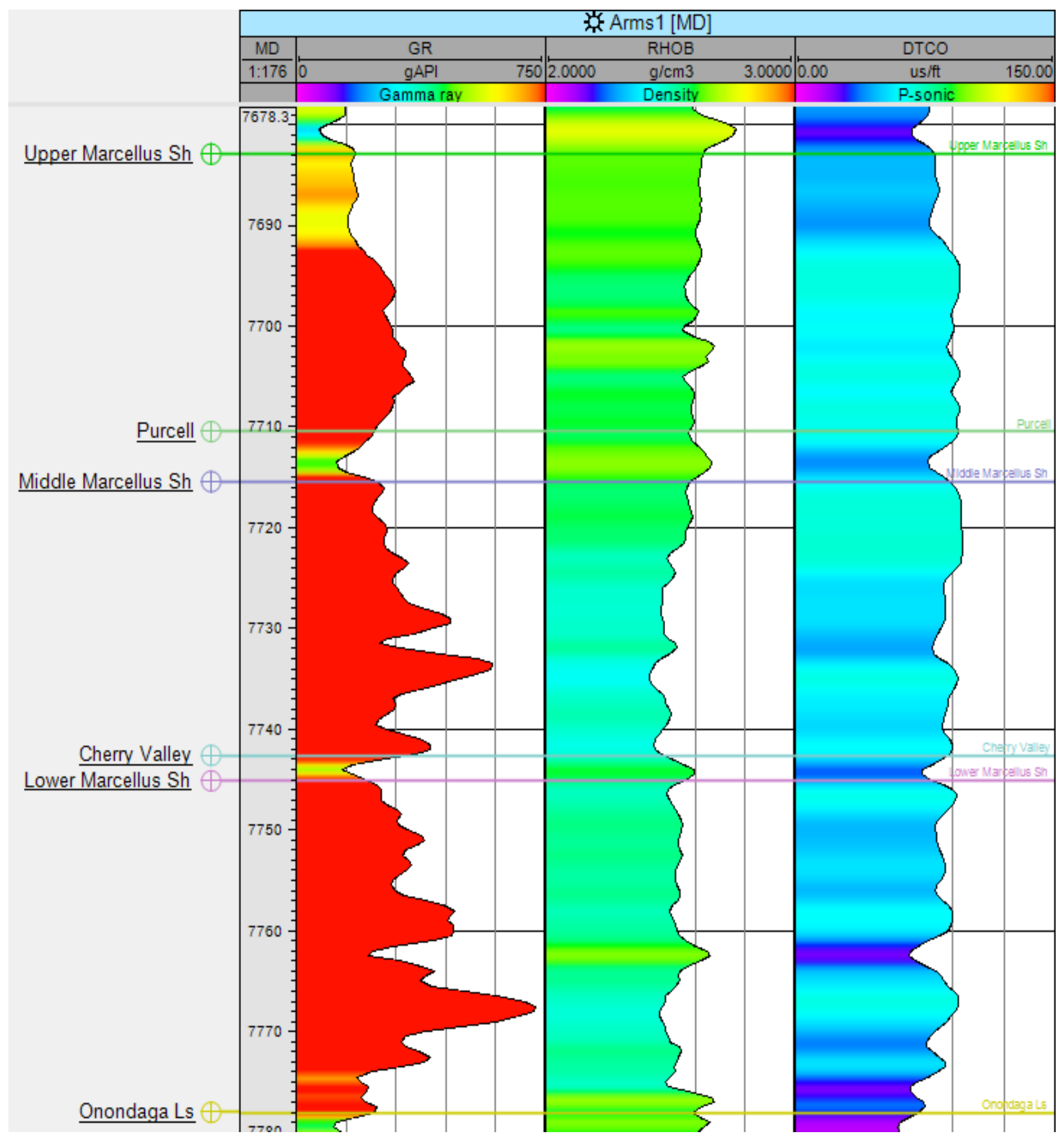

Figure 2-3b. Log response of the Marcellus Shale section observed in the Armstrong \#1 well in Taylor County, WV. 


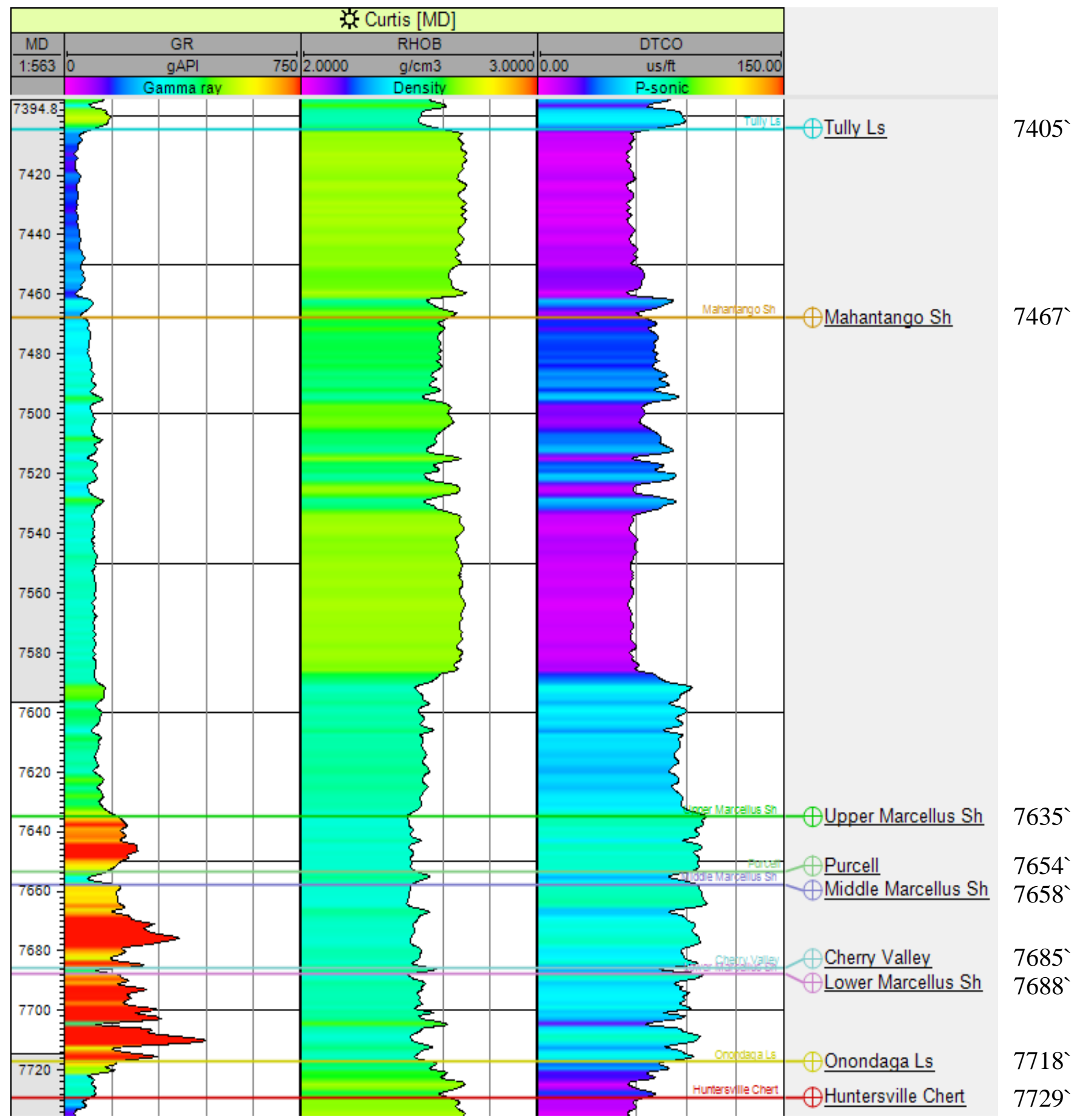

Figure 2-4a. Log responses of the Middle Devonian stratigraphic section observed in the Curtis well. 


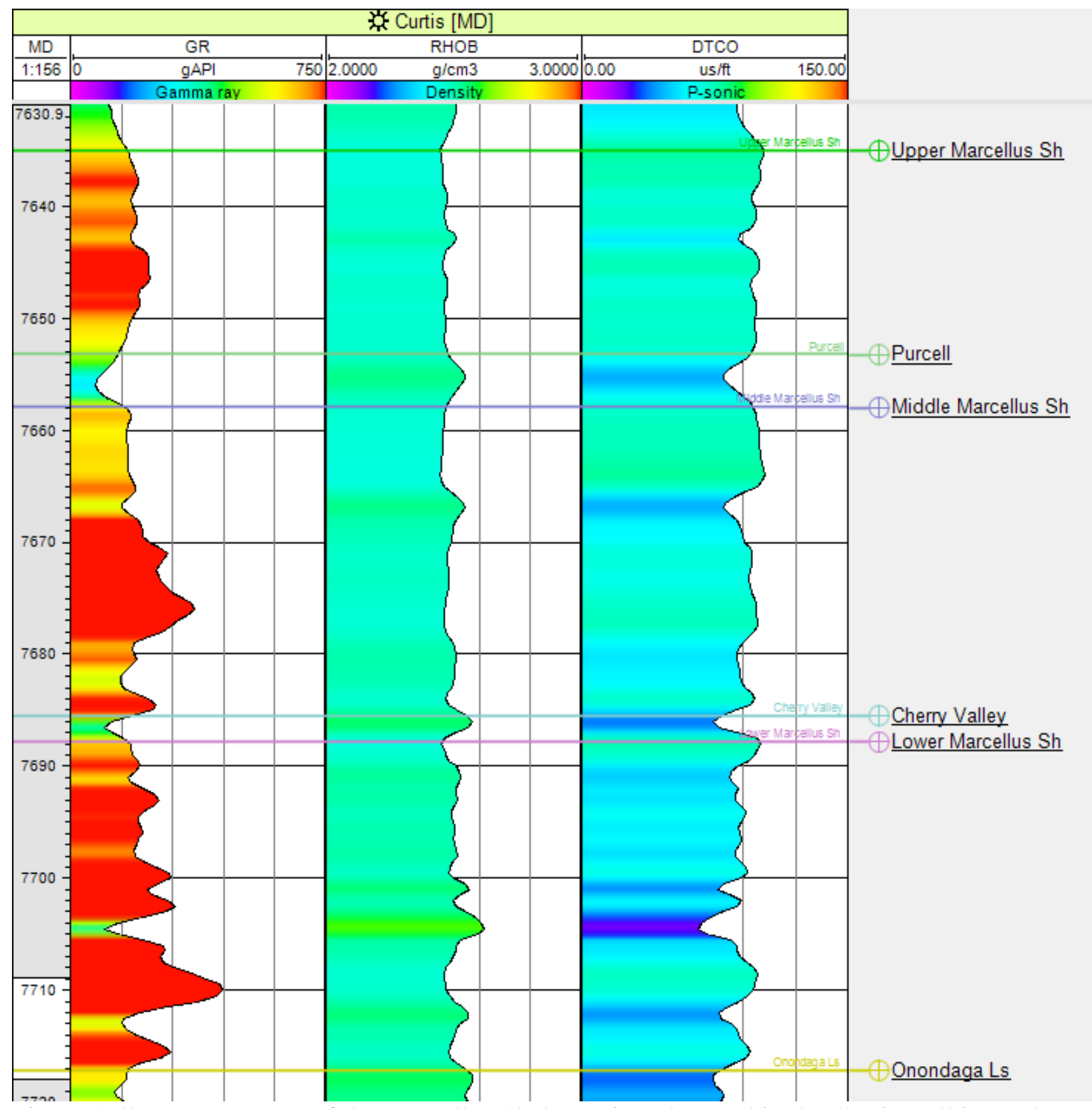

Figure 2-4b. Log response of the Marcellus Shale section observed in the Curtis well in Taylor County, WV. 


\subsection{Tectonic Events}

The Appalachian basin was formed from a series of orogenies that took place from the Pre-Cambrian through the Pennsylvania and Permian time periods. Before the Paleozoic (in the Pre-Cambrian) the Grenville Orogeny (1250-980 Ma) occurred. During the Grenville Orogeny the supercontinent Rodinia was formed. Throughout the Cambrian and Ordovician, Rodinia was broken up during rifting. The separation of Rodinia caused the opening/formation of the Iapetus Ocean. In the early Paleozoic Era the Appalachian region was situated on a passive continental margin near the equator. The Taconic orogeny (550-440 Ma) occurred during the Ordovician and initial closing of the Iapetus Ocean. Subduction of the Iapetus oceanic plate beneath the North American Craton continued throughout the remainder of the Paleozoic (Faill, 1997).

The collision of the Iapetus plate and the North American Craton shifted the passive margin to a now active margin. The Devonian Acadian orogeny (375-325 Ma) resulted from the collision of the continent of Baltica and a series of Avalonian continental fragments with the Laurentia continent. This accretion of continents and continental fragments formed the Euramerica/Laurussia continent. Erosion of the Avalonian highlands initiated deposition of the Marcellus Shale. The Alleghenian orogeny (325-260 Ma) occurred during the Carboniferous and Permian when Africa collided with the eastern side of North America as the supercontinent Pangaea was beginning to form. The Alleghenian orogeny created the major fold, thrust and strike-slip faulted region that highlights the surface expression of the Appalachian basin (Figure 8) (Faill, 1997). 


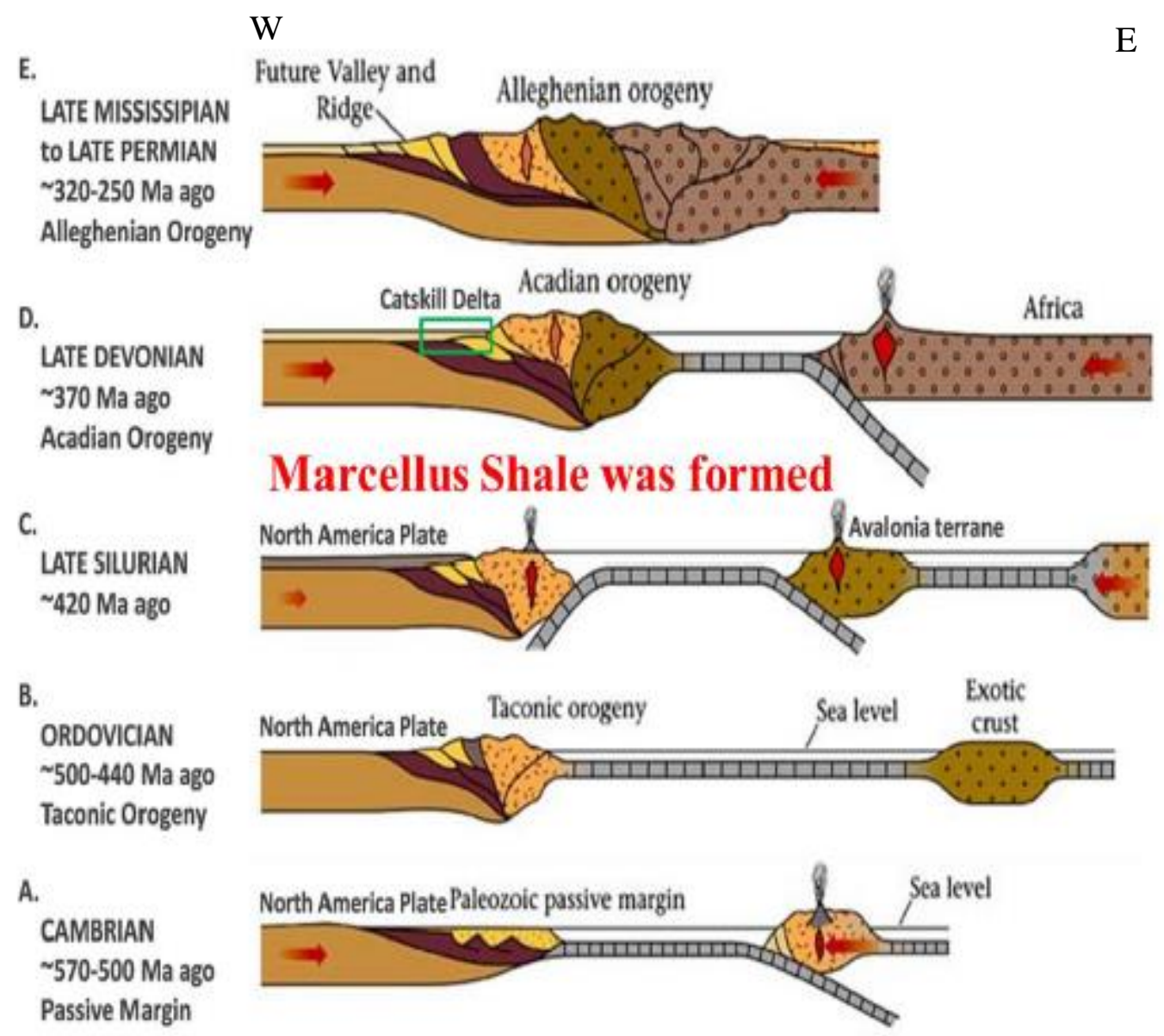

Figure 2-5. Formation of eastern Appalachian Mountains by time period. Modified from Zhu (2013) and USGS publication.

\subsection{Deposition}

The deposition of the Marcellus in the Appalachian basin took place during the second of these three orogenies, the Acadian orogeny (375 to 325 million years ago). This shale was formed by deposition of small clay and mud sized particles within an ancient deltaic environment in a proximal shallow inland sea (Soeder and Kappel, 2009). The clastic sediments eroded from the Acadian mountains formed the expansive Catskill Delta. The distal Marcellus Shale was deposited in a relatively deep ocean. The organic rich mud was then buried beneath younger Devonian sediment which created the Hamilton Group. During this deposition there was a series of small transgressions and regressions and changing anoxic to oxic conditions that deposited 
thin limestone units that separate the Marcellus Shale into the lower, middle, and upper facies. The Marcellus Shale contains primarily dry gas in the east (and gets wetter to the west). The gas was produced by thermogenic maturation of the shale in response to increased temperature and pressure resulting from increased burial depth (Soeder and Kappel, 2009).



Figure 2-6. Depositional wedge of the Marcellus shale (Boyce, 2010). 


\section{Chapter 3}

\section{Seismic Interpretation}

The purpose of further seismic investigation in this study is to enhance resolution of the seismic data to detect subtle features in the seismic response of the Marcellus that were not previously identified. This is primarily achieved using spectral blueing to enhance post-stack processed seismic data which increases high frequency content in the data and, thus, seismic resolution.

\subsection{Synthetic Generation, Tie to Well, and Vertical Resolution Limits}

A synthetic seismogram was generated using sonic and density logs from the Armstrong \#1 well to tie seismic reflection events to the subsurface stratigraphic intervals. The synthetic seismic response is a function of the acoustic impedance:

$$
\mathrm{Z}=\rho \mathrm{V},
$$

where $\rho$ is the density in $\mathrm{g} / \mathrm{cc}$ and $\mathrm{V}$ is the velocity in $\mathrm{m} / \mathrm{s}$. The reflection coefficient $(\mathrm{R})$ is computed from acoustic impedance:

$$
\mathrm{R}=\left(\mathrm{Z}_{2}-\mathrm{Z}_{1}\right) /\left(\mathrm{Z}_{2}+\mathrm{Z}_{1}\right)
$$

where $Z_{2}$ is the acoustic impedance of the lower formation and $Z_{1}$ is the acoustic impedance of the upper formation. The reflection coefficient represents the fraction of incident seismic wave amplitude reflected back to the surface. The seismic wavelet is convolved with the reflection coefficient sequence to yield the synthetic response.

$$
\mathrm{S}=\mathrm{R} * \mathrm{~W}
$$

where $\mathrm{S}$ is the synthetic seismic response, $\mathrm{R}$ is the reflectivity, * is the convolution operation, and $\mathrm{W}$, the seismic wavelet. The wavelet used for creation of the synthetic was an extracted 
wavelet from the post stack migration data. The extracted wavelet (Figure 3-1) was extracted over the time of 0.9 to 1.3 seconds, which is centered on the arrival time of Marcellus reflection events. This wavelet was used to create the resulting synthetic seismogram (Figure 3-4). The amplitude spectrum shows the bandwidth is approximately $34 \mathrm{~Hz}$ to $54 \mathrm{~Hz}$ with a dominant frequency around $45 \mathrm{~Hz}$ (Figure 3-1). The bandwidth was estimated to extend between frequencies at one-half the peak amplitude on the low and high sides of the amplitude/frequency spectrum curve shown by the vertical black bars in Figure 3-1.

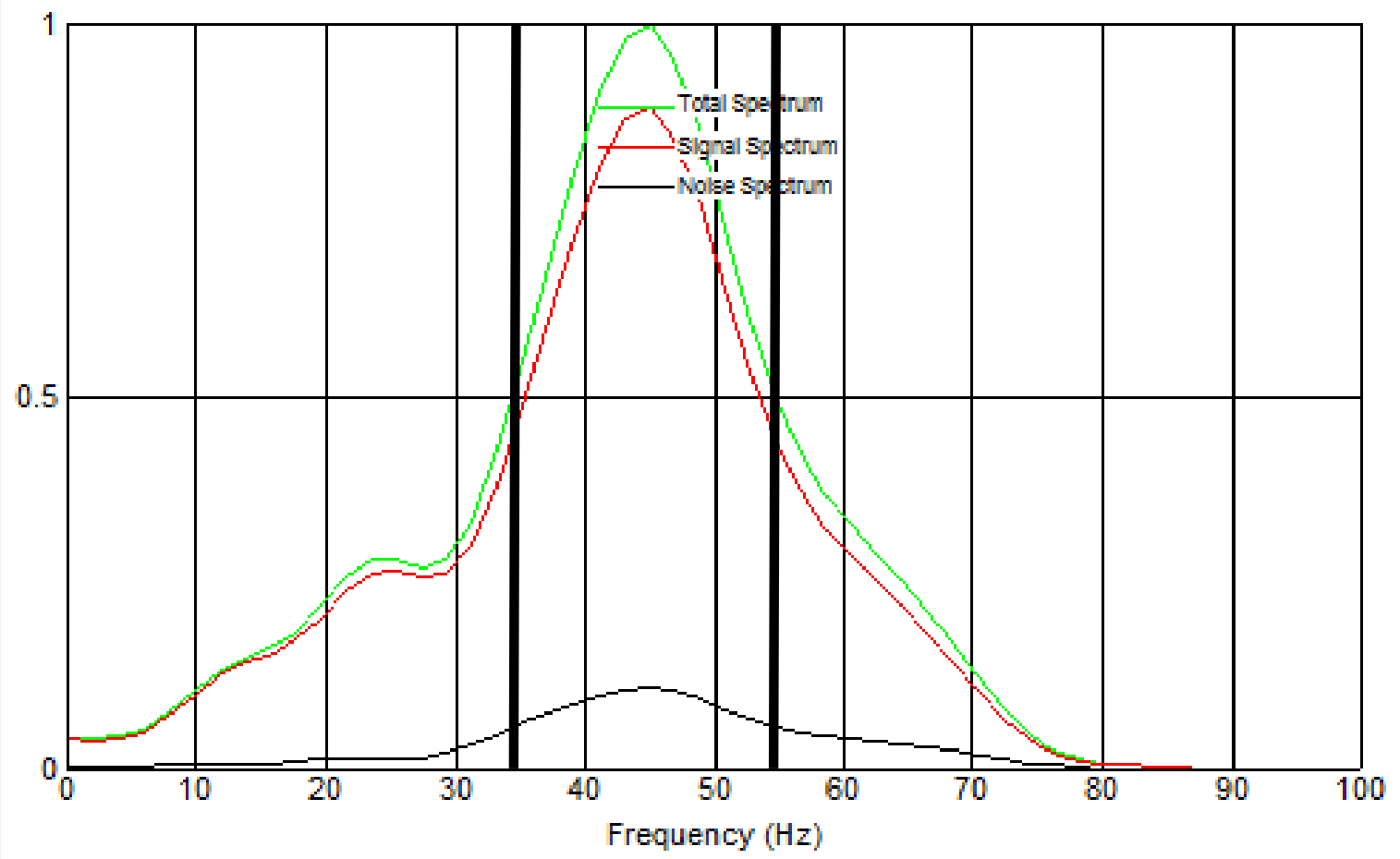

Figure 3-1. Spectrum of the extracted wavelet of the post stack migration data over the time of 0.9 to 1.3 seconds. The bandwidth is 34 to $54 \mathrm{~Hz}$. 


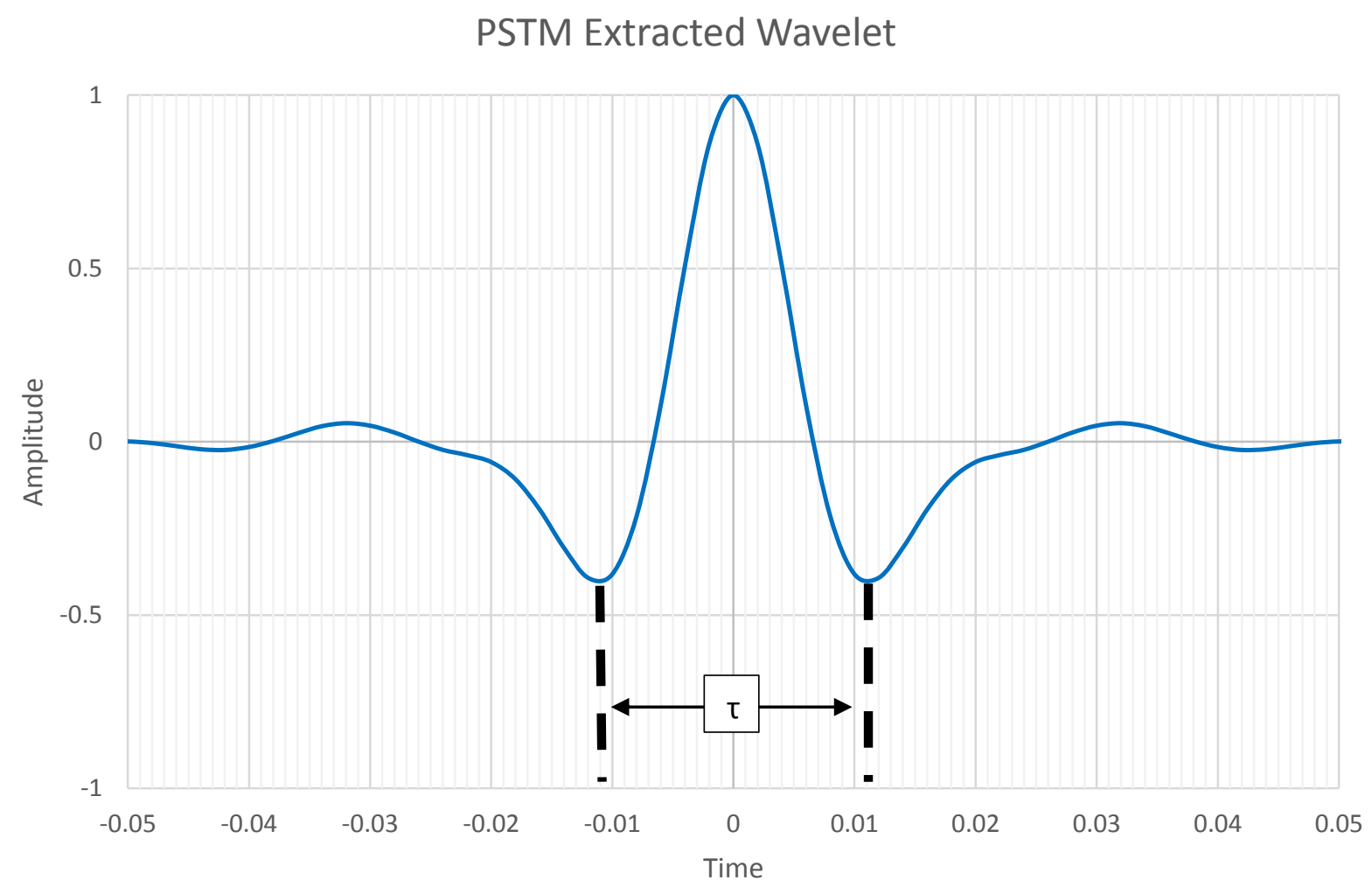

- Post Stack Migration

Figure 3-2. View of the extracted wavelet created from parameters in the previous figure. The dominant period $(\tau)$ is noted.

The peak-to-trough time of the extracted wavelet is 0.011 seconds and is equal to one half the dominant period $(\tau)$ from side lobe to side lobe of 0.022 seconds (figures 3-2 and 3-3). The reciprocal of the dominant period represents the dominant frequency of the wavelet seismic response, which is calculated to be $45 \mathrm{~Hz}$.

The synthetic was overlain on the seismic data to obtain correlation between seismic response and subsurface stratigraphy figures 3-5a and 3-5b. The Tully Limestone is denser and has a faster velocity $(\sim 14,000 \mathrm{ft} / \mathrm{s})$ than the underlying shales $(\sim 11,000$ to $13,000 \mathrm{ft} / \mathrm{s})$ as shown in figure 3-4. These produce a positive reflection event from the top of the Tully, shown by a red color in the seismic data. The velocity of the underlying Mahantango is less so that the reflection 
from the base of the Tully is negative, appearing as a blue colored negative reflection event in the seismic data. The velocity of the Onondaga and Huntersville is about 15,000 ft/s (as shown by the $\log$ velocity in Figure 3-4) and produces a positive reflection event at the base of the Marcellus.

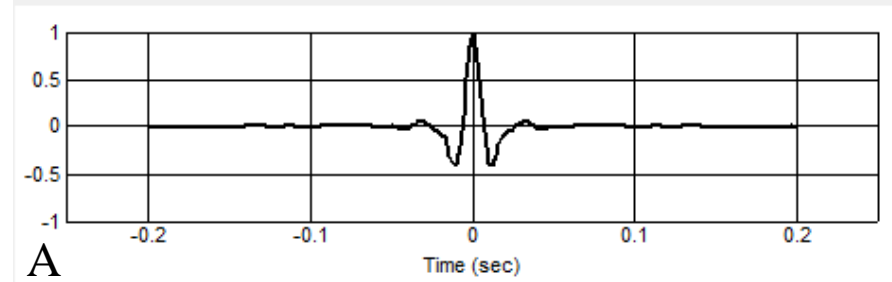

Tuning Thickness Chart:

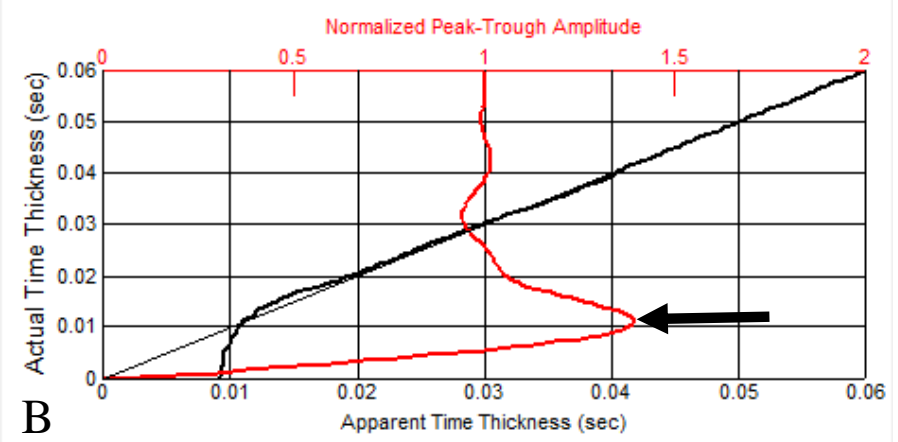

Figure 3-3. A) Seismic wavelet, B) Calibration curves used to identify tuning time, which corresponds to $0.022 \mathrm{~s}$.

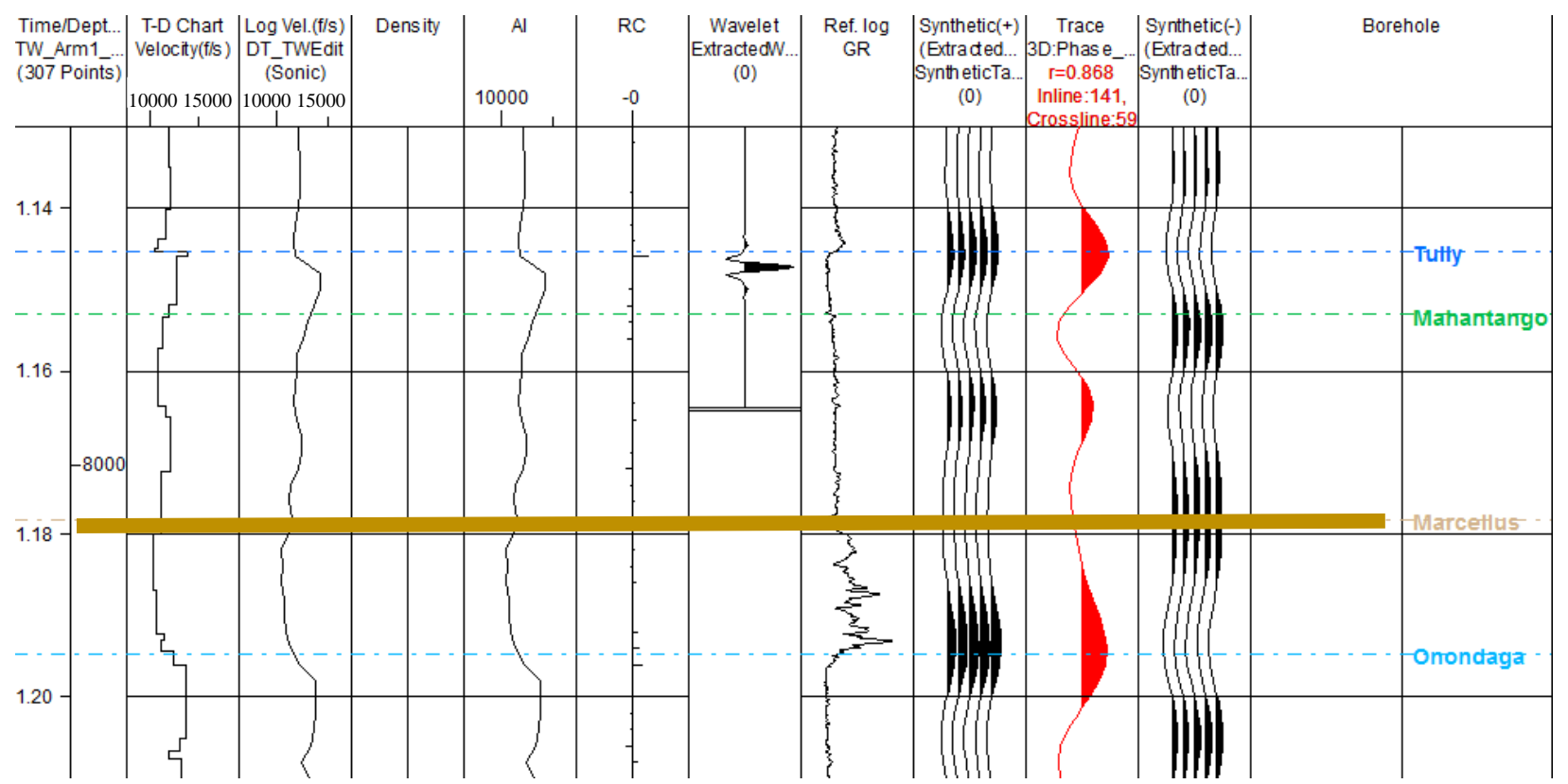

Figure 3-4. Synthetic seismogram computed for the Armstrong \#1 well. Key formation tops are labeled for reference. 


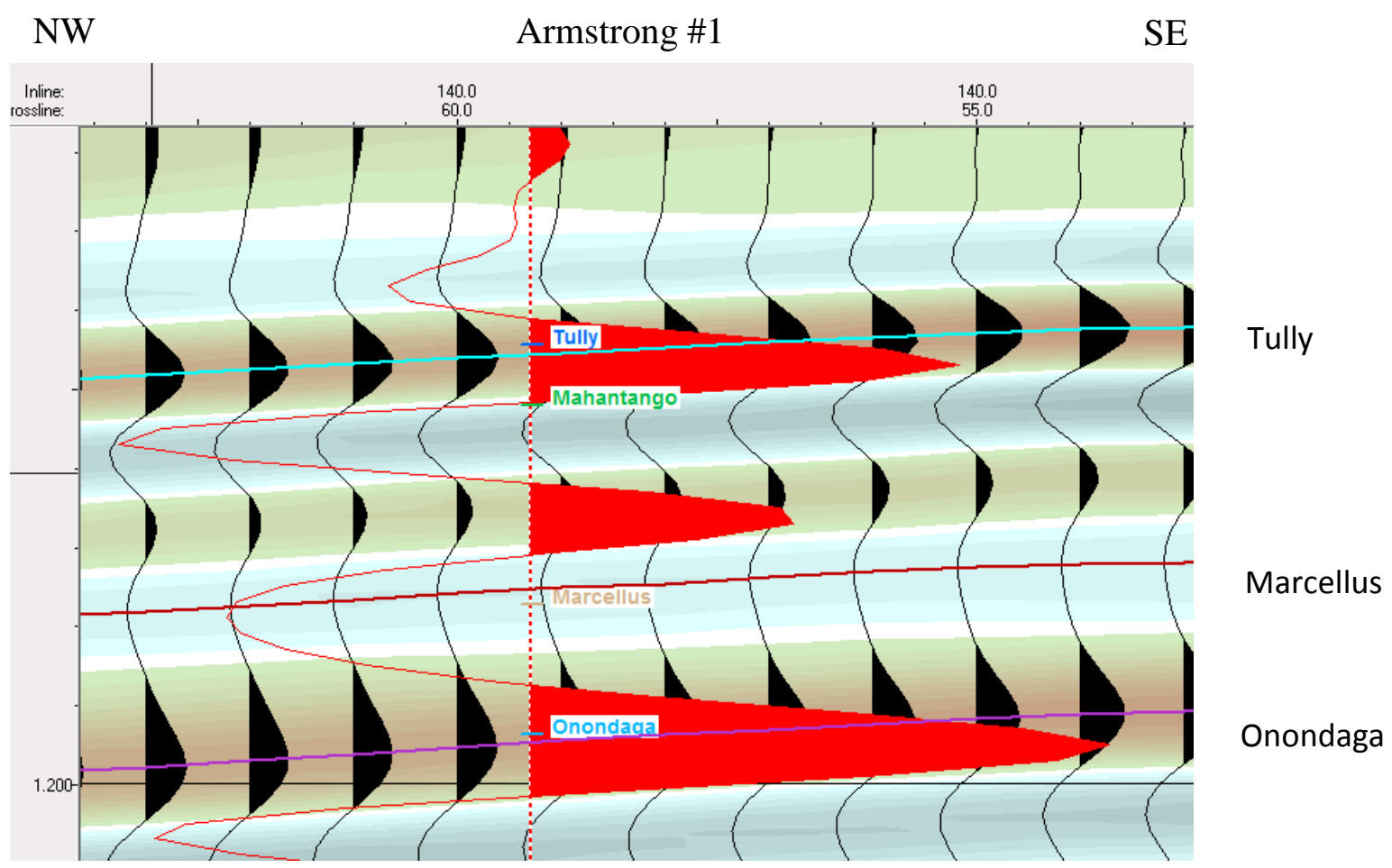

Figure 3-5a. Armstrong \#1 well synthetic shows the correlation of events associated with the Marcellus and bounding strata to the local seismic response. The synthesis is overlain on the seismic at Inline 140.

$\mathrm{NE}$ Armstrong \#1

SW

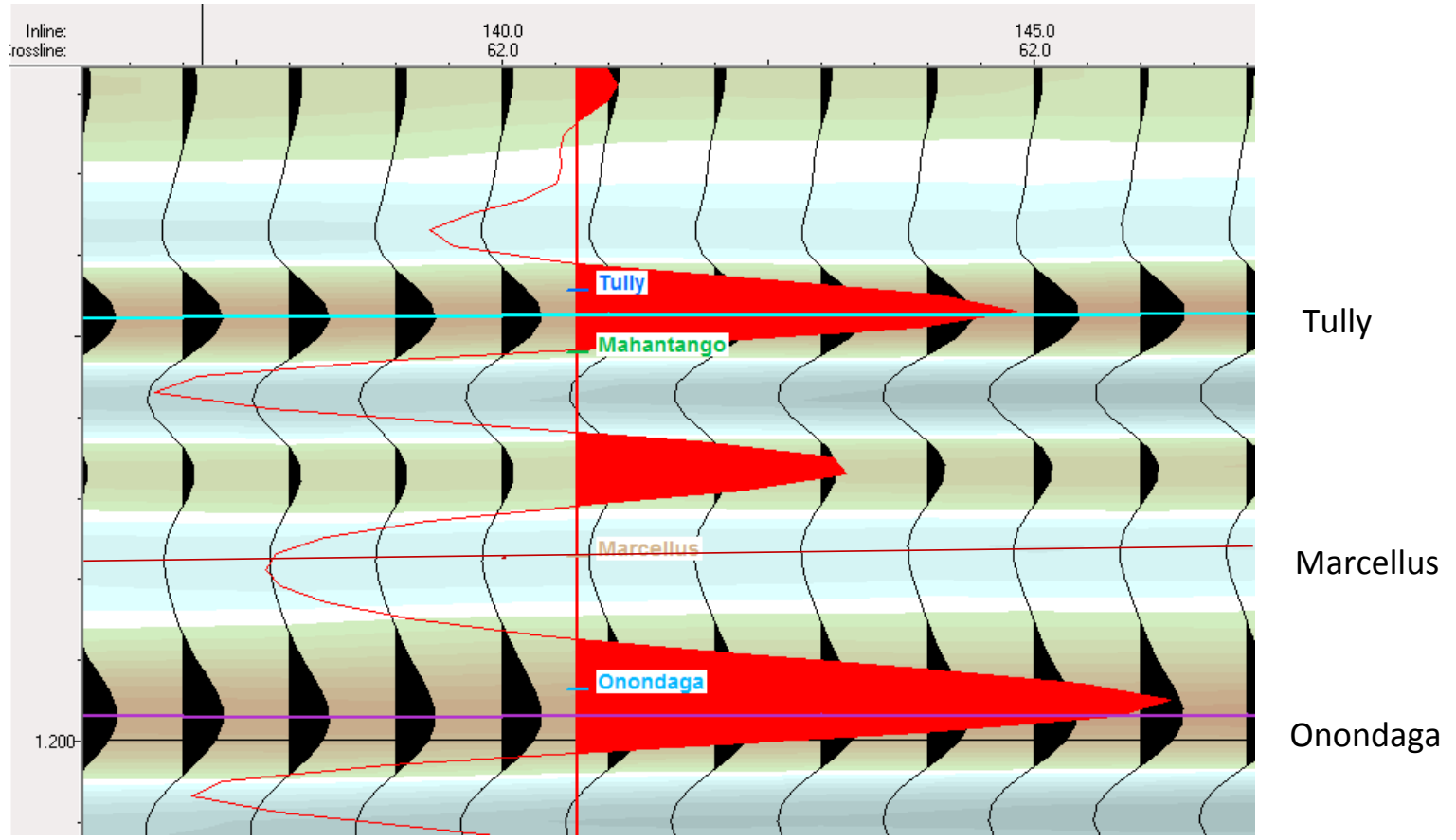

Figure 3-5b. Armstrong \#1 well synthetic shows the correlation of events associated with the Marcellus and bounding strata to the local seismic response. The synthetic is overlain on the seismic at crossline 60. 
The velocity log in figure 3-4 indicates an average velocity for the Marcellus Shale of about 11,000 feet per second. This velocity, along with the dominant period of the wavelet noted above of .022s is used to compute the minimum resolvable thickness,

$$
\mathrm{T}=\mathrm{V}^{*} \tau / 4
$$

where $\mathrm{T}$ is the tuning thickness, $\mathrm{V}$ is the velocity, and $\tau$ is the dominant period. The minimum resolvable thickness of the Marcellus is determined to be approximately 61 feet. In the study area the thickness of the Marcellus is around 95 feet thick at the Armstrong \#1 well and around 83 feet thick at the Curtis well, as determined from the log response. The minimum resolvable thickness is less than the actual thickness of both wells, but many features in the Marcellus still cannot be resolved at this thickness. Enhancing the resolution of the seismic data is a primary goal to improve the potential resolve the Marcellus and bounding strata that was not previously been able to be resolved.

\subsection{Spectral Blueing}

The spectral blueing process increases the amplitude of higher frequencies in the signal using a spectral filter derived from the spectrum of the log-derived reflectivity sequence. The increase in higher frequency content produced by the process increases bandwidth, dominant frequency and resolution. Spectral blueing is a zero-phase convolution that shapes the amplitude spectrum to a band-limited version of the reflection coefficient spectrum as computed from well logs. Resolution is increased by using the properties of the reflection coefficient spectrum to enhance high frequency components of the signal. The output is quality controlled to ensure that higher frequencies are not dominated by noise (Blache-Fraser and Neep, 2004).

Spectral blueing was performed in Opendtect ${ }^{\mathrm{TM}}$ using their spectral blueing attribute calculator. The seismic spectrum was calculated over a $1000 \mathrm{~ms}$ window extending from $750 \mathrm{~ms}$ 
to $1750 \mathrm{~ms}$ to center on the Marcellus. The design window includes the Marcellus shale and bounding intervals located in the earlier part of the time window at approximately $1184 \mathrm{~ms}$. The acoustic impedance log was calculated using the Armstrong \#1 sonic and density logs. The seismic spectrum from the processed data was quality controlled by comparing it to the spectrum calculated from the well logs to make sure they were similar. The average seismic spectrum was smoothed using an $11 \mathrm{~Hz}$ smoothing operator lens. The high cut frequency was set to $150 \mathrm{~Hz}$ since that was the frequency range of interest.

The seismic spectrum (Figure 3-6) shows enhanced higher frequencies content to about $60 \mathrm{~Hz}$. The spectrum of the $750 \mathrm{~ms}$ to $1750 \mathrm{~ms}$ window produces an increase in dominant frequency from $45 \mathrm{~Hz}$ to $59 \mathrm{~Hz}$ and a larger bandwidth of $31 \mathrm{~Hz}-67 \mathrm{~Hz}$ in the spectral blueing volume (Figure 3-6) compared to the bandwidth of $34 \mathrm{~Hz}-54 \mathrm{~Hz}$ (Figure 3-1) in the post stack migration. The bandwidth increased from $20 \mathrm{~Hz}$ to $36 \mathrm{~Hz}$. The dominant period $(0.017 \mathrm{~s})$ and average velocity of $11,000 \mathrm{ft} / \mathrm{s}$ in the Marcellus yields a minimum resolvable thickness of about 47 feet (see equation 3-4). This represents an increase in resolution of 14 feet from the 61 foot limit of the previous post stack migration seismic resolution. The comparison of wavelets in Figure 3-7b shows the improved wavelet side lobe to side lobe time from the post stack migration to the spectral blueing. The new synthetic created from the spectral blueing wavelet is shown in figure $3-9$. 


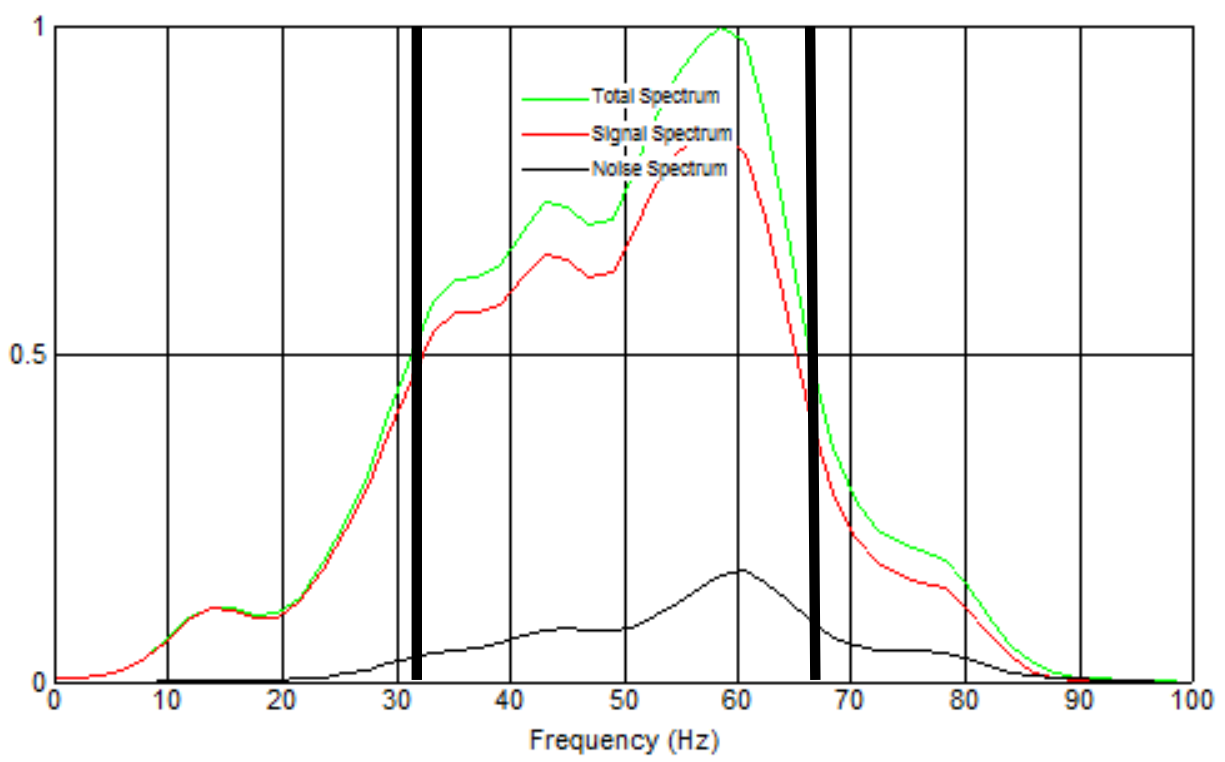

Figure 3-6. Computed spectrum of the extracted wavelet over the time of 0.9 to 1.3 seconds. The bandwidth is 31 to $67 \mathrm{~Hz}$.

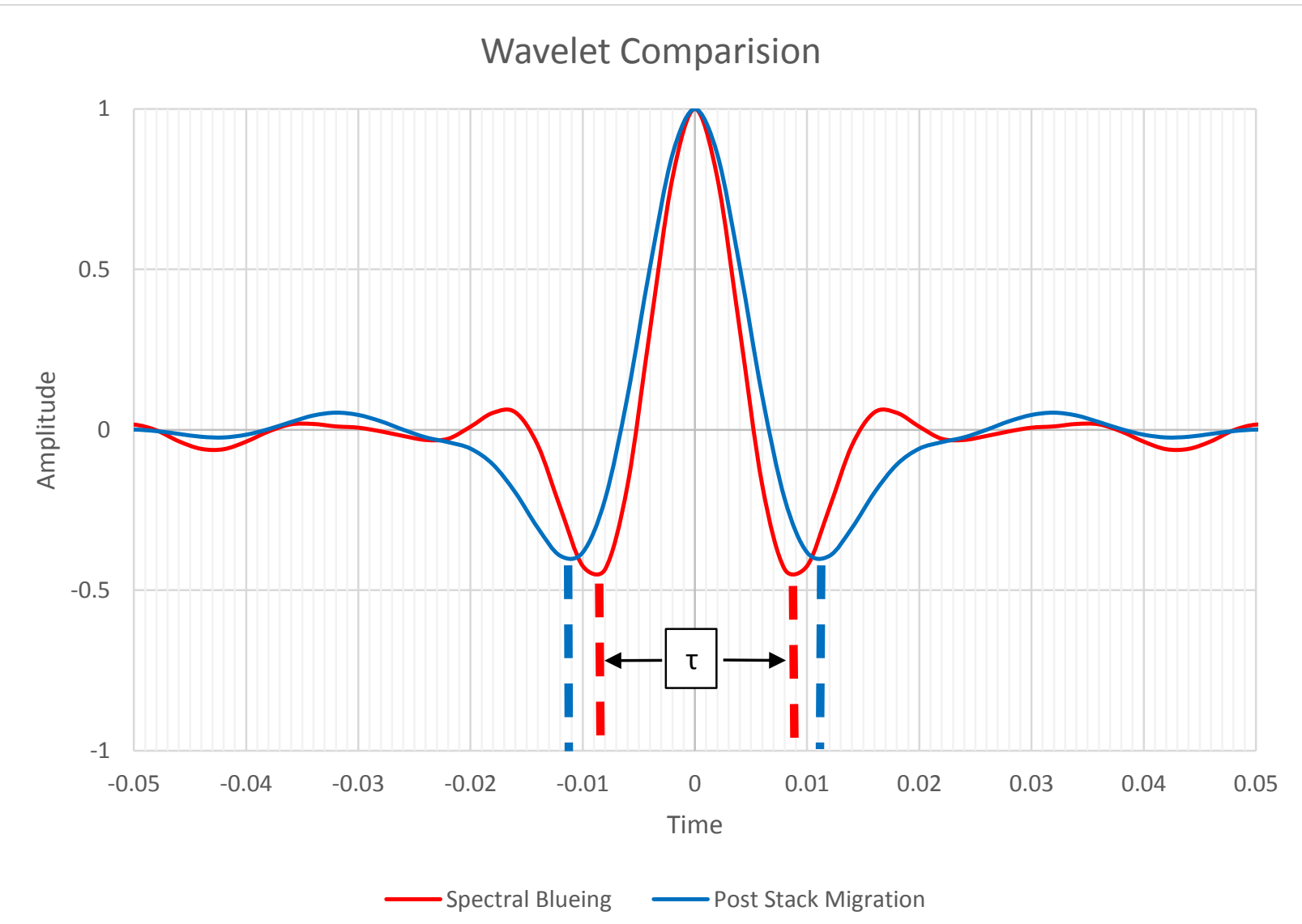

Figure 3-7b. Wavelet extracted from the original seismic (blue) with a time from side lobe to side lobe of $22 \mathrm{~ms}$ and spectral blueing (red) with a time from side lobe to side lobe of $17 \mathrm{~ms}$. 


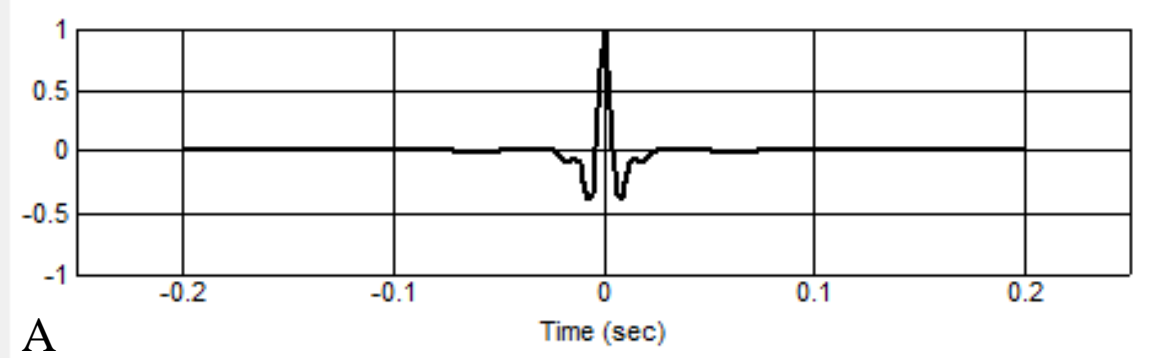

Tuning Thickness Chart:

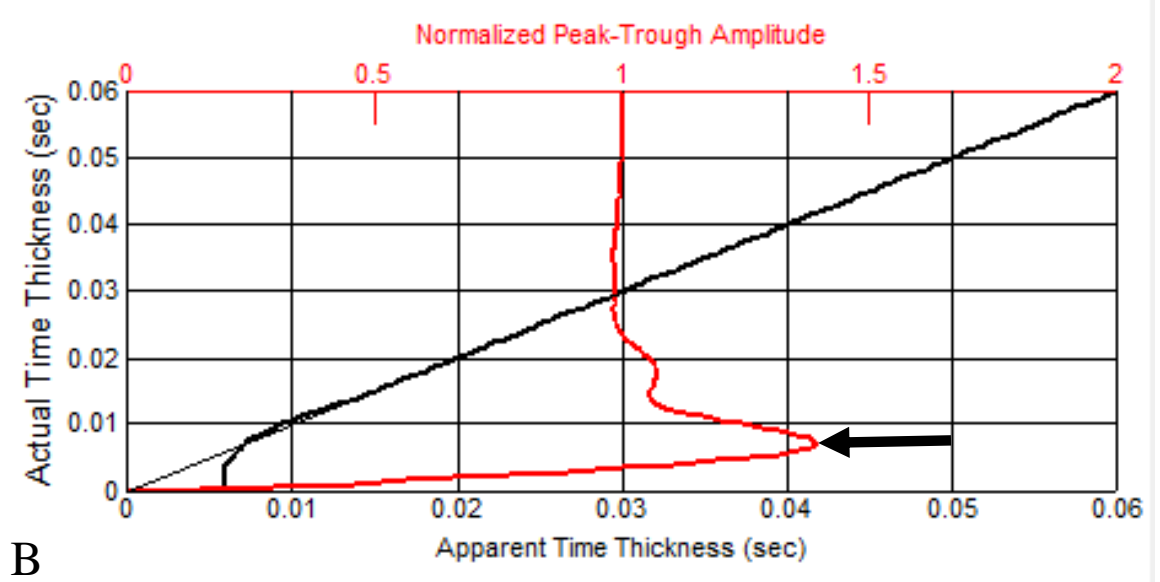

Figure 3-8. A) Seismic wavelet, B) Calibration curves used to identify tuning time, which corresponds to $0.017 \mathrm{~s}$.

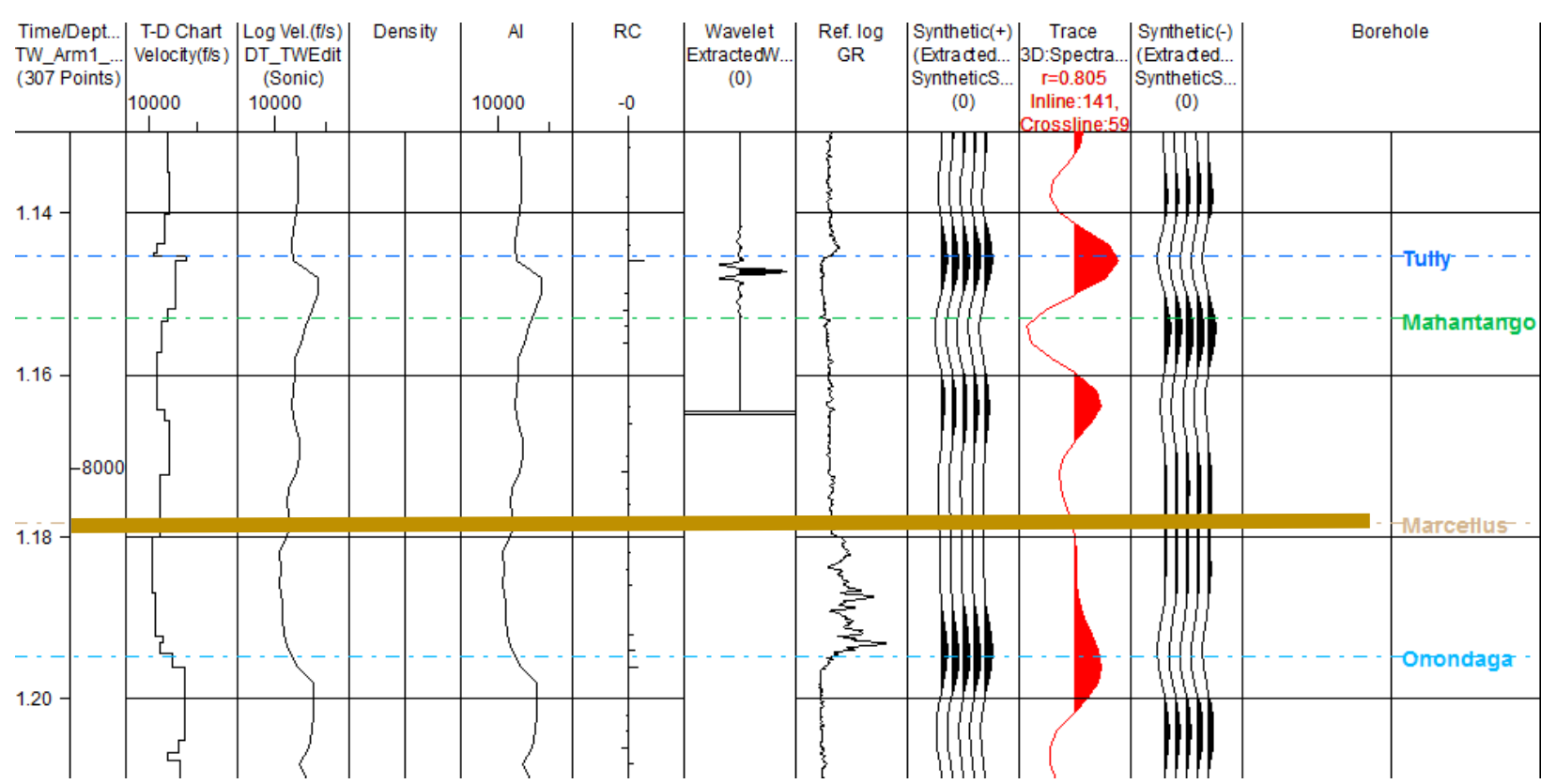

Figure 3-9. New synthetic created based on a wavelet extracted from the spectral blueing volume.

The difference between the original seismic and the spectral blueing volumes is shown in figures 3-10 and 3-11 at the Armstrong \#1 well and in figures 3-14 and 3-15 at the Curtis well. 
The seismic sections are inline 140 that crosses the Armstrong \#1 well (figures 3-10 and 3-11) and inline 80 that crosses the Curtis well (figures 3-14 and 3-15). Spectral blueing reveals increased detail and resolution of the seismic response. Improved resolution can especially be seen in the Marcellus (marked by the yellow dashed line). In the south-eastern section there appears to be definite enhanced resolution, shown by two troughs, one at the top of the Upper Marcellus and the other at the top of the Lower Marcellus. The second trough of the Lower Marcellus vaguely appeared in the original seismic (figures 3-12 and 3-13). Portions of the Lower Marcellus could be picked in the spectral blueing volume where the Marcellus appears to be thickening, so the ability to resolve more of the Marcellus allows for improved interpretation in the seismic.

In many seismic lines, the top of the Marcellus was able to be adjusted from previous picks due to the enhanced resolution from spectral blueing (Figure 3-12). The improved detail in the seismic wavelet also shows lateral variation in the Marcellus that could not previously be visualized (figures 3-13 and 3-15). Near both the Armstrong \#1 and Curtis wells, there were more gradational changes between the base of the Marcellus and top of the Onondaga that was not present in the post stack migration seismic (figures 3-11, 3-14, and 3-15). 


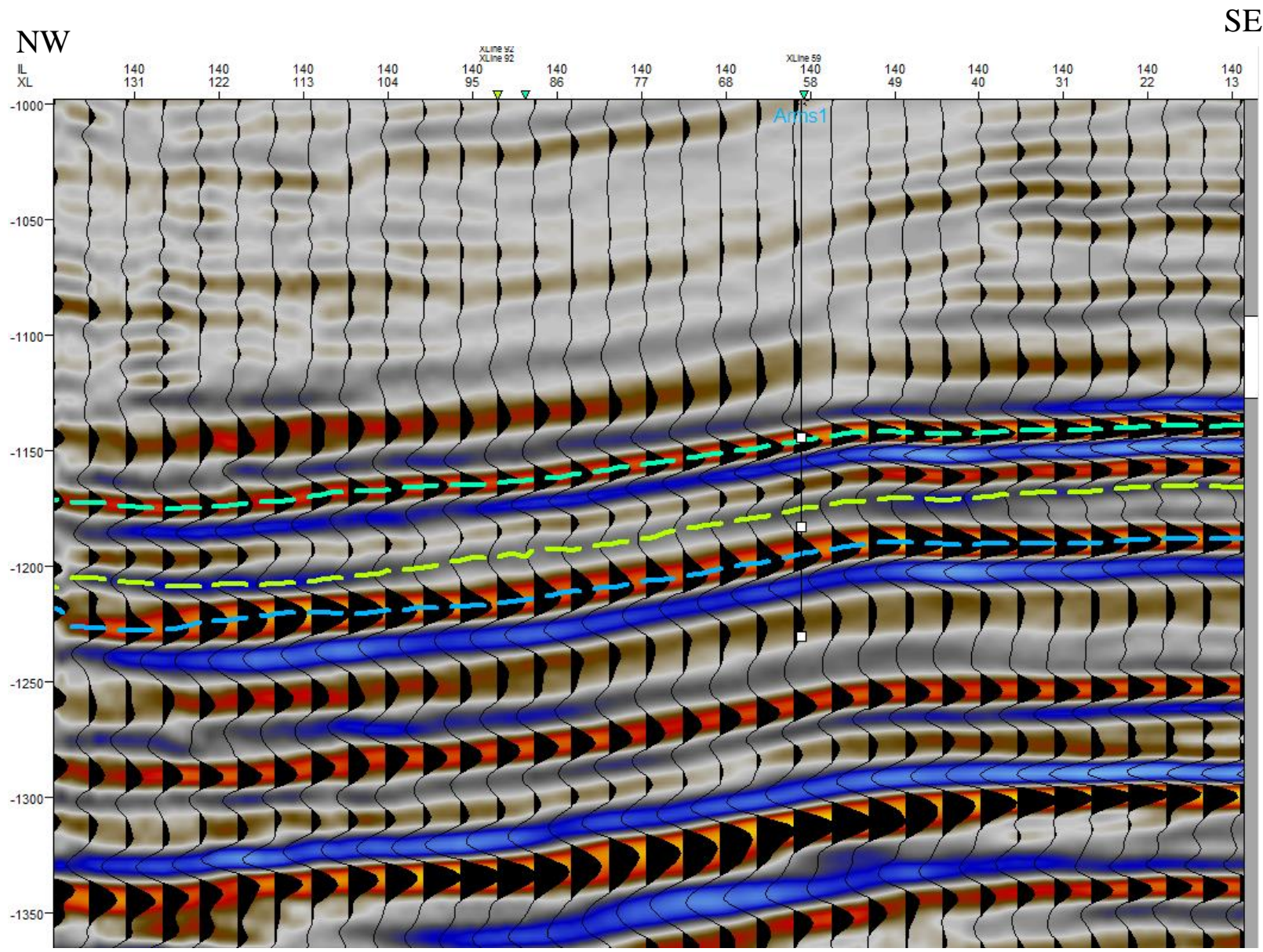

Figure 3-10. Post stack migration - original seismic volume at the Armstrong \#1 well at inline 140. 


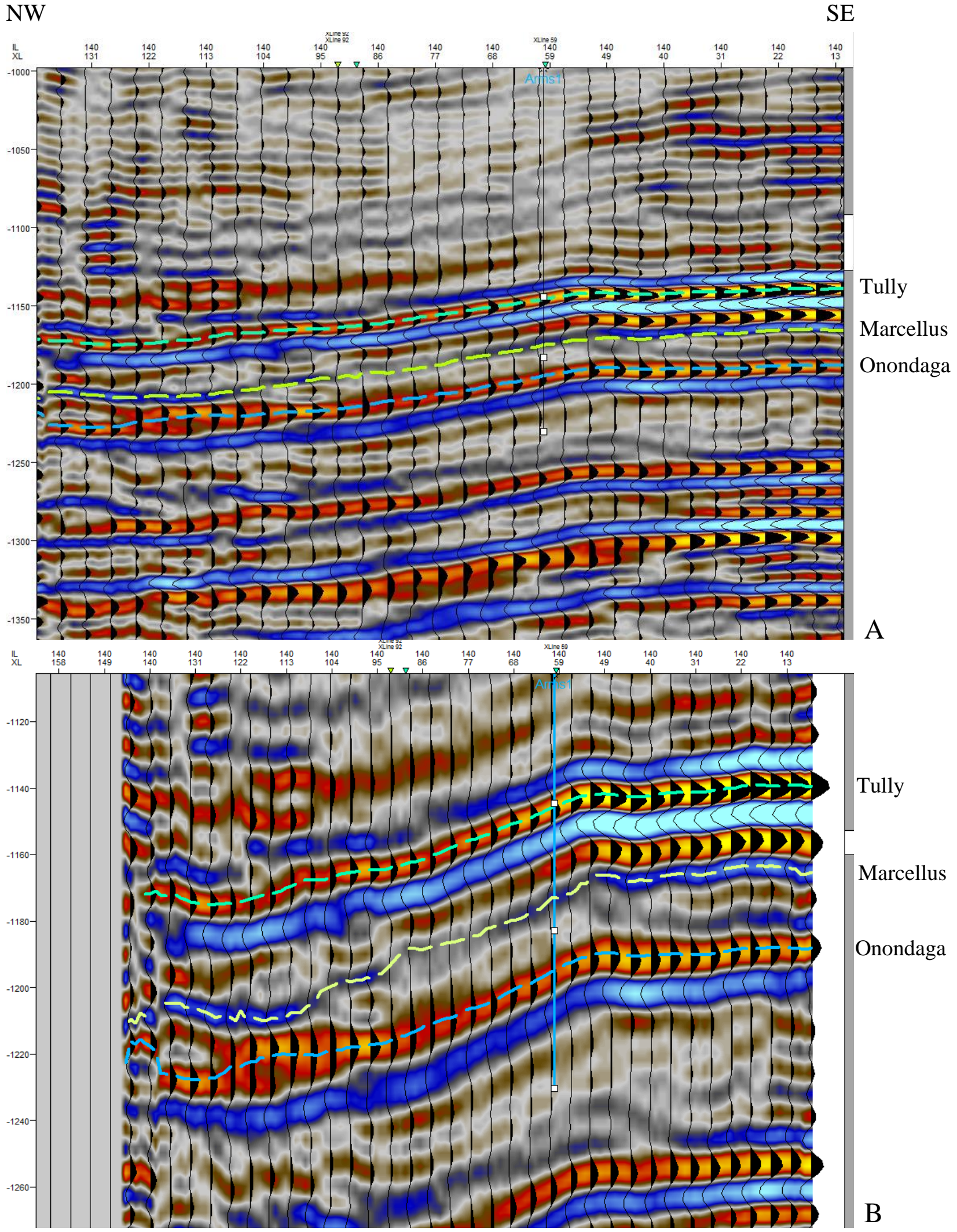

Figure 3-11. A) Spectral Blueing applied to seismic. B) Zoomed in view of the Marcellus and bounding intervals. 


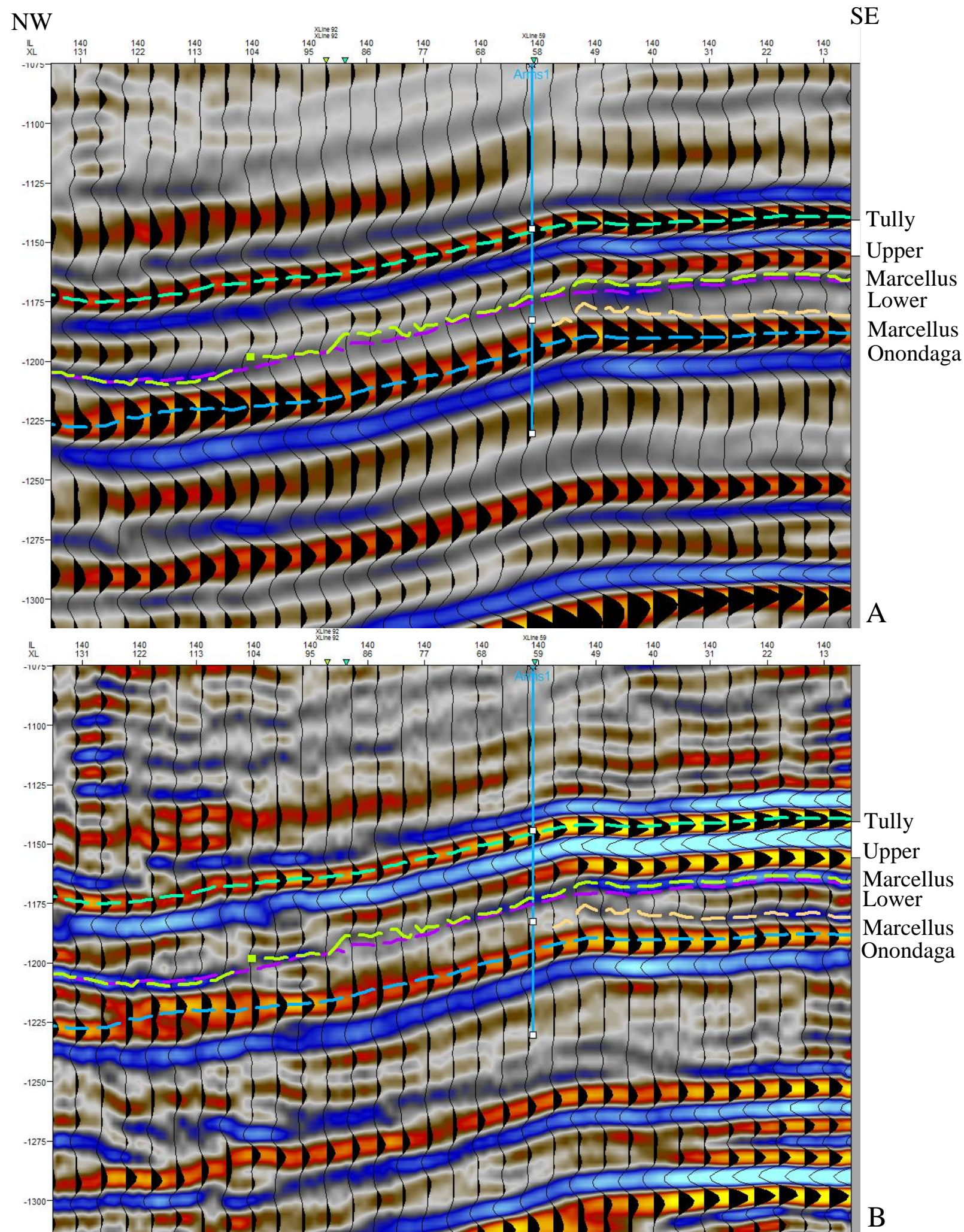

Figure. 3-12. Improved pick comparison in the original seismic (A) and spectral blueing (B).

Purple line is the pick from Zhu (2013) and the yellow line is the new pick based on the spectral blueing. 


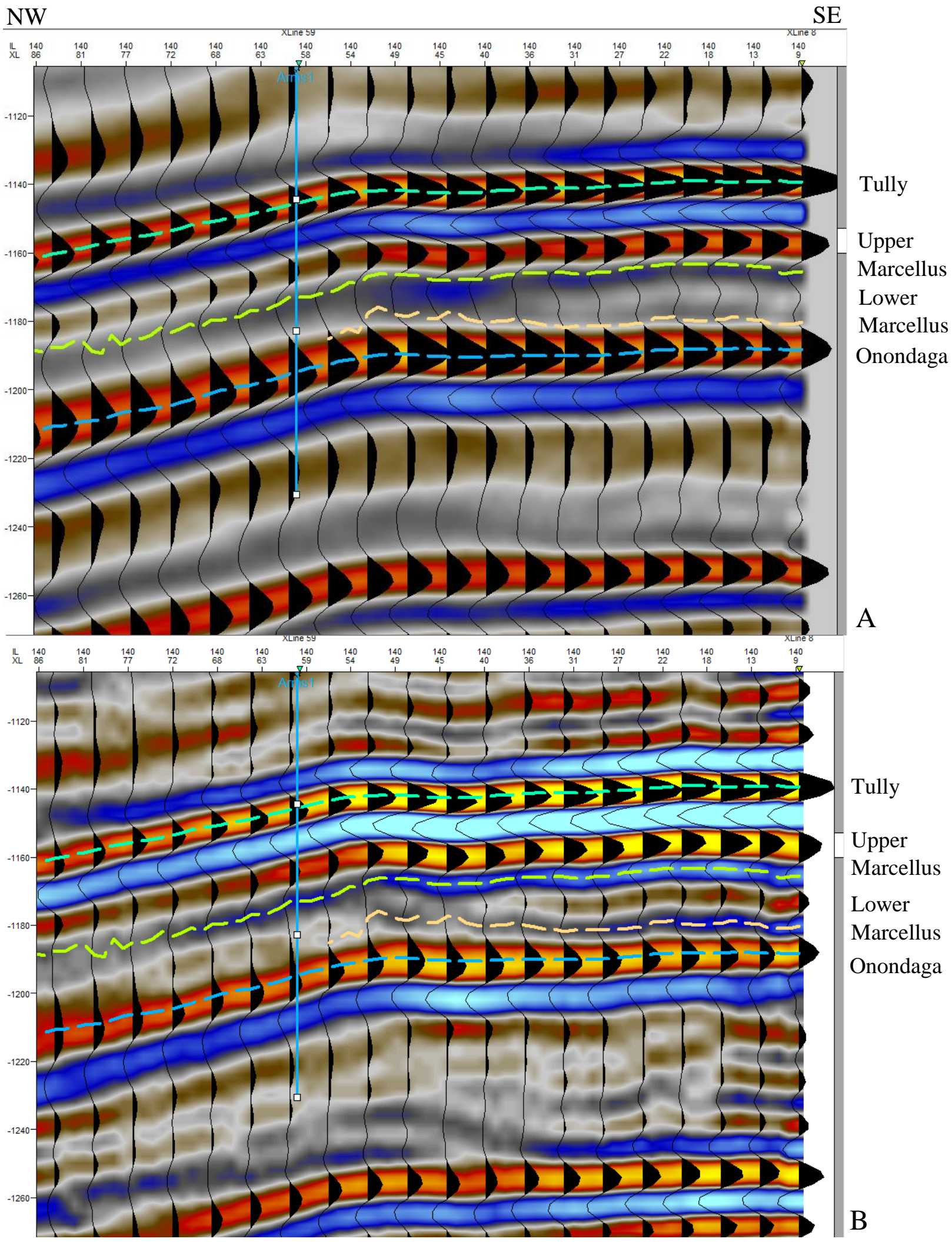

Figure. 3-13. Zoomed in view of the picks from the Tully to Onondaga in the original seismic (A) and spectral blueing (B). 


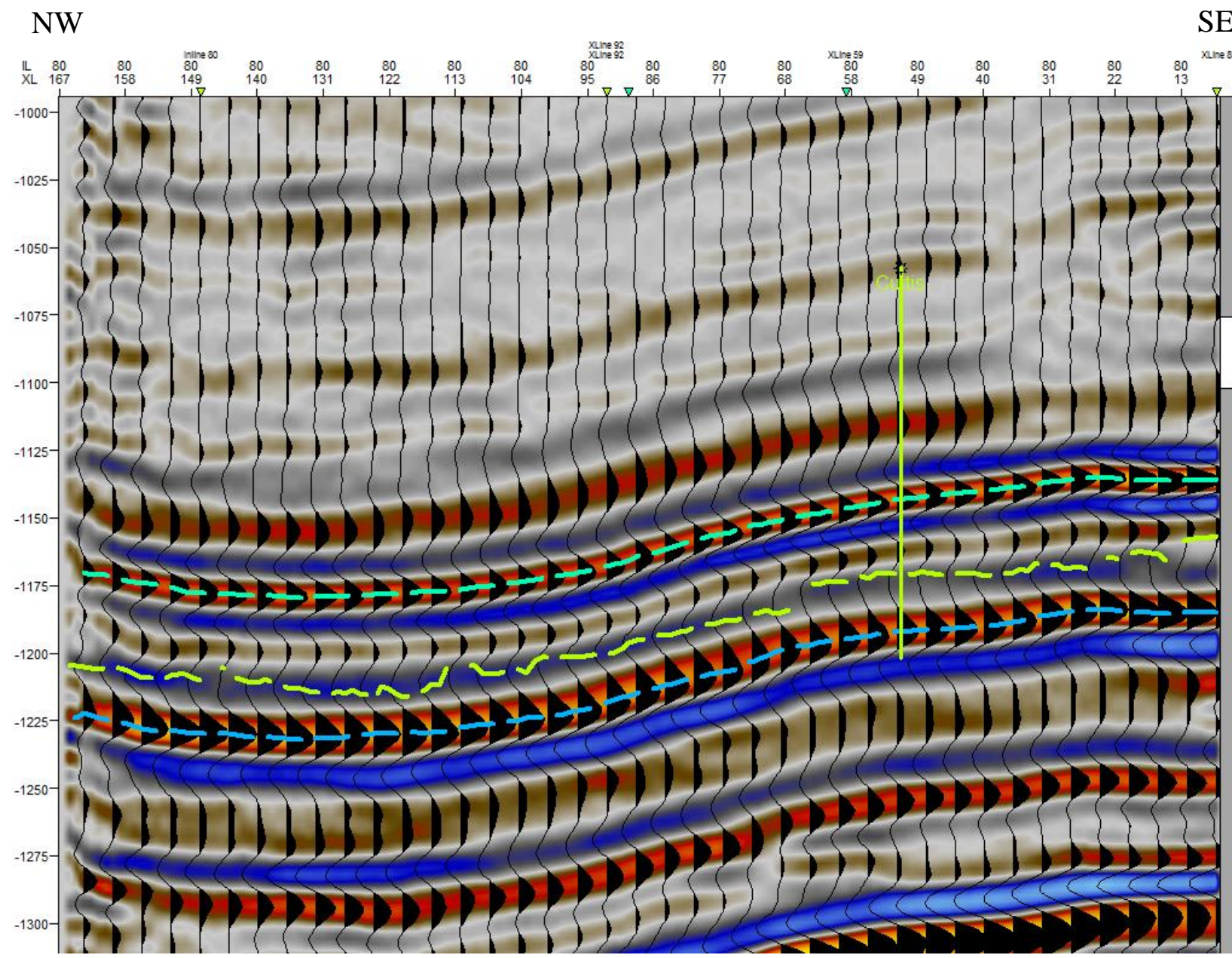

Figure 3-14. View of the post stack migration at the Curtis well. 


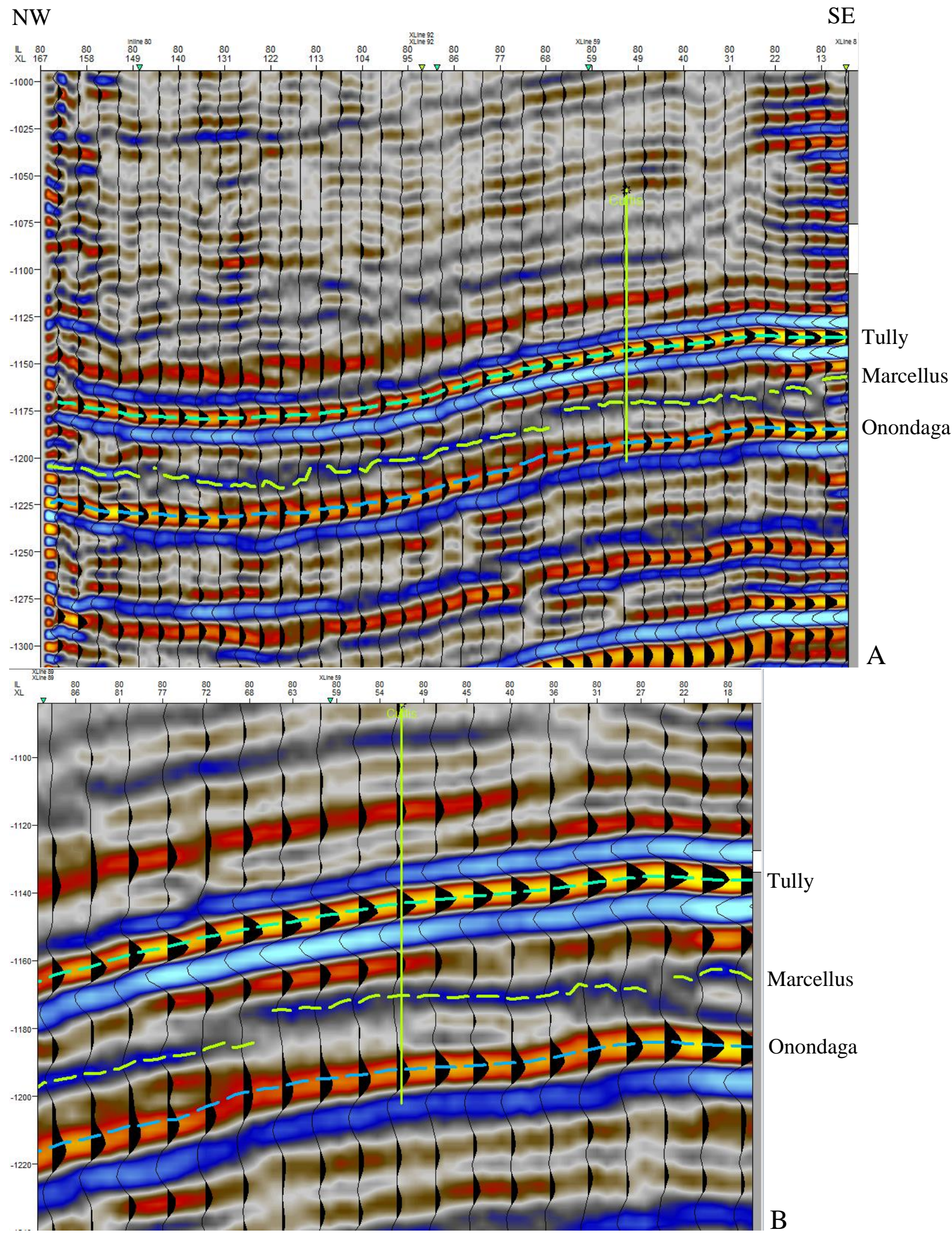

Figure 3-15. A) Spectral Blueing applied to seismic. B) Zoomed in view of the Marcellus and bounding intervals data at the Curtis well. 


\subsection{Structural Analysis}

The subsurface structure on the Marcellus and bounding intervals was interpreted in Petrel using formation picks from the 3-D migrated stack and spectral blueing volumes.

Prominent reflection events observed in the seismic response included the Tully Limestone, the Marcellus Shale, and the Onondaga Limestone. The Marcellus Shale interpretation presented by Zhu (2013) revealed a north-east/south-west trending syncline to the northwest part of the data and an anticline cross-strike structure to the southeast (Figure 3-16). A discontinuity was also interpreted to cross the northeast part of the study area with an orientation of approximately $\mathrm{N} 45 \mathrm{~W}$. The other bounding formations have very similar style structure. The Marcellus was repicked in the spectral blueing volume and revealed the same structures noted by Zhu (2013) (Figure 3-17).

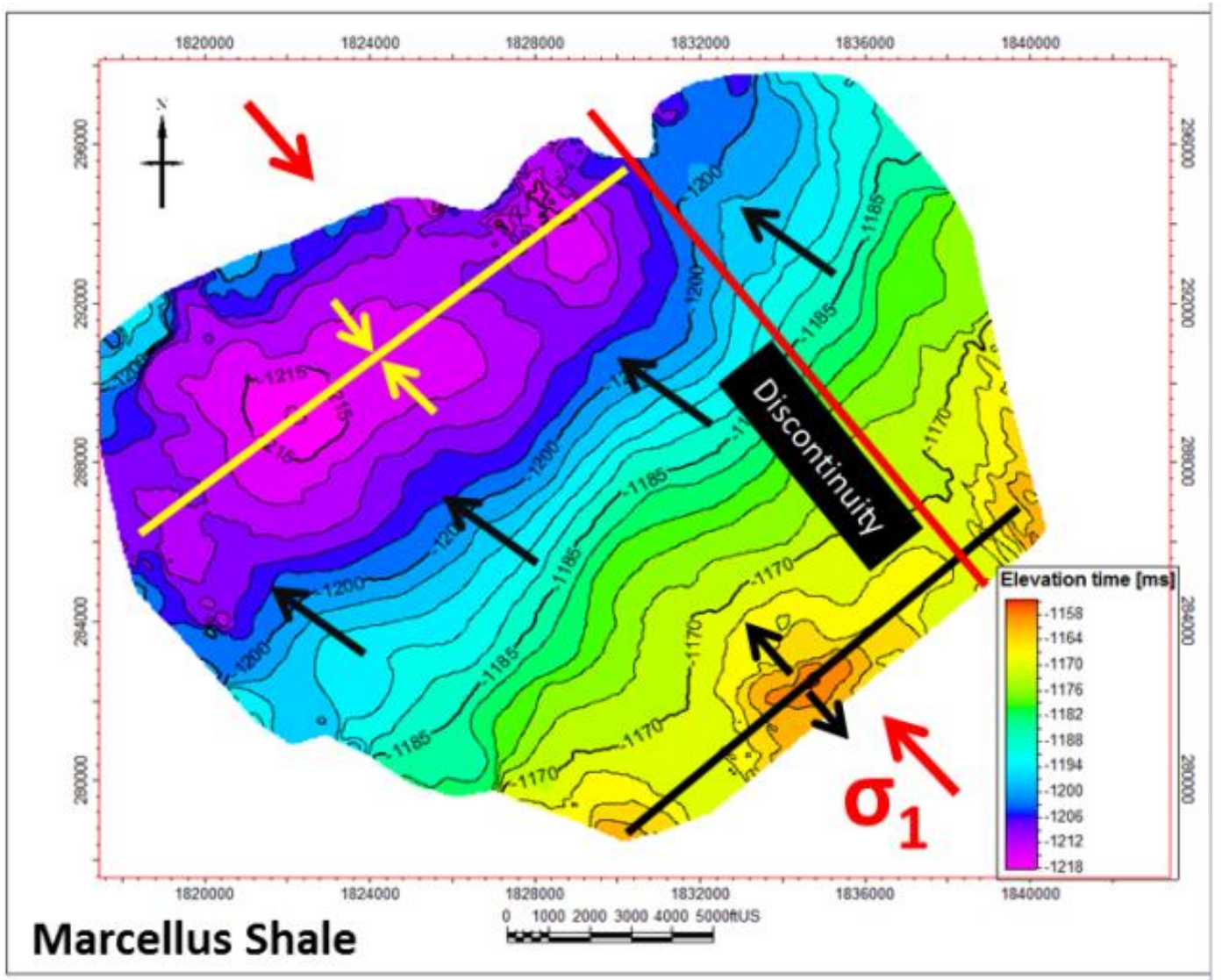

Figure 3-16. Marcellus Shale structure interpreted by Zhu (2013). The direction of $\sigma_{1}$ is interpreted as the direction of the paleo maximum compressive principle stress. 


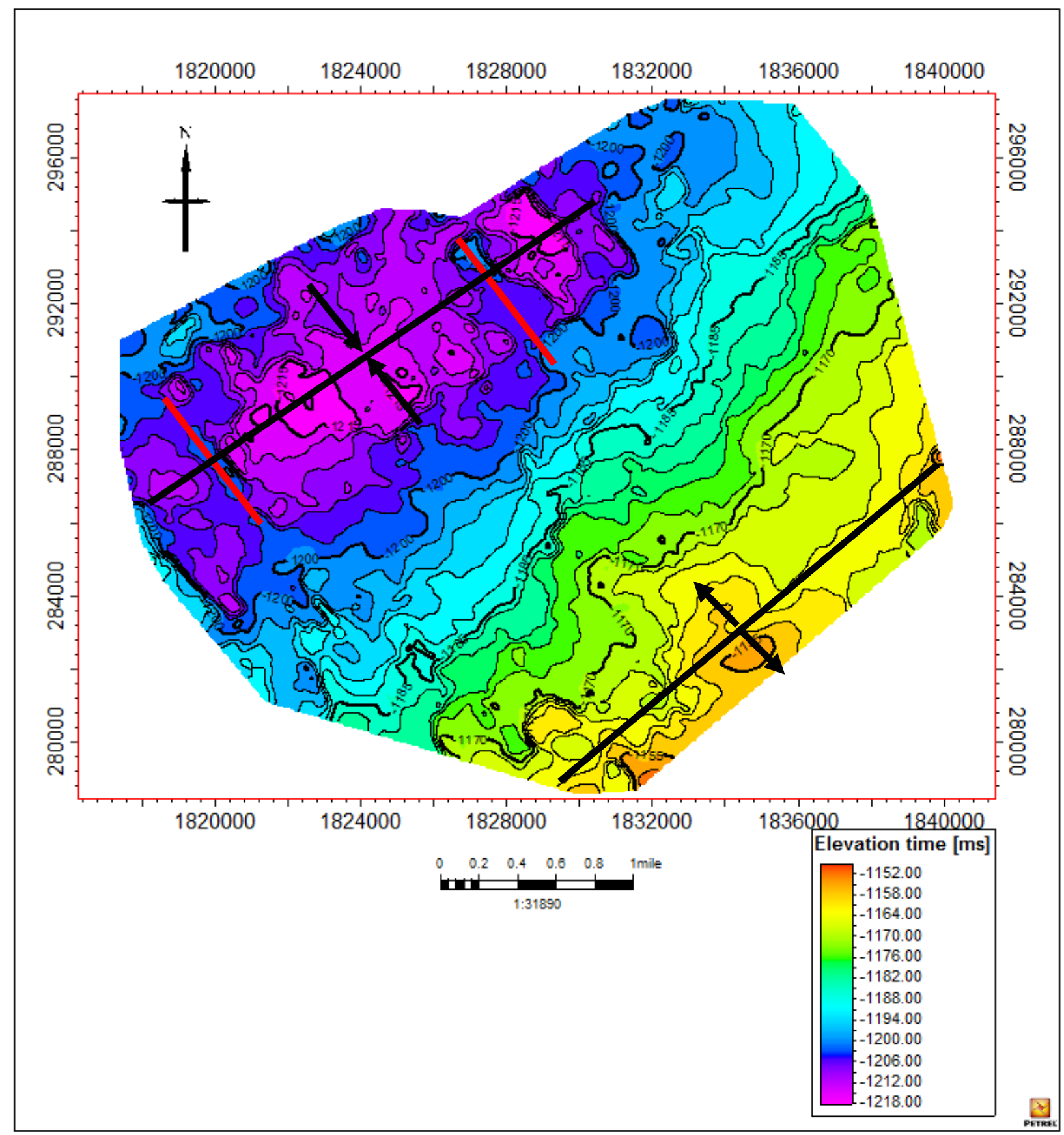

Figure 3-17. Marcellus structure map based on the picks from the spectral blueing. Improved visualization of structural disruption (red lines) in the syncline to the northwest can be seen. 
Isochore maps represent two-way travel time differences between individual reflection events. Isochore maps are created by taking the time value (two-way time) at the base of the horizon of interest minus the time value at the top of the horizon of interest. In these relatively low dipping strata, the isochore is directly related to the thickness of the formation where thickness $=1 / 2$ interval velocity $*$ time thickness (isochore). The time difference between the top and base of the Marcellus can be converted into thickness assuming a constant interval velocity from the logs of about 11,000ft/s. The isochore map reveals a general thickening to the east from about 90 feet in the central area to around 120 feet in the east in the post stack migration seismic (Figure 3-18). An isochore map produced from the picks in the spectral blueing seismic volume revealed that the majority of the thickening occurs to the east and southeast and the thickness of the Marcellus is a little greater ( 85 feet to 140 feet) and much more variable than previously shown (Figure 3-19). 


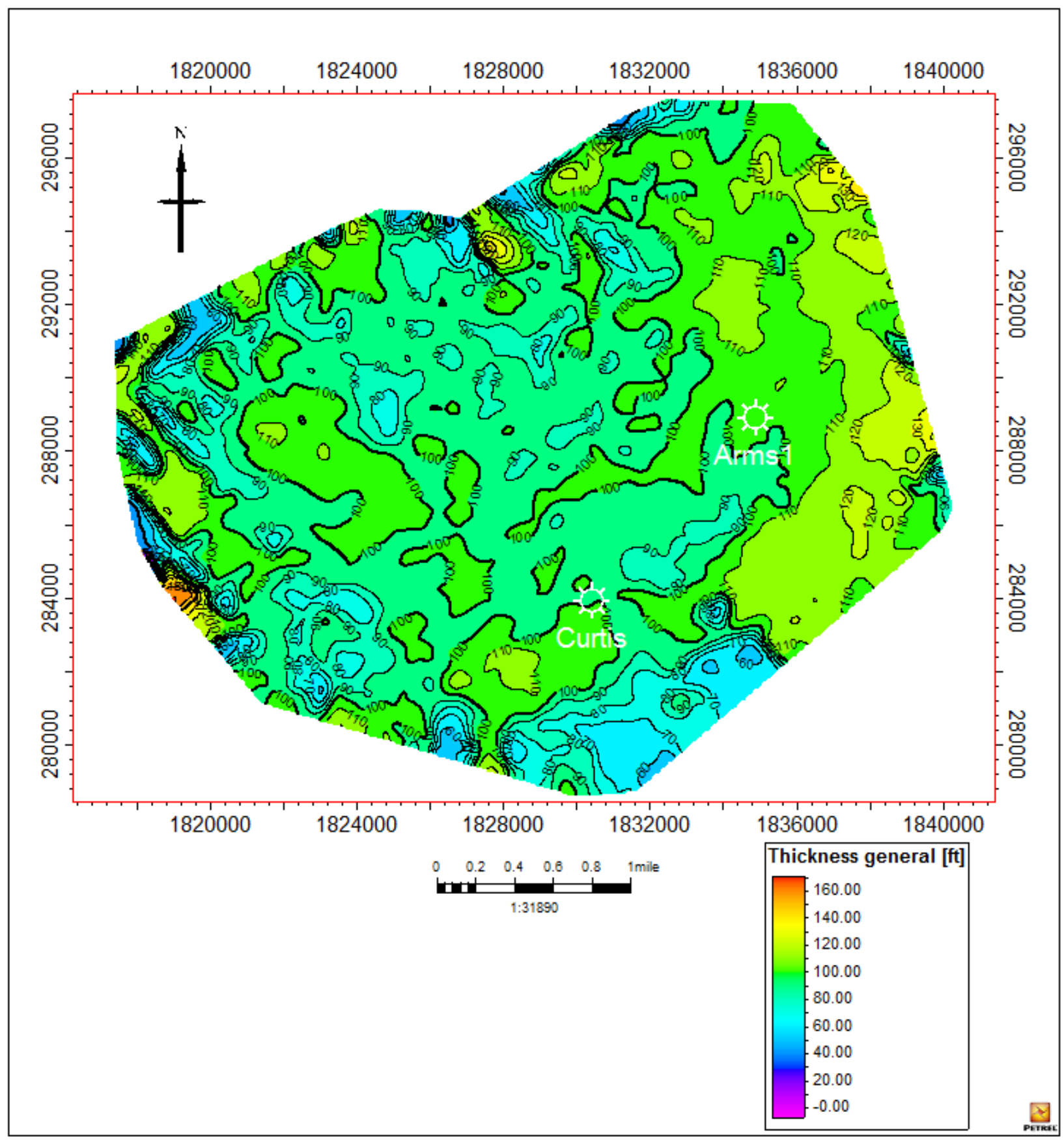

Figure 3-18. Isochore map of the Marcellus picked on the migrated stack volume showing some thickening toward the east. An estimated increase in thickness moving to the east from $90 \mathrm{ft}$ to $120 \mathrm{ft}$ is occurring. 


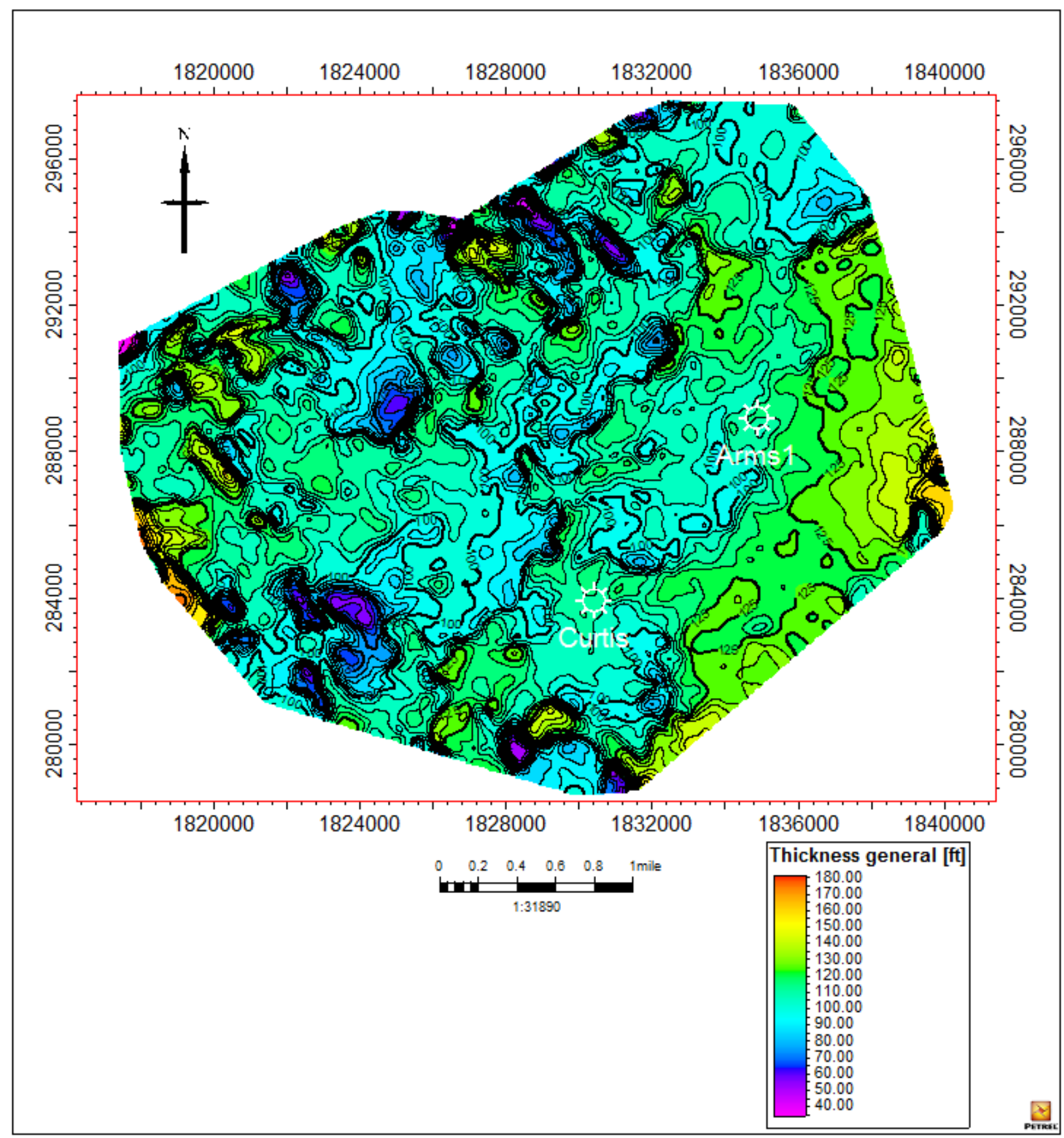

Figure 3-19. Isochore map of the Marcellus from horizons picked in the spectral blueing volume. The Marcellus seems to be generally increasing to the east (as indicated by the red arrow) from $85 \mathrm{ft}$ to about $140 \mathrm{ft}$, a bit more than the isochore interpretation from the post stack migration. The hummocky nature of this isochore map shows improved detail in the changing thickness of the Marcellus. 


\section{Chapter 4 \\ Mechanical Stratigraphy}

\subsection{Mechanical Properties}

"Mechanical stratigraphy subdivides stratified rock into discrete mechanical units defined by properties such as tensile strength, elastic stiffness, brittleness", and elastic moduli (such as Young's modulus and Poisson's ratio (Laubach et al., 2009). The well logs from the Armstrong

\#1 and Curtis wells included several mechanical property logs, such as Young's modulus and Poisson's ratio. Young's modulus is a measure of the stiffness of an elastic material:

$$
\mathrm{E}=\sigma / \varepsilon
$$

where E is Young's modulus, $\sigma$ is the tensile stress, and $\varepsilon$ is the extensional strain. Poisson's ratio is the negative ratio of transverse to axial strain:

$$
\mathrm{v}=-\varepsilon_{\text {trans }} / \varepsilon_{\text {axial }}
$$

where $\mathrm{v}$ is Poisson's ratio, $\varepsilon_{\text {trans }}$ is the transverse strain, and $\varepsilon_{\text {axial }}$ is the axial strain. The transverse strain is negative for axial tension/stretching and positive for axial compression and axial strain is positive for axial tension and negative for axial compression. Poisson's ratio can also be calculated from the well logs:

$$
\mathrm{V}=\frac{V_{p}^{2}-2 V_{s}^{2}}{2\left(V_{p}^{2}-V_{s}^{2}\right)}
$$

where $\mathrm{V}_{\mathrm{p}}$ is the primary (compressional) velocity, and $\mathrm{V}_{\mathrm{s}}$ is the secondary (shear) velocity. A completely incompressible material, such as rubber, has a Poisson's ratio of about 0.5 .

Conversely, cork has a Poisson's ratio near zero and undergoes significant axial strain with little 
transverse strain. These properties are used to evaluate the mechanical stratigraphy of formations.

\subsection{Brittleness}

The brittleness average was suggested by Grieser and Bray (2007) as an empirical relationship between Poisson's ratio and Young's modulus to separate ductile zones from brittle zones. Brittle intervals are those with a lower Poisson's ratio and a higher Young's modulus, and ductile intervals are those with a higher Poisson's ratio and a lower Young's modulus (Figure 4-1). These two mechanical properties can be used to calculate the brittleness average using the equations:

$$
\mathrm{E}_{\text {brittleness }}=\mathrm{E}-\mathrm{E}_{\min } / \mathrm{E}_{\max }-\mathrm{E}_{\min }
$$

where $\mathrm{E}$ is the Young's modulus, $\mathrm{E}_{\min }$ is the minimum Young's modulus, and $\mathrm{E}_{\max }$ is the maximum Young's modulus.

$$
\text { V brittleness }=\mathrm{v}-\mathrm{V}_{\max } / \mathrm{v}_{\min }-\mathrm{V}_{\max }
$$

where $\mathrm{v}$ is the Poisson's ratio, $\mathrm{V}_{\min }$ is the minimum Poisson's ratio, and $\mathrm{V}_{\max }$ is the maximum Poissons ratio. The brittleness average is defined using the equation:

$$
\text { Brittleness }_{\text {average }}=\left(\mathrm{E}_{\text {brittleness }}+\mathrm{v}_{\text {brittleness }}\right) / 2
$$

As the rock is put through increasing amounts of stress, the rock will pass through the elastic and ductile stages of deformation and eventually fracture. This allows rocks to be classified as either ductile or brittle. If a rock can be subject to a large amount of strain and absorb a lot of energy without failing, it is considered ductile. On the other hand, if a rock goes through a large amount of elastic behavior and little ductile reaction, the rock will fracture quickly and is considered brittle. Brittleness was calculated using this method to be consistent with the brittleness calculations from Alzate (2012). 
Although the high Young's modulus and low Poisson's ratio zones discussed in the next section would be more easily fractured based on brittleness alone, the TOC must be considered for its ability to produce (see Chapter 5). Combine the brittleness with the high TOC in the formation, makes the Marcellus, as a whole, very favorable to target. Specific zones within the Marcellus that are the most favorable to target have a higher Young's modulus and lower Poisson's ratio relative to the rest of the formation.

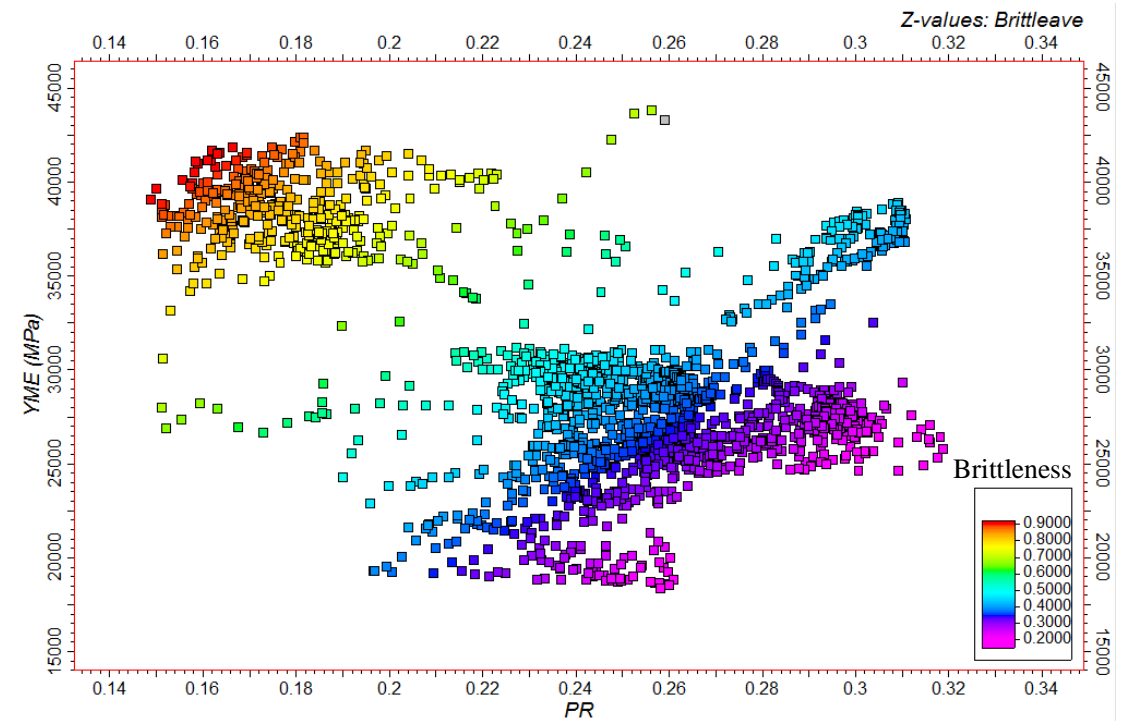

Figure 4-1. Cross plot of Young's modulus and Poisson's ratio colored by brittleness at the Armstrong \#1 well.

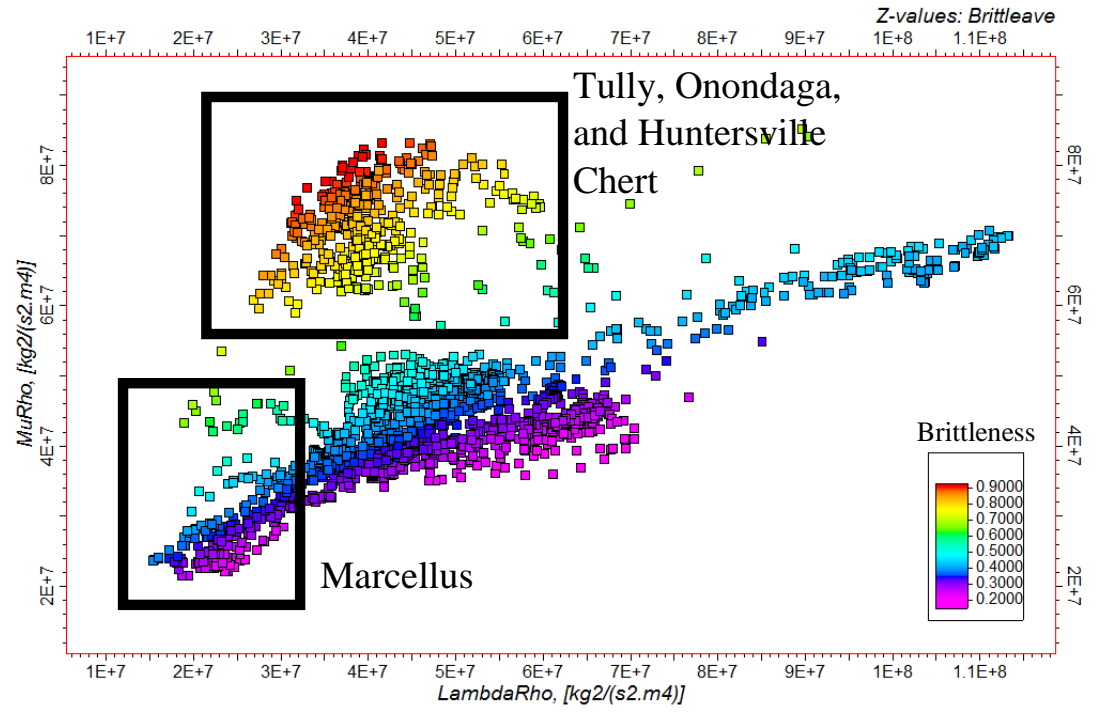

Figure 4-2. Cross plot of Mu-rho and Lambda-rho colored by brittleness at the Armstrong \#1 well. 


\subsection{Lambda/Rho - Mu/Rho}

In this study I use Lames parameters, lambda $(\lambda)$, the incompressibility, and mu $(\mu)$, the rigidity, to locate brittle and TOC rich intervals. Lambda-rho/mu-rho cross-plots give an indication of the overall lithology and can be related to other parameters, such as Young's modulus (E) or Poisson's ratio (v) (Alzate and Devegowda, 2013).

Lame's parameters are calculated using the following equations:

$$
\begin{gathered}
\text { Lambda: } \lambda=\rho\left(\mathrm{V}_{\mathrm{p}}^{2}-2 \mathrm{~V}_{\mathrm{s}}^{2}\right) \\
\mathrm{Mu}: \mu=\rho \mathrm{V}_{\mathrm{s}}^{2}
\end{gathered}
$$

where $V_{p}$ is the primary velocity, $V_{s}$ is the shear velocity, and $\rho$ is the density. The primary velocity $\left(\mathrm{V}_{\mathrm{p}}\right)$ and the shear velocity $\left(\mathrm{V}_{\mathrm{s}}\right)$ were calculated from the sonic logs provided by the logging company. To calculate lambda-rho and mu-rho, the Lame's parameter equations are multiplied by the density.

$$
\begin{gathered}
\text { Lambda-rho: } \lambda \rho=\rho^{2}\left(\mathrm{~V}_{\mathrm{p}}^{2}-2 \mathrm{~V}_{\mathrm{s}}^{2}\right) \\
\text { Mu-rho: } \mu \rho=\rho^{2} \mathrm{~V}_{\mathrm{s}}^{2}
\end{gathered}
$$

Alzate (2012), for example, used lambda-rho/mu-rho cross plots to classify zones in the Barnett Shale as brittle or ductile and TOC rich or poor with brittle and rich zones being the best to target. He calculated lambda-rho and mu-rho from seismically inverted $V_{p}$ and $V_{s}$ data, which had a resolution limit of 79 feet based on a dominant frequency of $40 \mathrm{~Hz}$ and a $V_{p}$ of $12,651 \mathrm{ft} / \mathrm{s}$. This is much greater than the half-foot resolution of well logs. He identified brittle and TOC rich zones as having lower values of both lambda-rho and mu-rho. Higher lambda-rho and Poisson's ratio implied a zone was more ductile and higher mu-rho and Young's modulus implied a zone was TOC poor. Based on accompanying microseismic data, he observed higher production in areas that were brittle and TOC rich (figure 4-3a). He suggested targeting zones that were brittle, 
preferably TOC rich, but the brittleness was the more important factor, especially if there is a high TOC interval nearby.

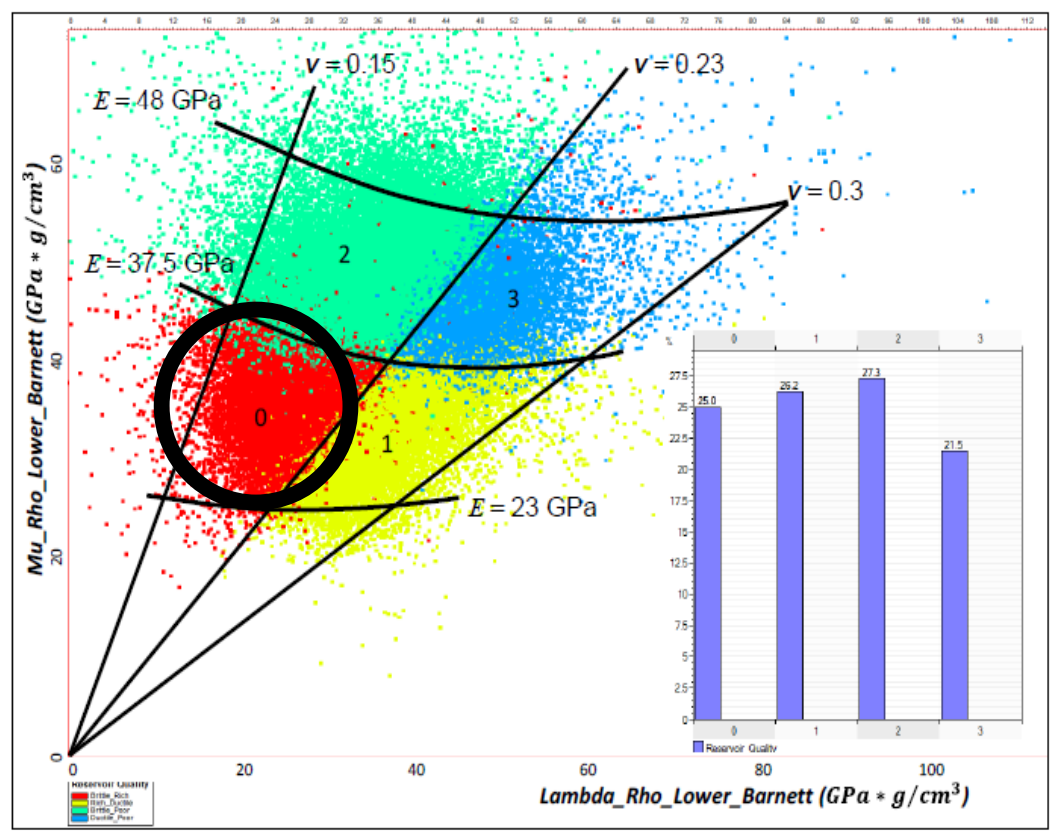

Figure 4-3a. Lower Barnett reservoir quality classification based on seismically inverted rock properties. Four groups are defined: Group 0 or Brittle and TOC rich (black circle), Group 1 or TOC rich and ductile, Group 2 or Brittle and TOC poor, and Group 3 or Ductile and TOC poor. Cut offs selected to make each group as even a possible. Figure from Alzate (2012).

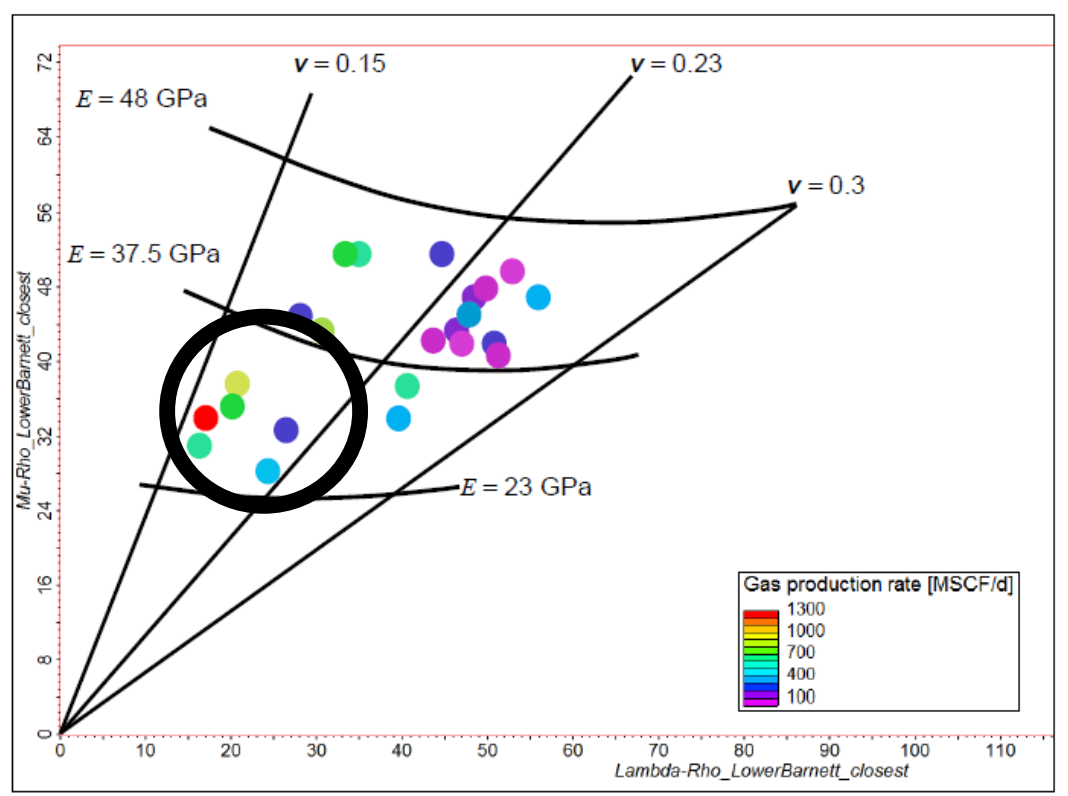

Figure 4-3b. Seismic Lambda-rho/Mu-rho extracted along the wellbores with production logs. The color indicates the gas rate at each individual perforation. Figure from Alzate (2012). The black circle represents the brittle and TOC rich zone. 
Under his classification, he implied that the most productive zones were associated with a lower range of observed Poisson's ratio of 0.15 to 0.23 and a lower range of observed Young's modulus between $21 \mathrm{GPa}$ and $37.5 \mathrm{GPa}$ (Table 1 ). These cut-offs were the highest producing zones in the Barnett Shale (figure 4-3b). Data points falling within the same cut-offs from the Armstrong \#1 data correspond to some intervals within the Marcellus Shale (figures 4-4, 4-5, and 4-6).

\begin{tabular}{|c|c|c|}
\hline Alzate (2012) & Poisson's ratio & $\begin{array}{c}\text { Young's modulus } \\
\text { (GPa) }\end{array}$ \\
\hline Low cut-off & 0.15 & 23 \\
\hline High cut-off & 0.23 & 37.5 \\
\hline
\end{tabular}

Table 1. Original cut-offs from Alzate (2012).

The need for adjustment in the cut-offs from Alzate (2012) is necessary and highlighted by figures $4-8$ and $4-9$, which show that very little of the Marcellus at the Curtis well falls into the brittle and TOC rich zone that Alzate (2012) suggested. The similar production between the two wells (discussed at the end of this chapter) indicates that one well cannot necessarily be the primary base for parameter modification. However, two wells are hardly sufficient to refine the parameters to target the most optimal zones in the Marcellus Shale. This portion of the study provides a basis for future studies of lambda-rho/mu-rho in the Marcellus, which should use many additional wells to further refine the cut-offs presented in this research. The targets based on the lambda-rho/mu-rho cross-plots would classify additional zones for even more production from both these and other wells. 


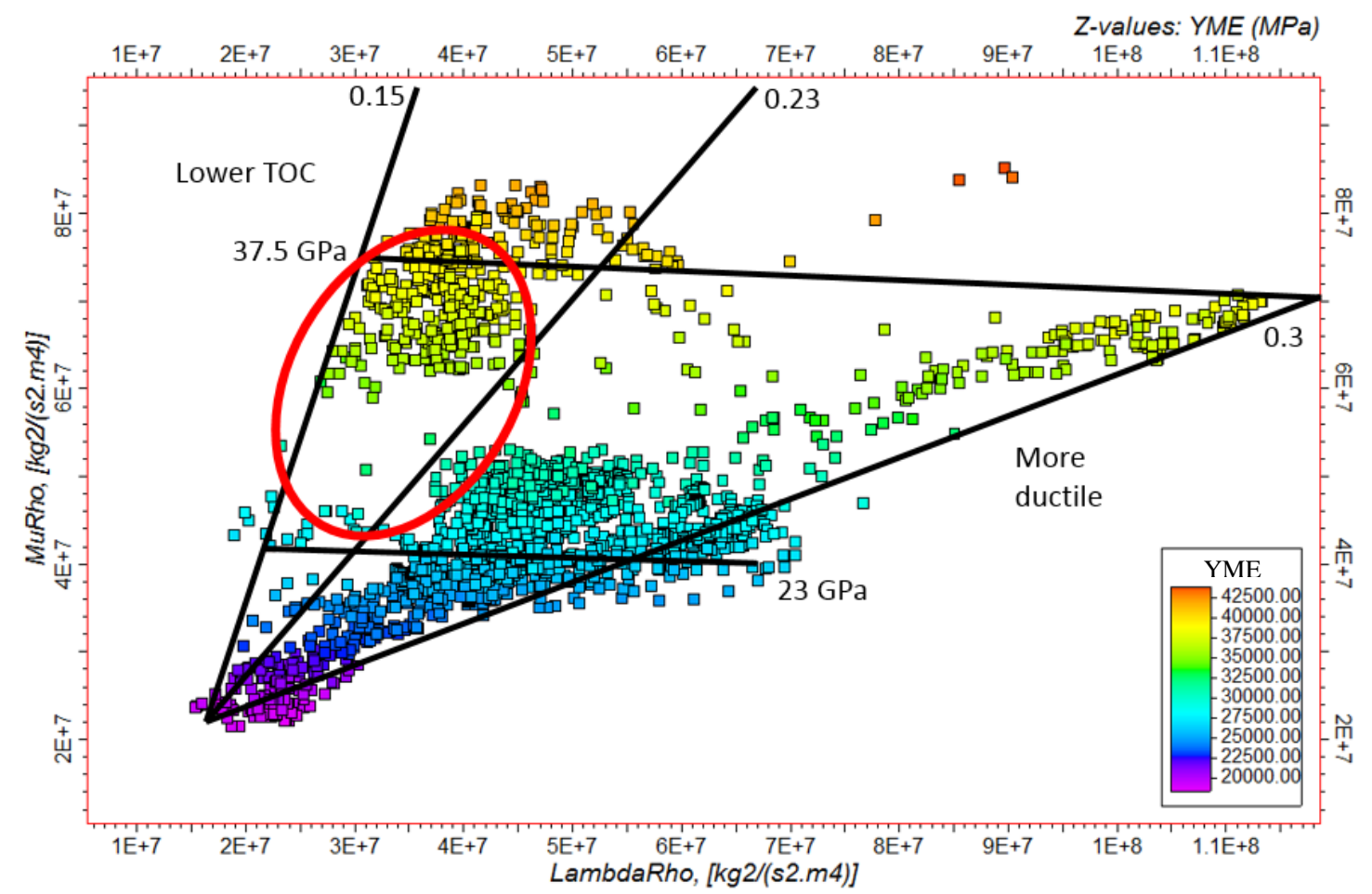

Figure 4-4a. Cross plot of Mu-rho and Lambda-rho colored by Young's Modulus at the Armstrong \#1 well. The brittle and TOC rich zone based on Alzate (2012) is circled in red.

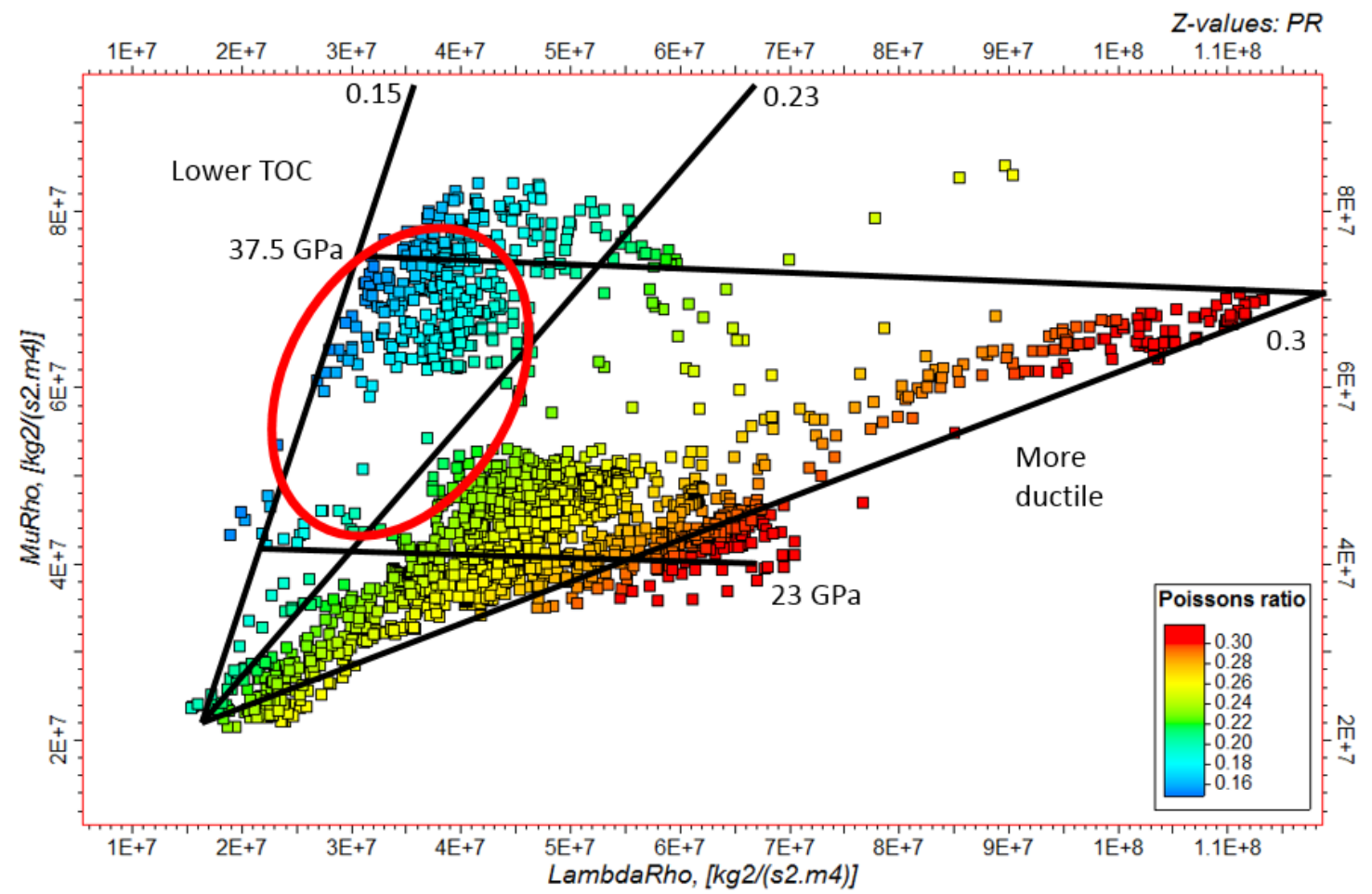

Figure 4-4b. Cross plot of Mu-rho and Lambda-rho colored by Poisson's Ratio at the Armstrong \#1 well. The brittle and TOC rich zone based on Alzate (2012) is circled in red. 


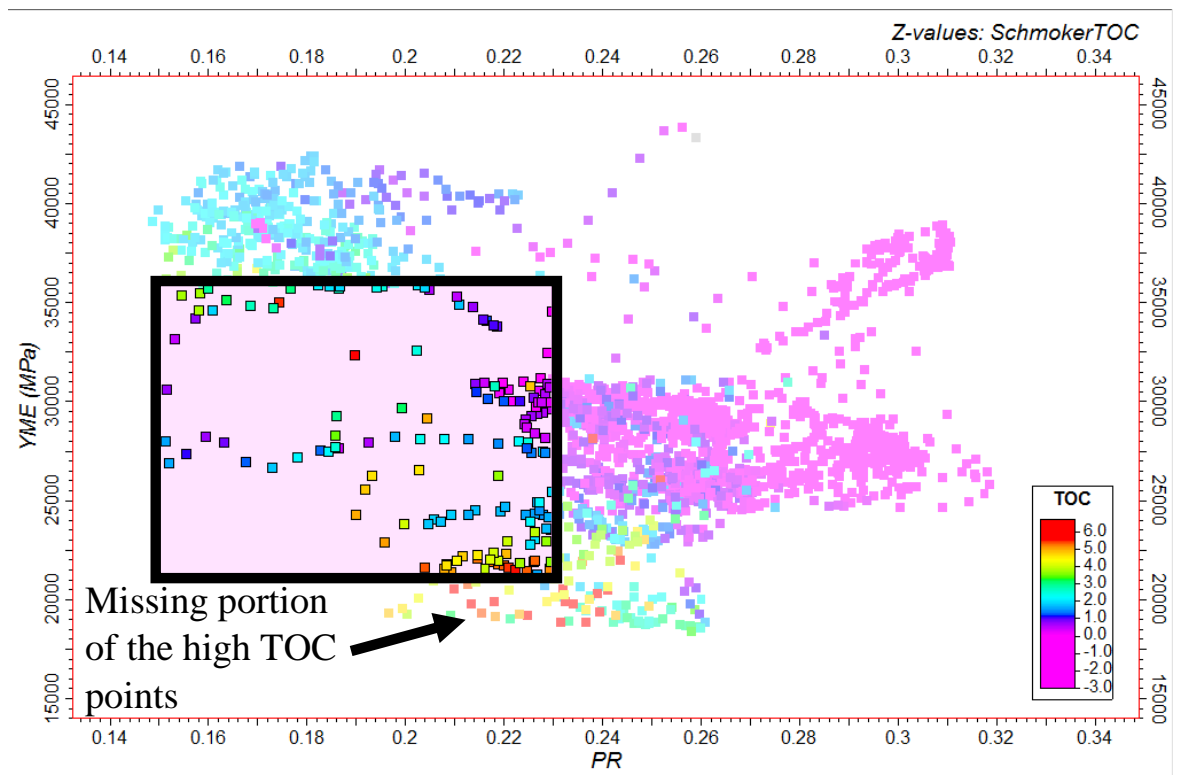

Figure 4-5. Cross plot of Young's modulus and Poisson's ratio colored by TOC at the Armstrong \#1 well. The data points within the purple box are those that fall into the Alzate (2012) classification of brittle and rich. Data points within the purple box are shown stratigraphically in the next figure.

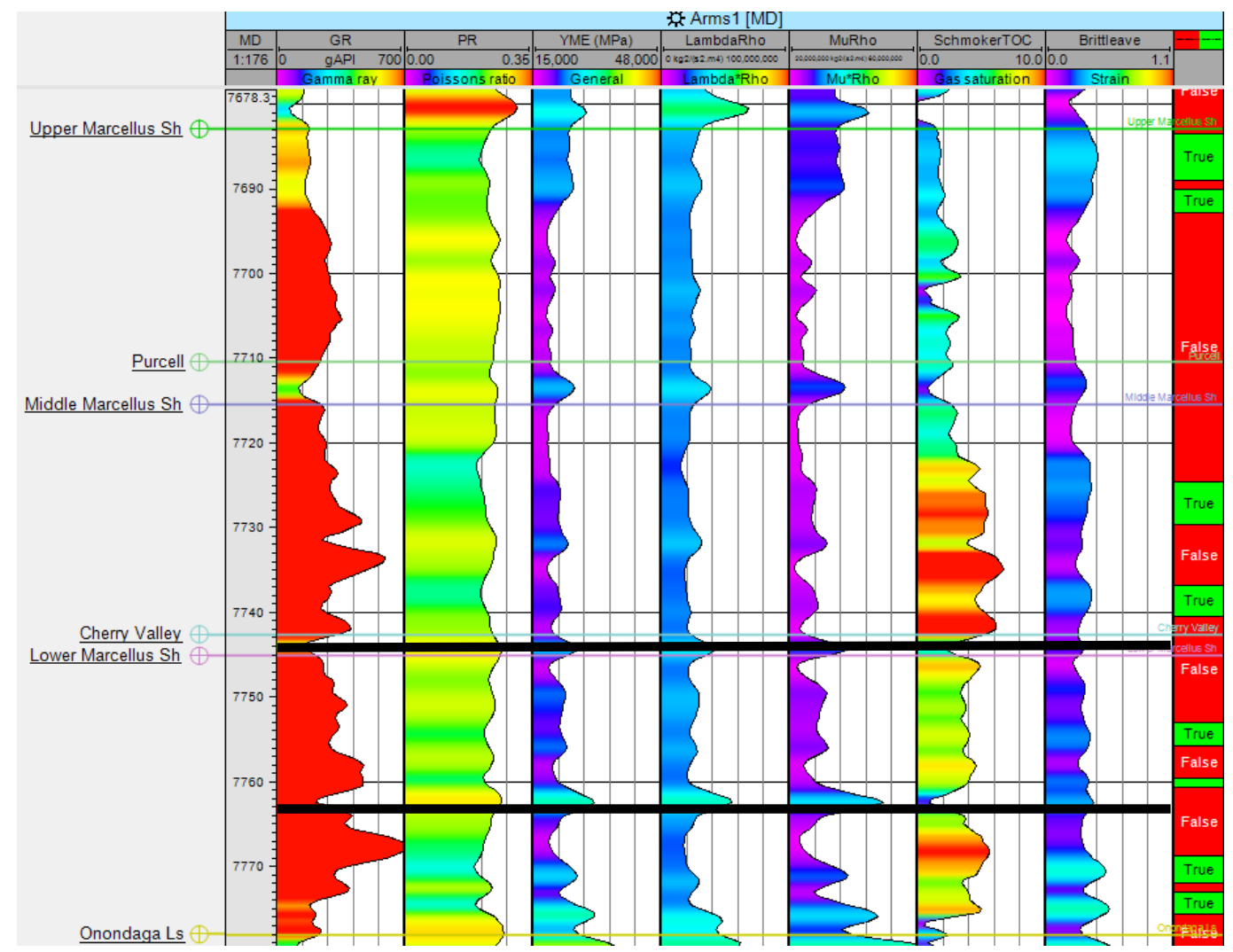

Figure 4-6. Boolean log created based on previous figure of the brittle and rich data points. Areas labeled with green "true" correspond to the purple region selected in previous figure, which is the TOC rich and brittle zone. The upper and lower limits of the producing zone is distinguished by the black lines. 


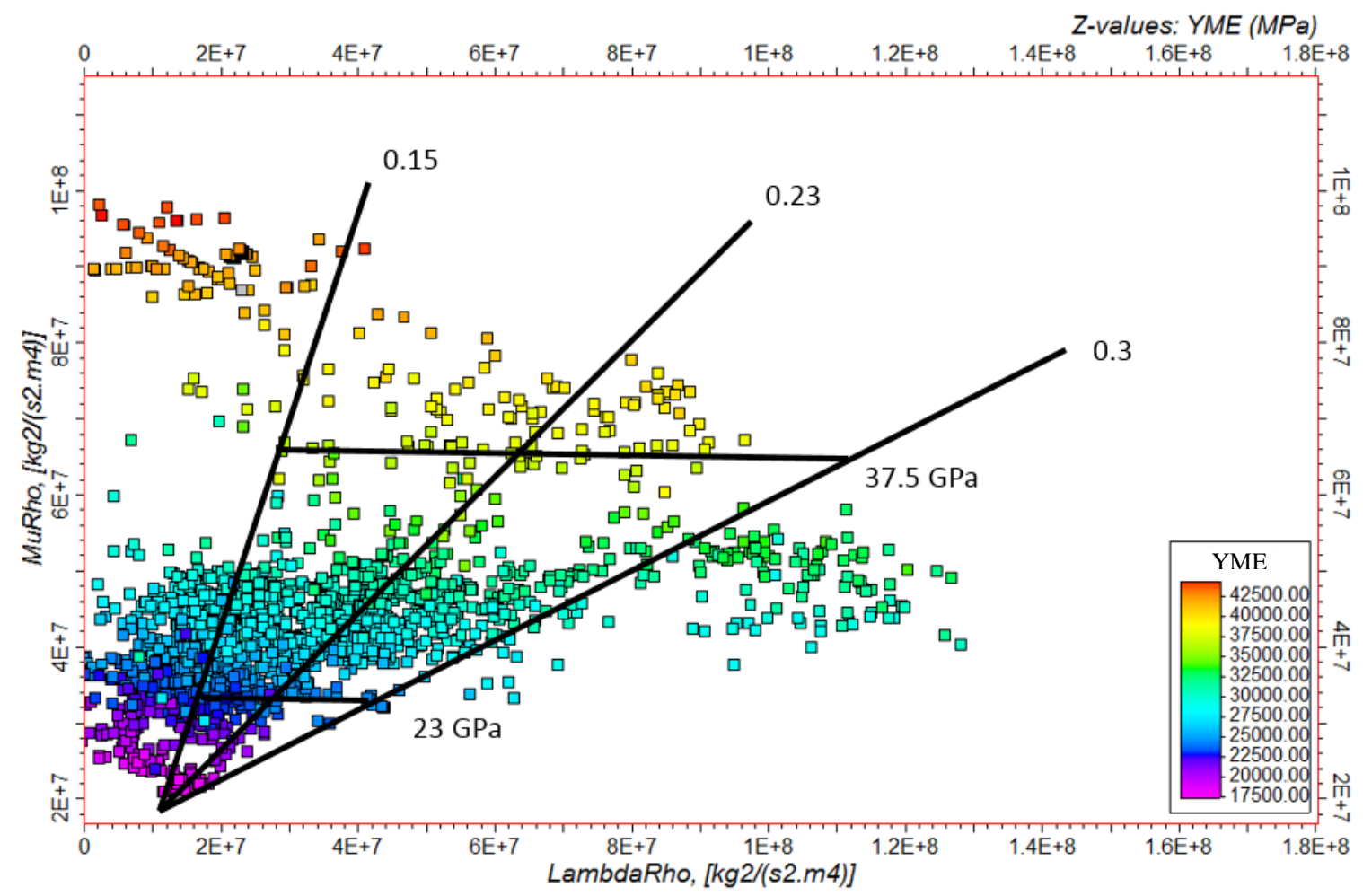

Figure 4-7a. Lambda-rho/Mu-rho cross-plot colored by Young's modulus with Alzate (2012) cut-offs at the Curtis well.

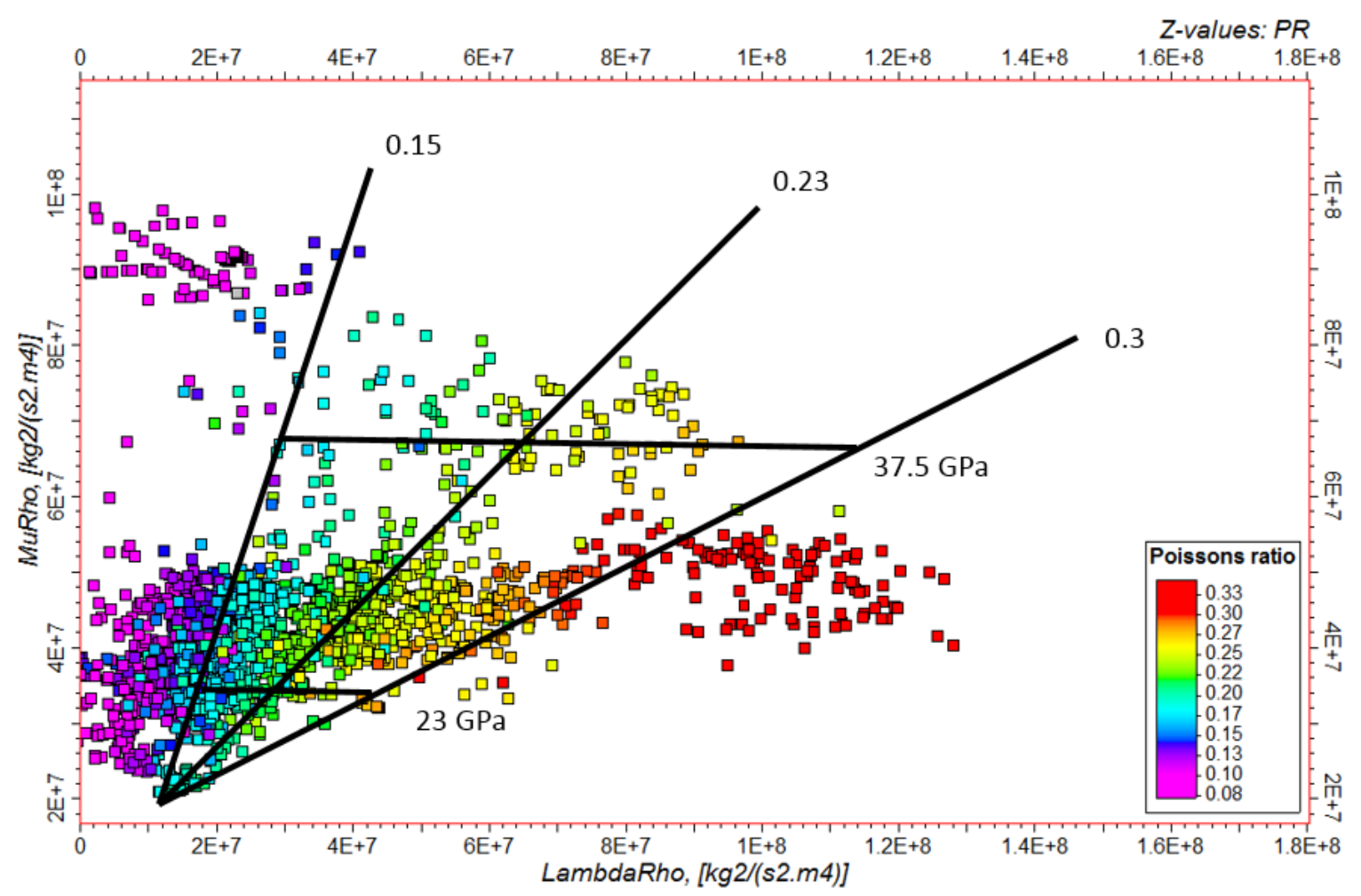

Figure 4-7b. Lambda-rho/Mu-rho cross-plot colored by Poisson's ratio with Alzate (2012) cutoffs at the Curtis well. 


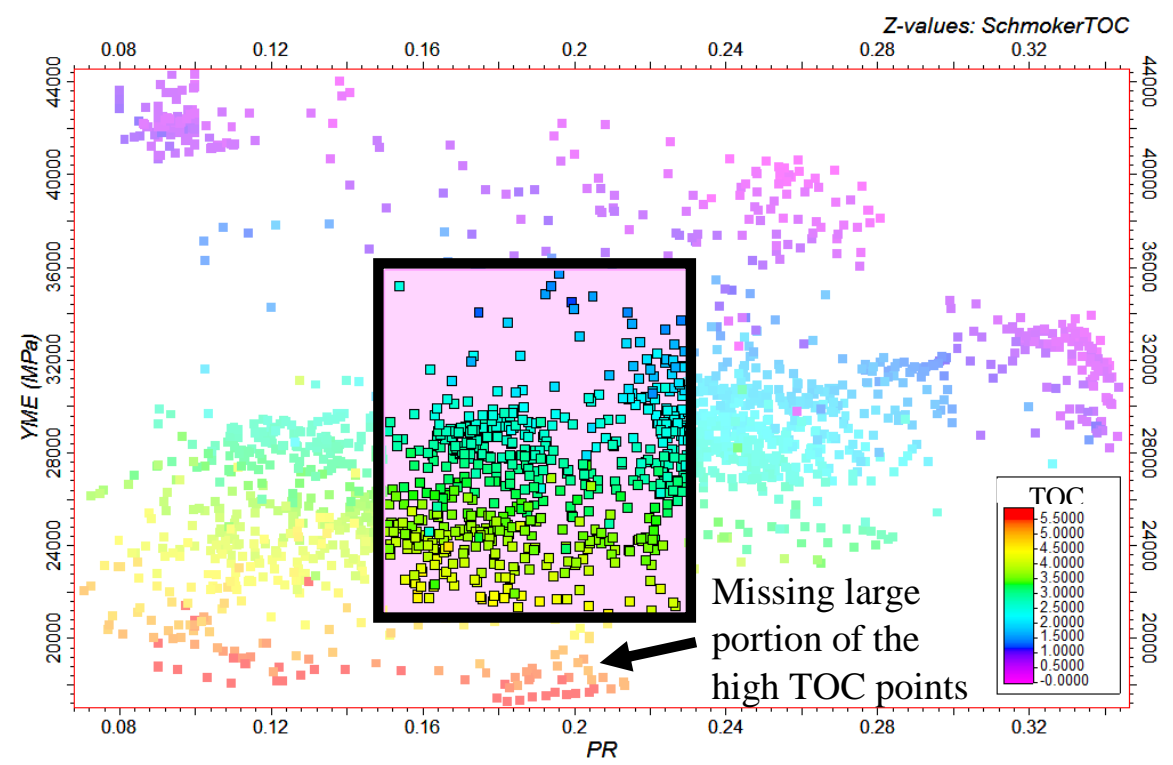

Figure 4-8. Cross plot of Young's modulus and Poisson's ratio colored by TOC at the Curtis well. The data points within the purple box are those that fall into the Alzate (2012) classification of brittle and rich. Data points within the purple box are shown stratigraphically in the next figure.

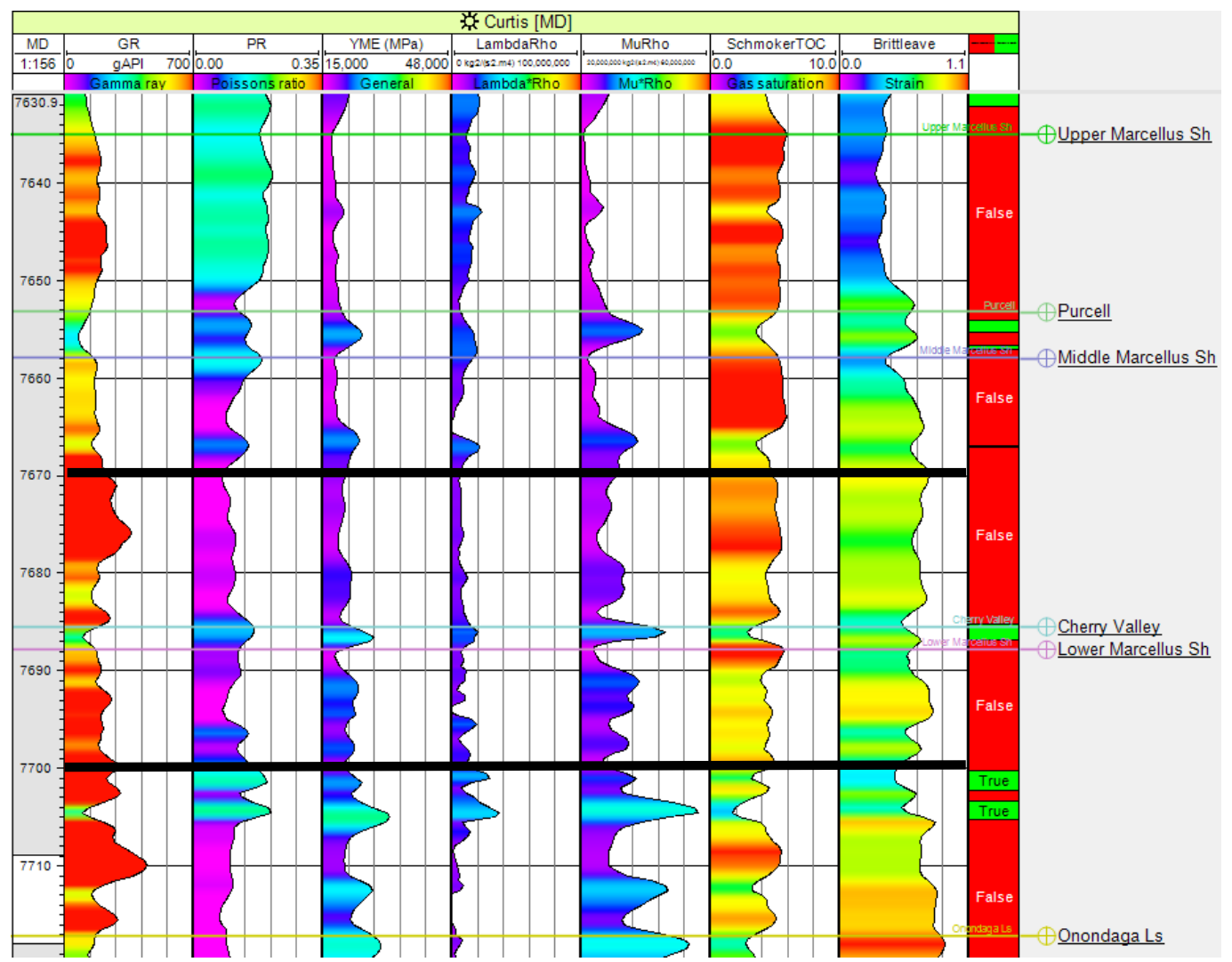

Figure 4-8. Boolean log created based on previous figure of the brittle and rich data points. Areas labeled with green "true" correspond to the green region selected in previous figure, which is the TOC rich and brittle zone. The upper and lower limits of the producing zone is distinguished by the black lines. 
The Marcellus Shale generally falls into a region of the lower left of the Lambda-rho/Murho plot at both the Armstrong \#1 and Curtis wells (figure 4-10 through 4-13). The Young's moduli are relatively low in the Marcellus, however, the Poisson's ratios fall into a low to intermediate value range. At the Armstrong \#1 well, the producing interval and highest brittleness/TOC intervals fell into a zone where the Poisson's ratio was between 0.21 and 0.27 and the Young's modulus was between 19.2GPa and 26.3GPa. At the Curtis well, the producing interval fell within a Poisson's ratio of 0.10 and 0.16 and a Young's modulus of 21.2GPa and 25.7GPa.

\begin{tabular}{|c|c|c|}
\hline Armstrong \#1 Well & Poisson's ratio & $\begin{array}{c}\text { Young's modulus } \\
(\mathrm{GPa})\end{array}$ \\
\hline Low cut-off & 0.21 & 19.2 \\
\hline High cut-off & 0.27 & 26.3 \\
\hline Curtis Well & & \\
\hline Low cut-off & 0.10 & 21.2 \\
\hline High cut-off & 0.16 & 25.7 \\
\hline
\end{tabular}

Table 2. Summary of the average Poisson's ratio and Young's modulus values at the Armstrong \#1 and Curtis wells. 


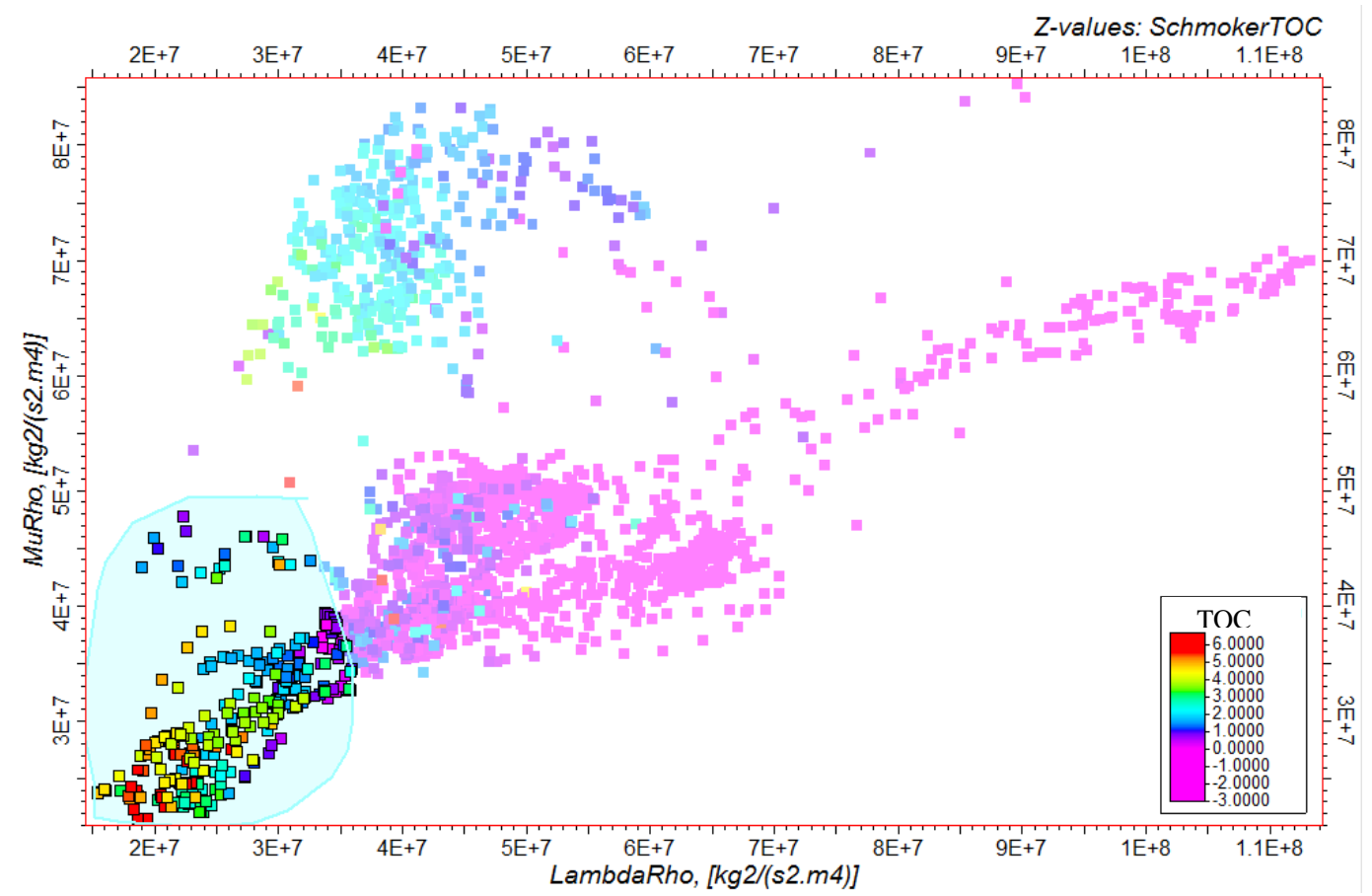

Figure 4-10. Cross plot of Mu-rho and Lambda-rho colored by TOC at the Armstrong \#1 well. Data points within the area selected in blue are shown stratigraphically in the next figure.

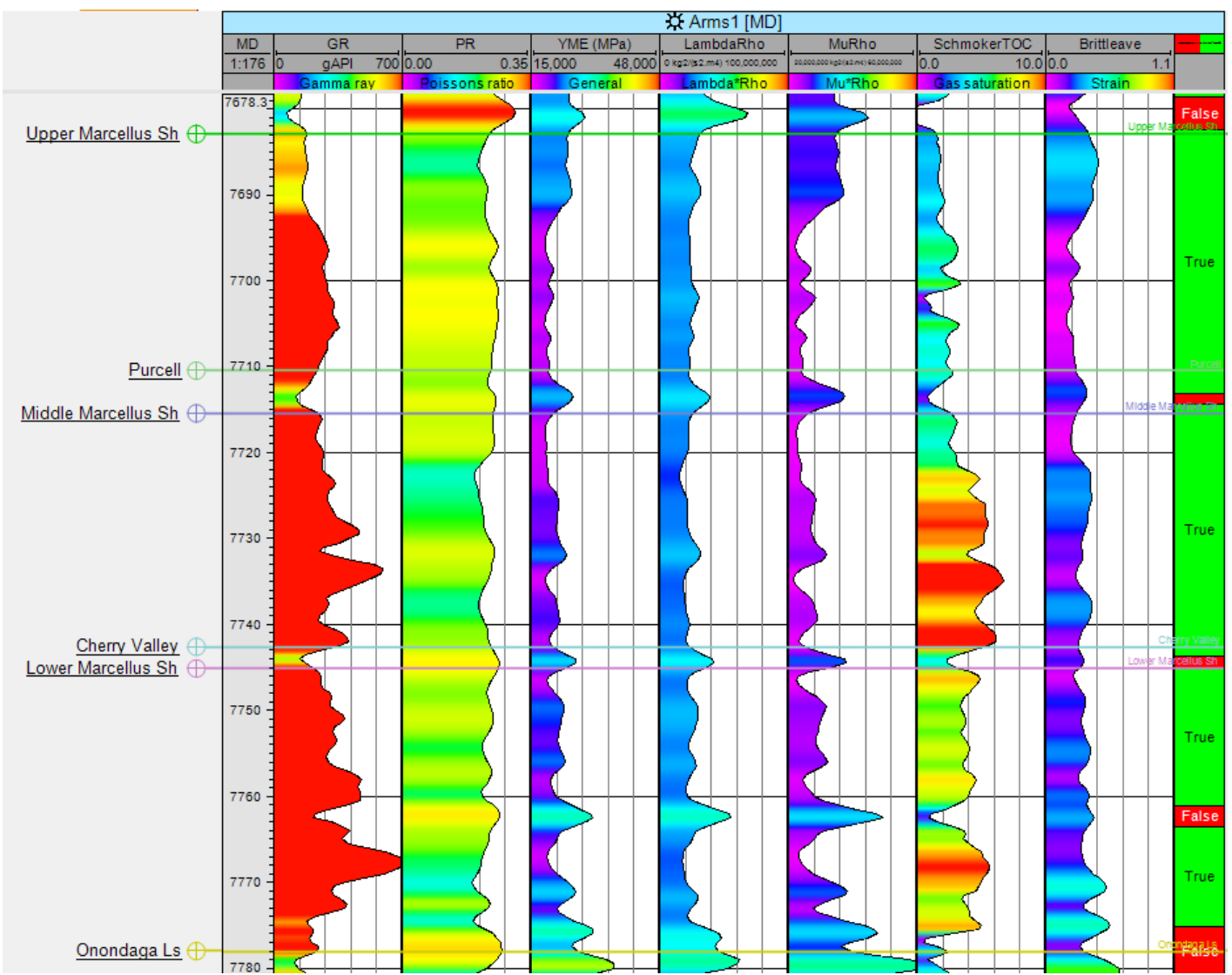

Figure 4-11. Boolean Log created based on previous figure. Areas labeled with green "true" correspond to the blue region selected in previous figure with low lambda-rho/mu-rho. 


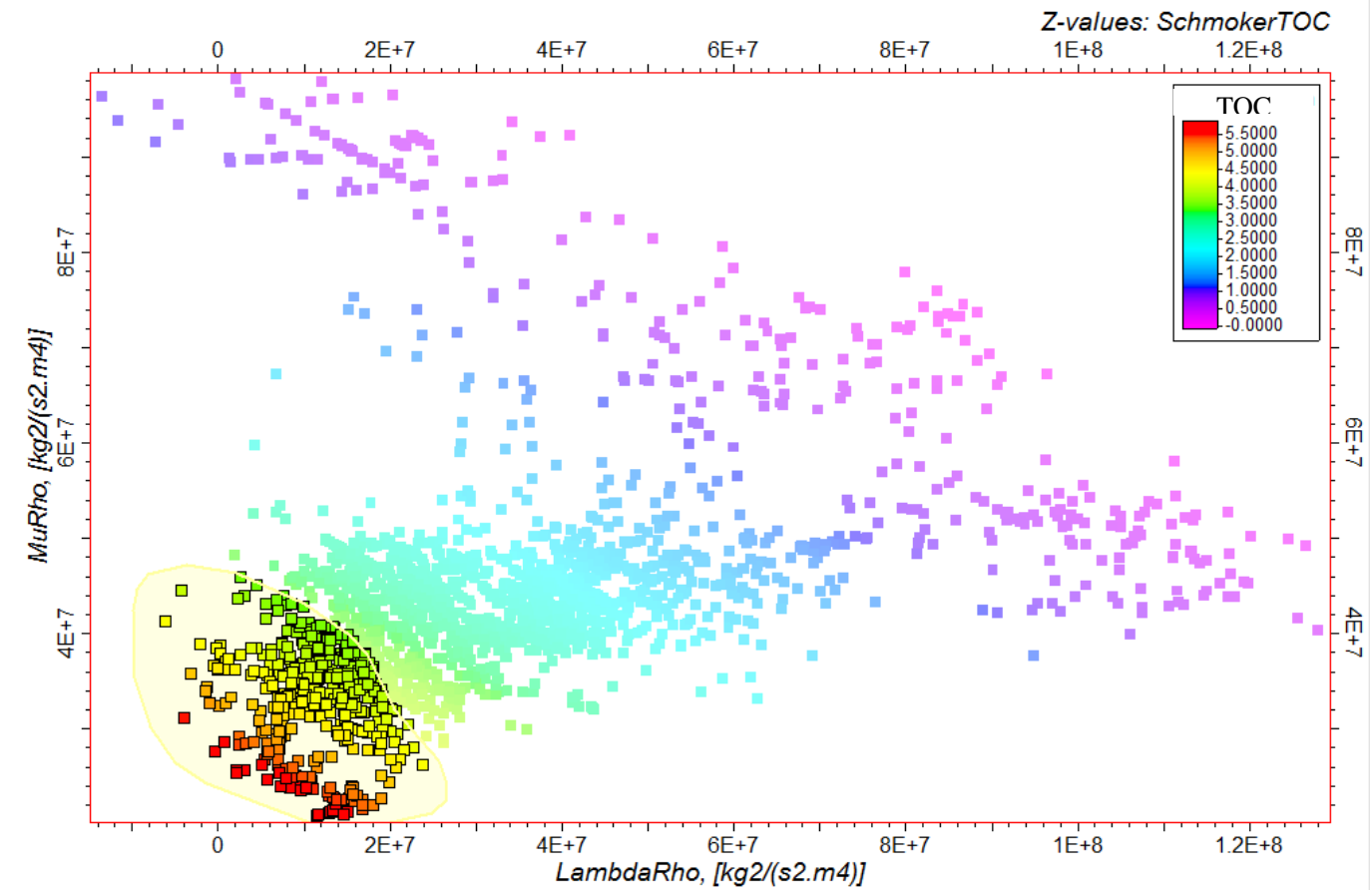

Figure 4-12. Cross plot of Mu-rho and Lambda-rho colored by TOC at the Curtis. Data points within the area selected in yellow are shown stratigraphically in the next figure.

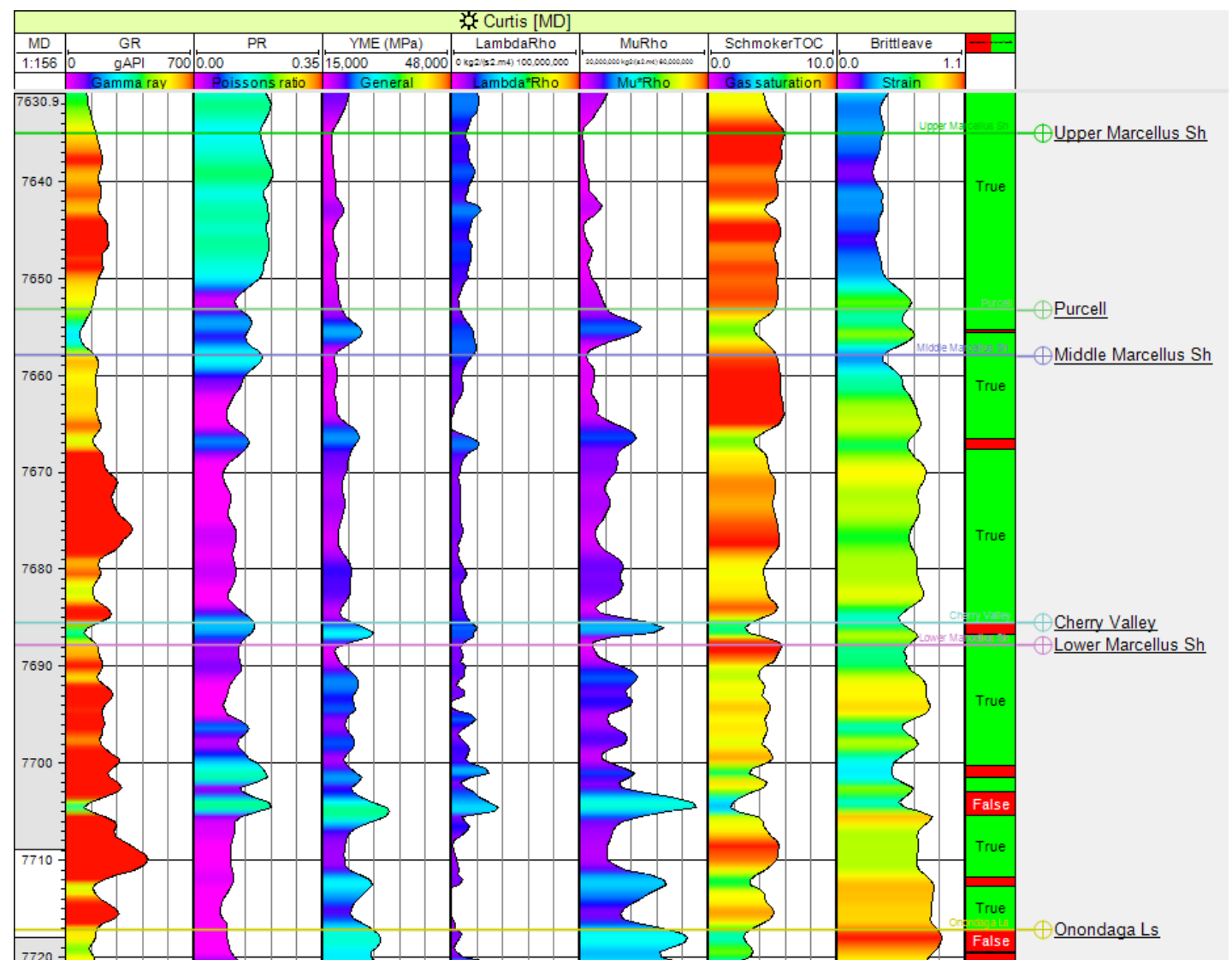

Figure 4-13. Boolean Log created based on previous figure. Areas labeled with green "true" correspond to the yellow region selected in previous figure with low lambda-rho/mu-rho. 
Based on the producing zones of the Marcellus at these wells, along with the TOC and brittleness calculations, the upper and lower cut-offs for the Young's modulus should be lowered to $18 \mathrm{GPa}$ and $25 \mathrm{GPa}$ respectively. The lower cut-off for the Poisson's ratio should be decreased to 0.14 while the upper cut-off should be increased to 0.24 . These parameters were adjusted based on the favorable brittle and TOC rich intervals within the Marcellus present at the wells (figures 4.14a and 4.15b). Figures 4-16 through 4-19 show results of the adjusted target parameters at the Armstrong \#1 and Curtis wells. Within the producing intervals oı me Armstrong \#1 and Curtis wells, the average Poisson's ratio is 0.24 and 0.12 with a Young's modulus of $23 \mathrm{GPa}$ and $22.5 \mathrm{GPa}$ respectively. The large differences in the Poisson's ratio between the two wells makes it difficult to choose an ideal value range.

\begin{tabular}{|c|c|c|}
\hline Alzate (2012) & Poisson's ratio & $\begin{array}{c}\text { Young's modulus } \\
(\mathrm{GPa})\end{array}$ \\
\hline Low cut-off & 0.15 & 23 \\
\hline High cut-off & 0.23 & 37.5 \\
\hline Modified & & 18 \\
\hline Low cut-off & 0.14 & 25 \\
\hline High cut-off & 0.24 & \\
\hline
\end{tabular}

Table 3. Comparison between Alzate (2012) cut-offs and the modified cut-offs. 


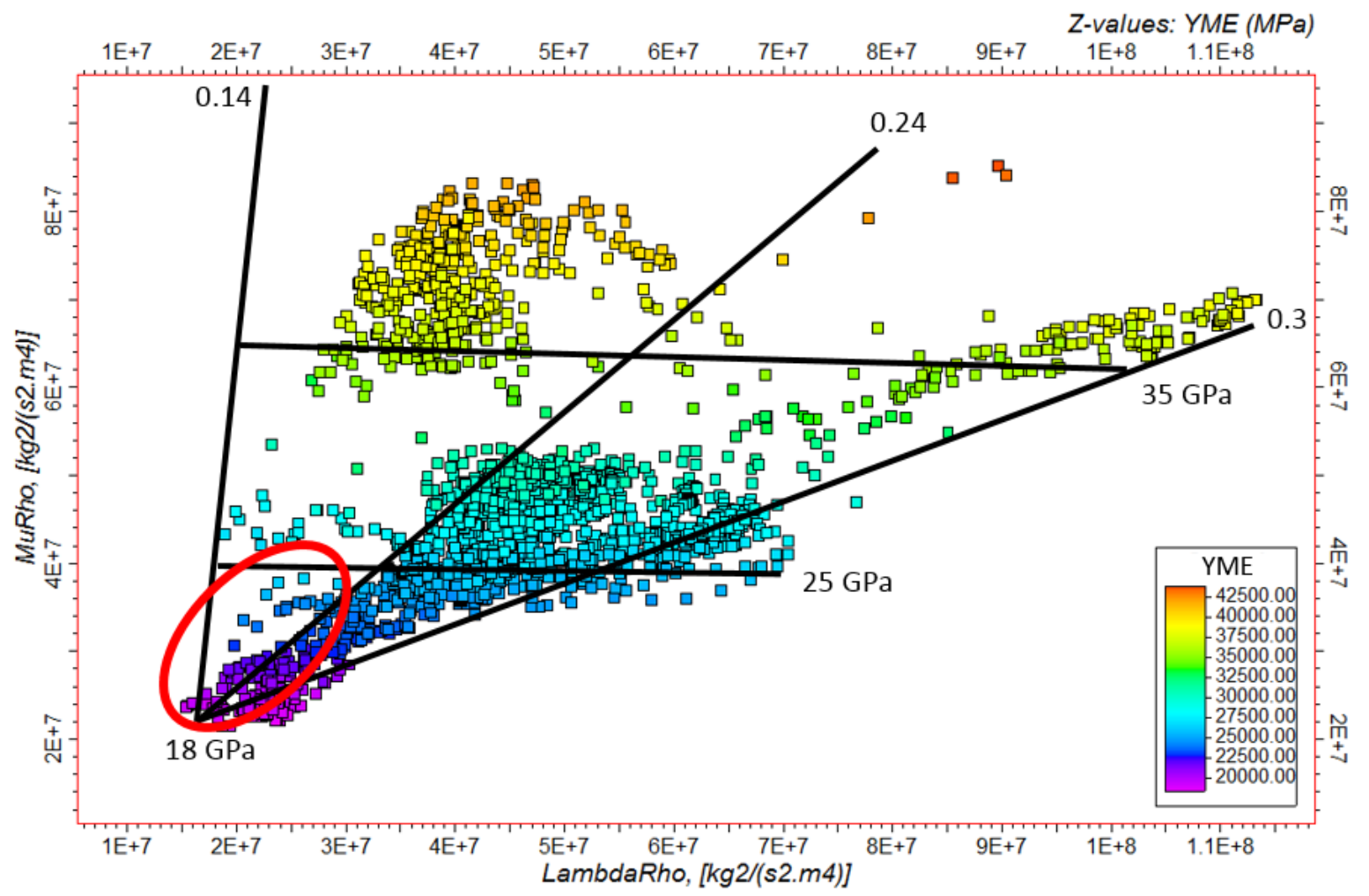

Figure 4-14a. Lambda-rho/Mu-rho colored by Young's modulus with modified cut-offs at the Armstrong \#1 well.

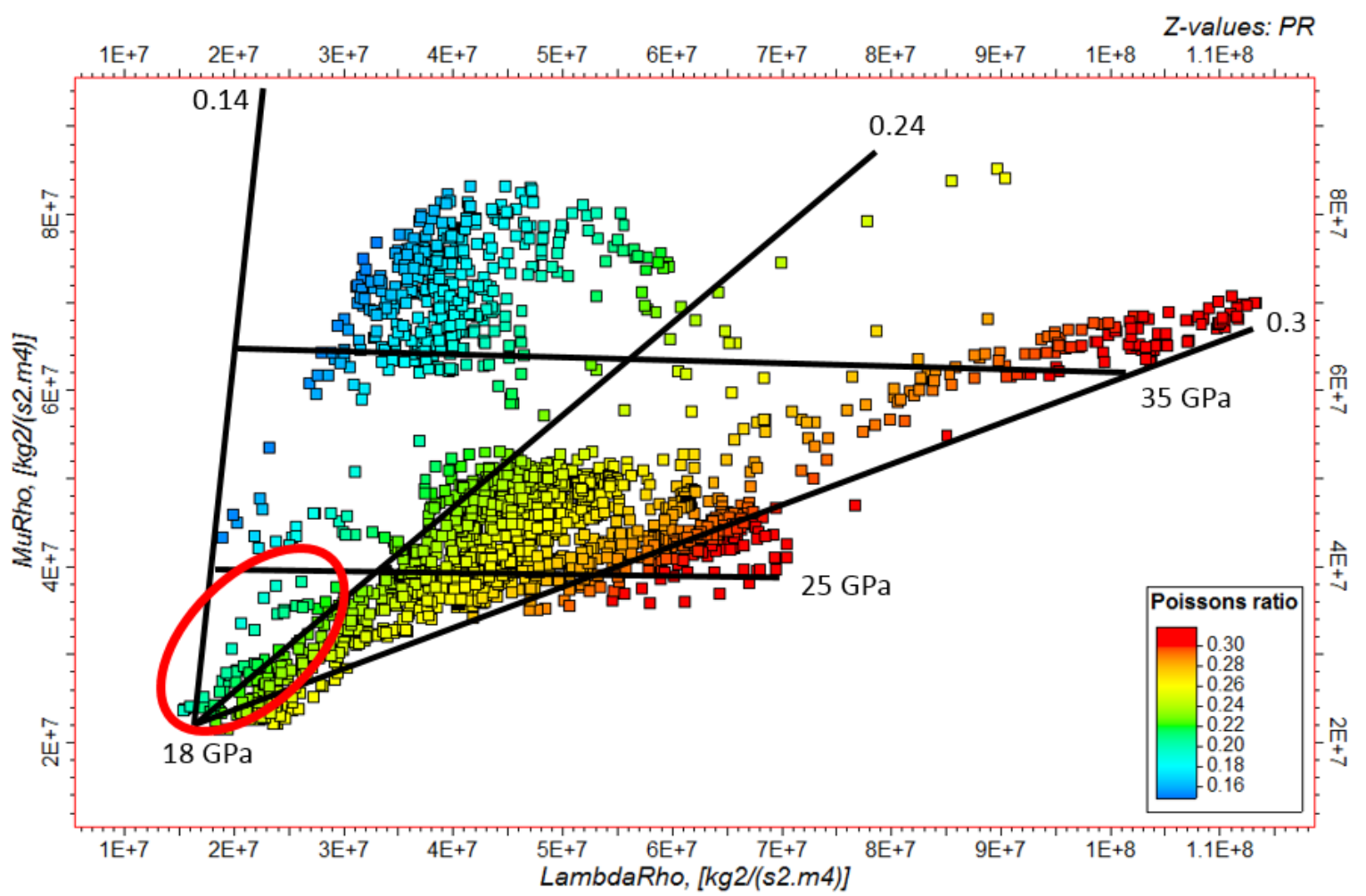

Figure 4-14b. Lambda-rho/Mu-rho colored by Poisson's ratio with modified cut-offs at the Armstrong \#1 well. 


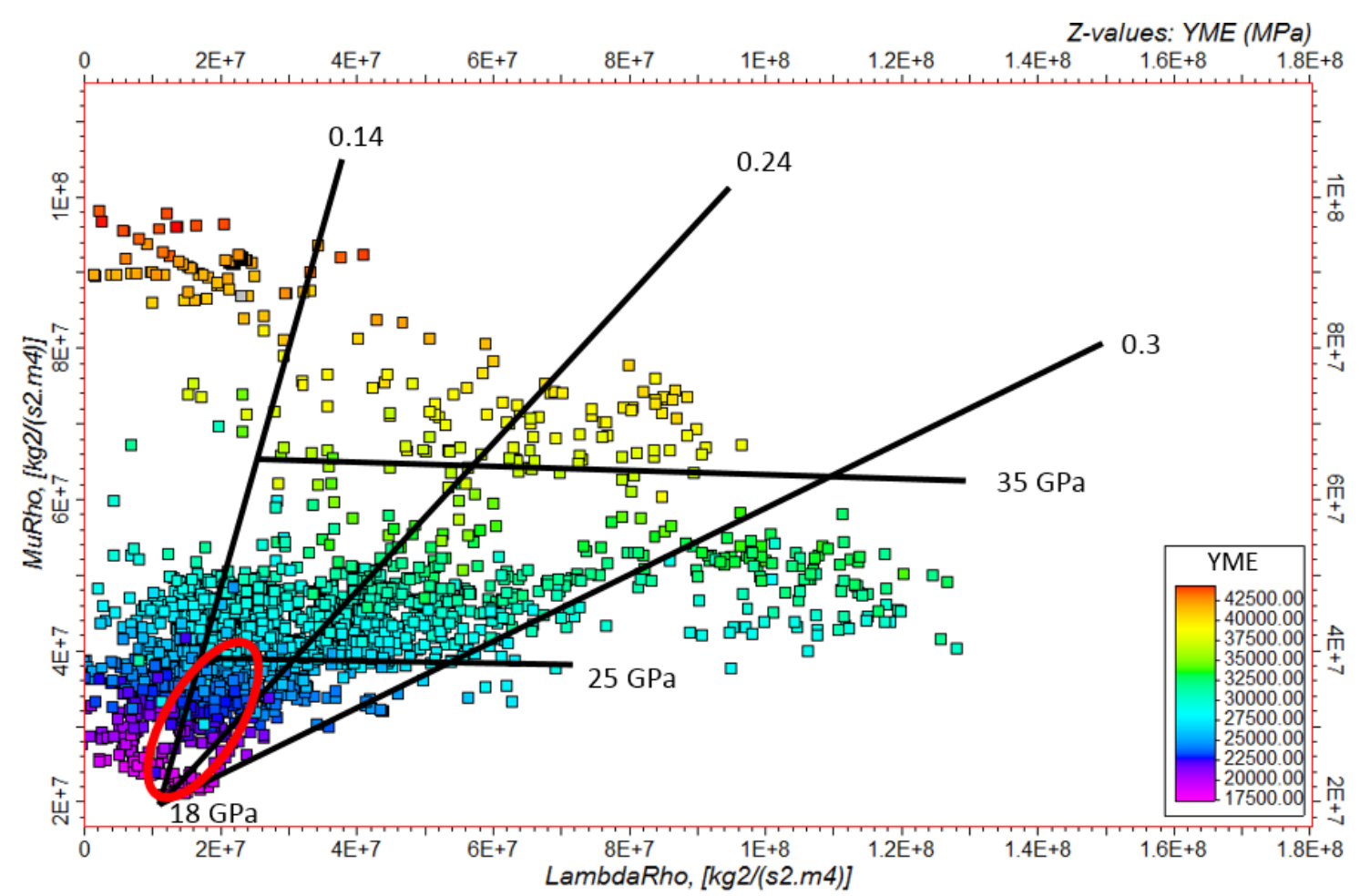

Figure 4-15a. Lambda-rho/Mu-rho cross-plot colored by Young's modulus with modified cutoffs at the Curtis well.

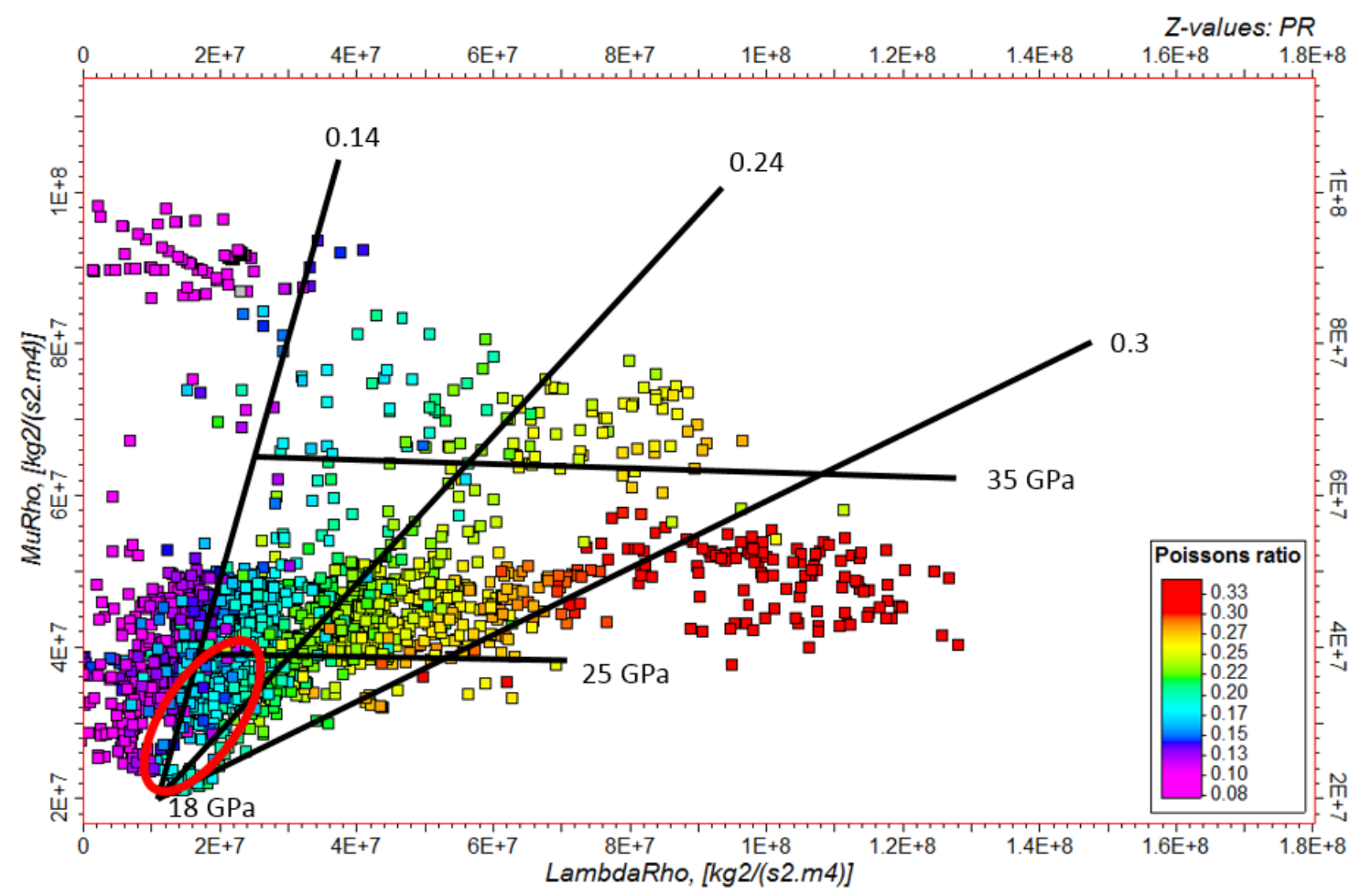

Figure 4-15b. Lambda-rho/Mu-rho cross-plot colored by Poisson's ratio with modified cut-offs at the Curtis well. 


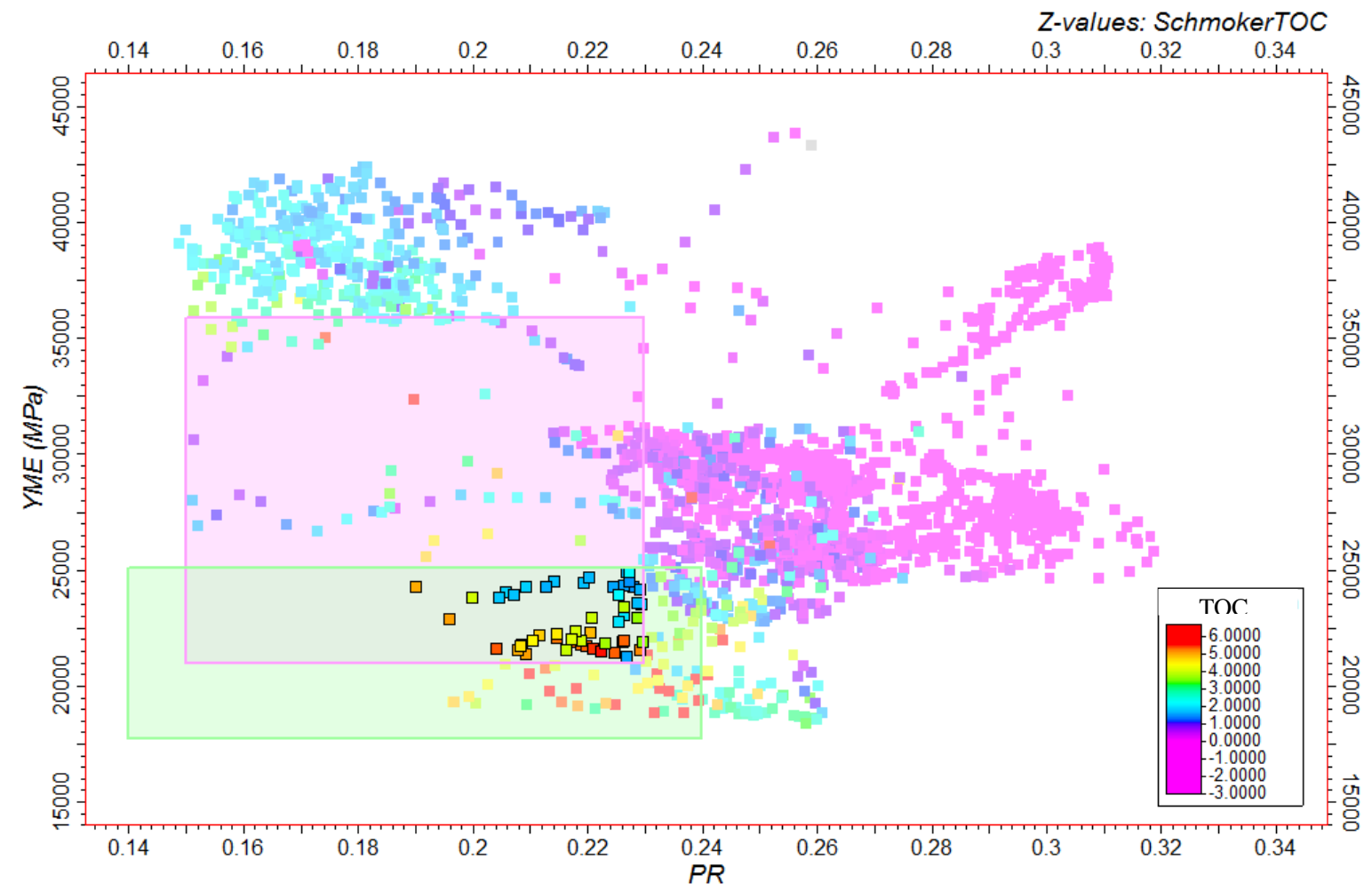

Figure 4-16. Modified selection criteria (green square) compared to the Alzate (2012) selection criteria (purple) with data from the Armstrong \#1 well.

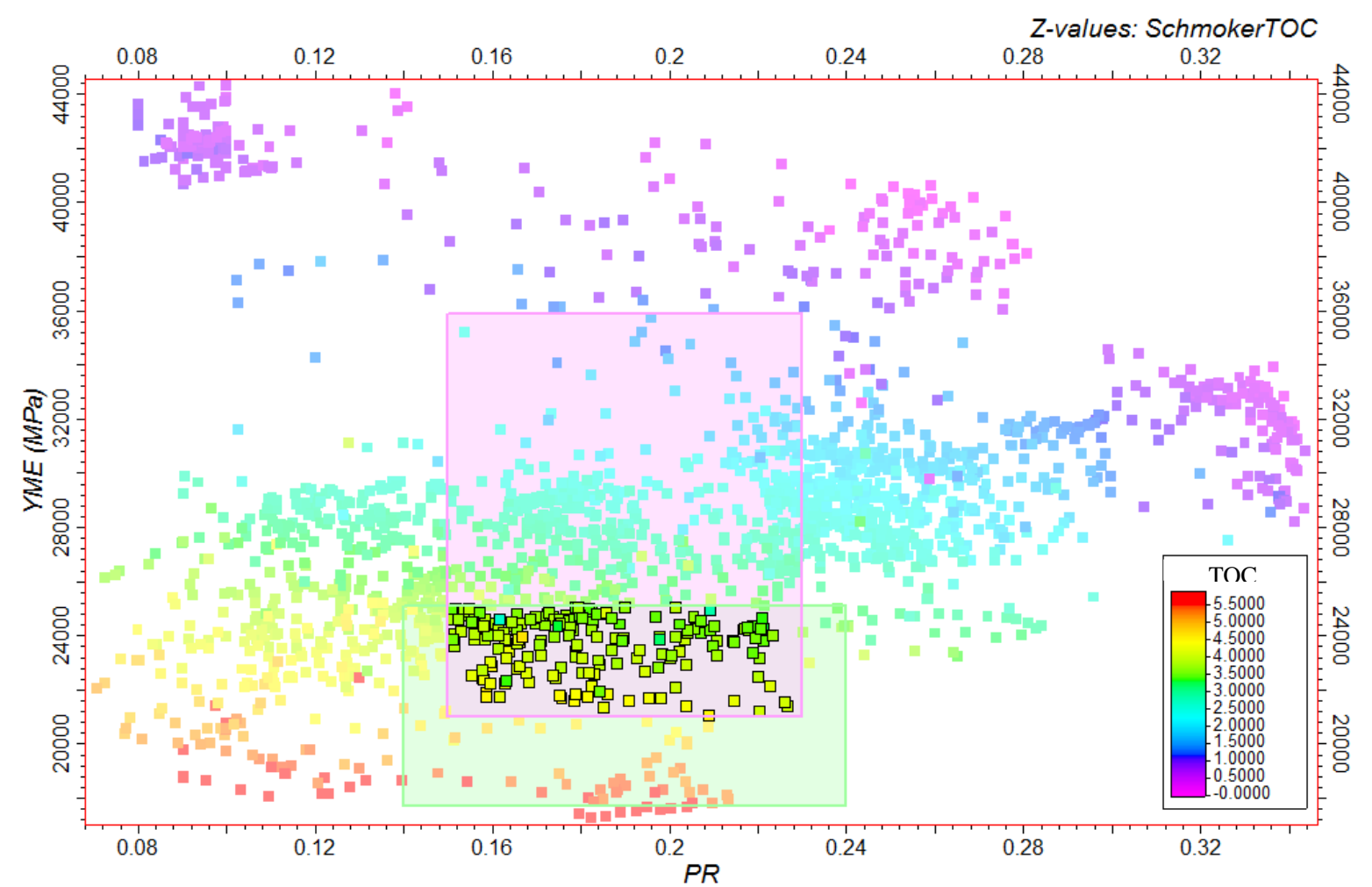

Figure 4-17. Modified selection criteria (green square) compared to the Alzate (2012) selection criteria (purple) with data from the Curtis well. 


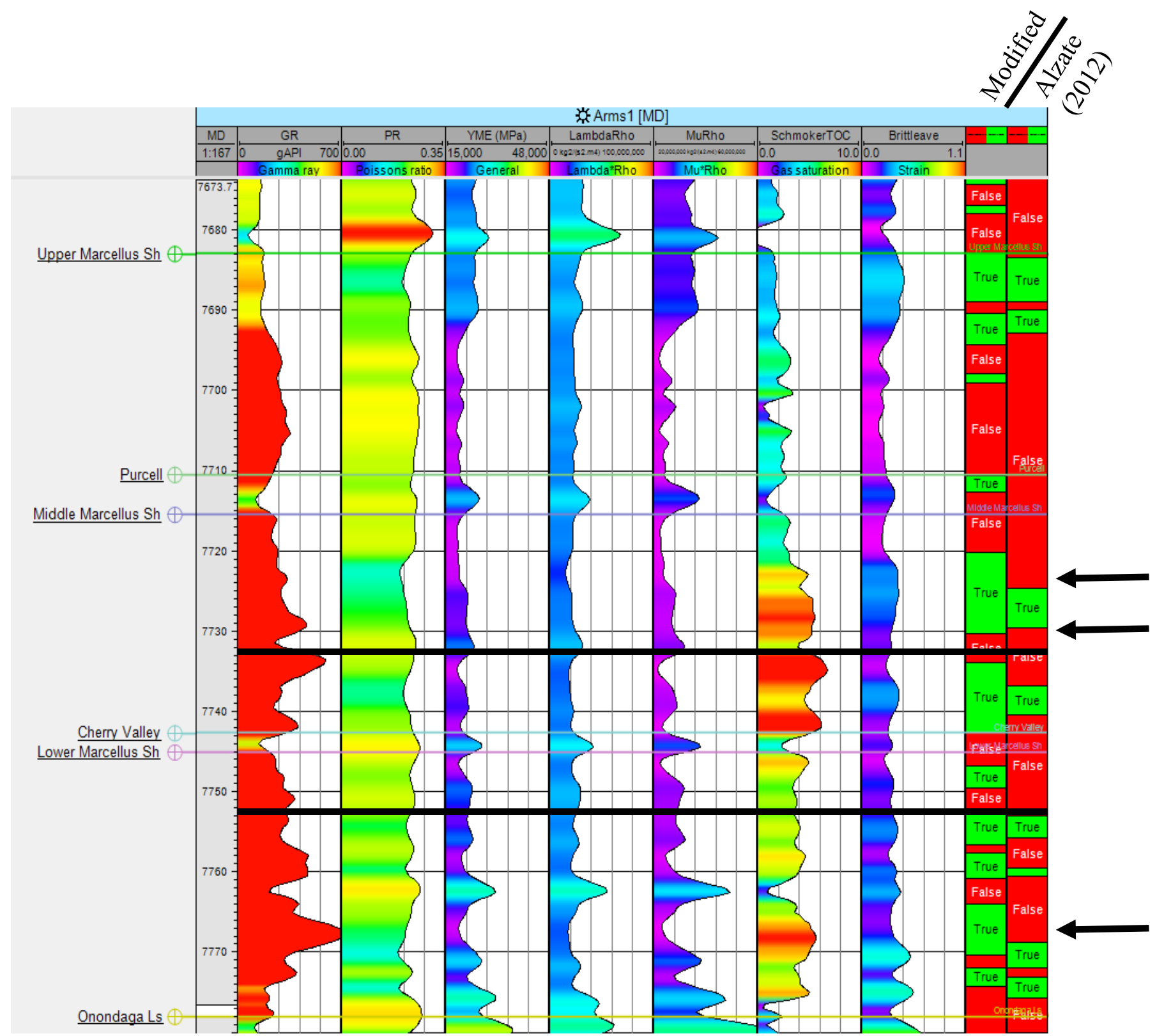

Figure 4-18. Armstrong \#1 well potential production intervals based on the modified parameters on the left Boolean log with Alzate (2012) parameters on the right log. The upper and lower limits of the producing zone is distinguished by the black lines. Potential new target zones are shown by the black arrows. 


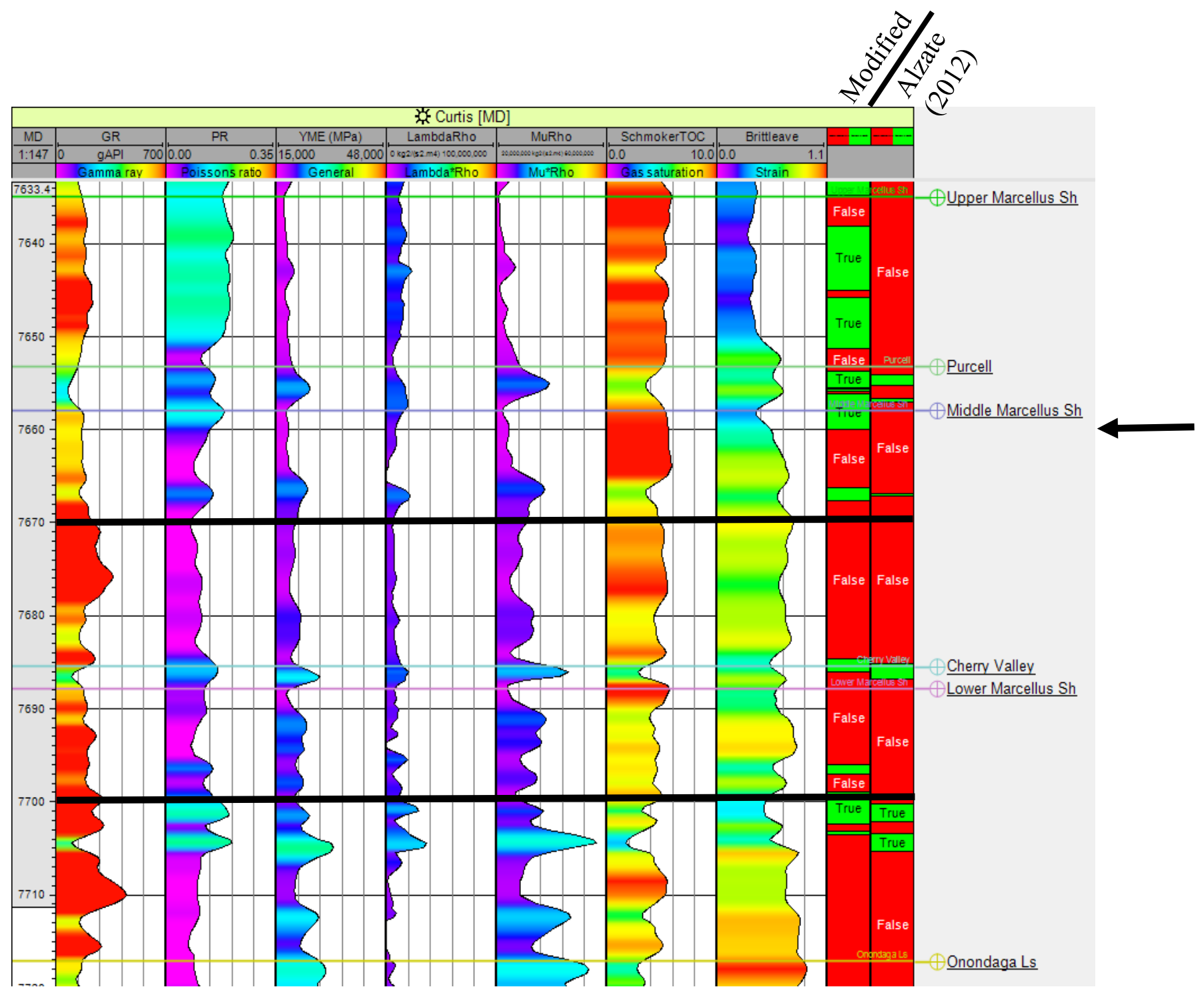

Figure 4-19. Curtis well potential production intervals based on the modified parameters on the left Boolean log with the Alzate (2012) parameters on the right log. The upper and lower limits of the producing zone is distinguished by the black lines. Potential new target zones are shown by the black arrows.

Both of these wells' production could benefit from new targets (highlighted by the black arrows in figures 4-18 and 4-19) from the lambda-rho/mu-rho cut-offs. These new targets appear in the Middle and Lower Marcellus at the Armstrong \#1 well (figure 4-18) and at the Curtis well (figure 4-19). The high TOC in the Upper Marcellus of the Curtis well indicates it may be a profitable target, however, the low brittleness may cause that zone to be very difficult to frack due to its ductility. 
Figure 4-20a and b shows the comparison in production between the Armstrong \#1 and the Curtis wells taken from the West Virginia Geological and Economic Survey. The Curtis well had greater production over the 5 year time period but declines more compared to the Armstrong \#1 well, which produced less but more consistently over the 5 year span. The production in 2009 is skewed because the Armstrong \#1 well began in August, whereas production in the Curtis began in February.

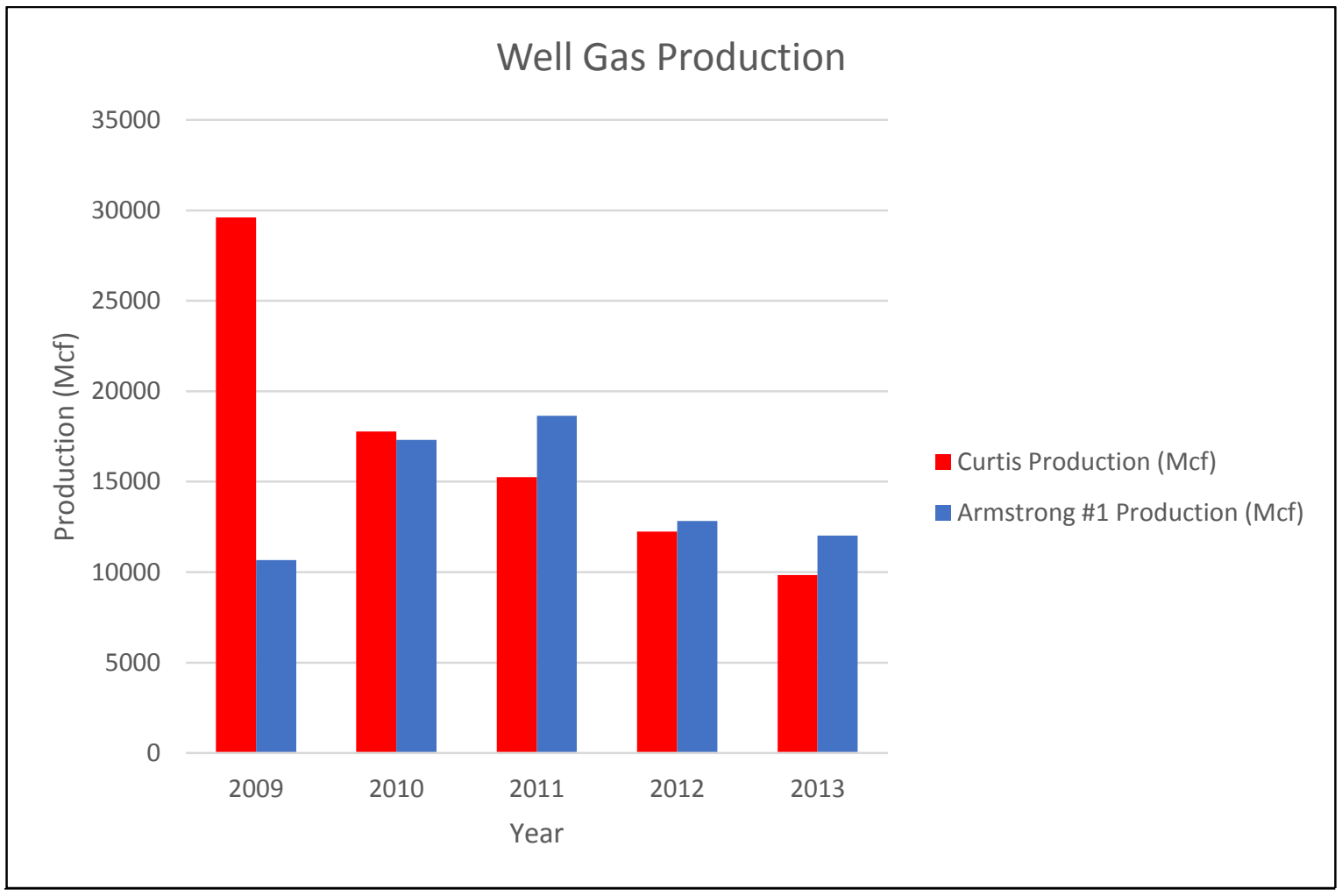

Figure 4-20a. Production comparison of the Armstrong \#1 and Curtis wells each year from 2009 to 2013. Production data was taken from WVGES Pipeline Plus.

\begin{tabular}{|c|c|c|c|}
\hline Well & Time (months) & $\begin{array}{c}\text { Total Production } \\
\text { (Mcf) }\end{array}$ & $\begin{array}{c}\text { Average Annual } \\
\text { Production over 5 } \\
\text { years (Mcf) }\end{array}$ \\
\hline Armstrong \#1 & 52 & 71,477 & 16,495 \\
\hline Curtis & 59 & 84,693 & 17,225 \\
\hline
\end{tabular}

Figure 4-20b. Production comparison of the average and total production of the Armstrong \#1 and Curtis wells from 2009 to 2013. Production data was taken from WVGES Pipeline Plus. 
Even though the modified lambda-rho/mu-rho parameters seem to miss some high TOC points or be devoid of any points (as shown in figures 4-16 and 4-17), multiple targets are still highlighted outside of the current producing zones. In addition to lambda-rho/mu-rho, a fracability estimate can indicate viable producing intervals. To create the fracability estimate, the brittleness and TOC are normalized:

$$
\begin{gathered}
\text { Normalized brittleness }=\text { Brittleness } / \text { Brittleness }_{\max } \\
\text { Normalized TOC }=\text { TOC} \text { TOC }_{\max }
\end{gathered}
$$

The resulting normalized brittleness and TOC will fall into a range between 0 and 1 . The fracability estimate can be calculated:

$$
\text { Fracability }=\text { Normalized brittleness } * \text { Normalized TOC }
$$

The fracability falls into a range between 0 and 1 , where zones closer to a value of 1 are the best to target. The fracability estimate highlighted similar potential high producing zones, when compared to lambda-rho/mu-rho, at the Armstrong \#1 well (Figure 4-21), however, it highlighted different intervals than lambda-rho/mu-rho at the Curtis well (Figure 4-22). The fracability estimate can be used as confirmation of potential targets, as at the Armstrong \#1 well, but it can also be useful to pick targets that lambda-rho/mu-rho may miss, such as at the Curtis well. Ultimately, this chapter provides initial insight on how lambda-rho/mu-rho can be utilized as a target indicator from the Barnett Shale and be applied to the Marcellus shale. However, other target zone identifiers, such as fracability, should be used together with lambda-rho/mu-rho to pick the best intervals to drill and frack. 


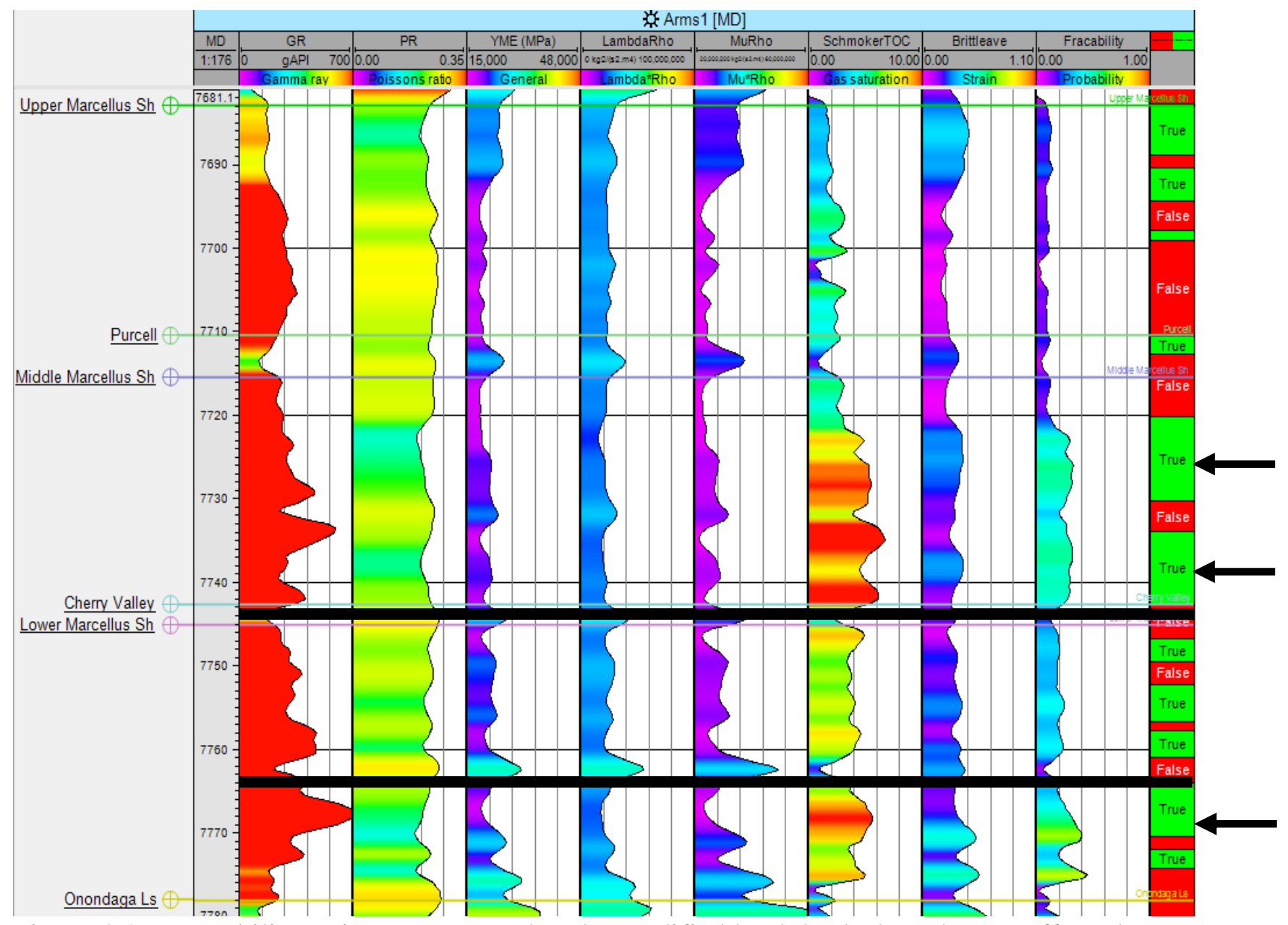

Figure 4-21. Fracability estimate compared to the modified lambda-rho/mu-rho cut-offs at the Armstrong \#1 well. The black lines correspond to the top and base of the current producing interval. Confirmation of new potential targets, based on the fracability and lambda-rho/mu rho, are highlighted by the black arrows. 


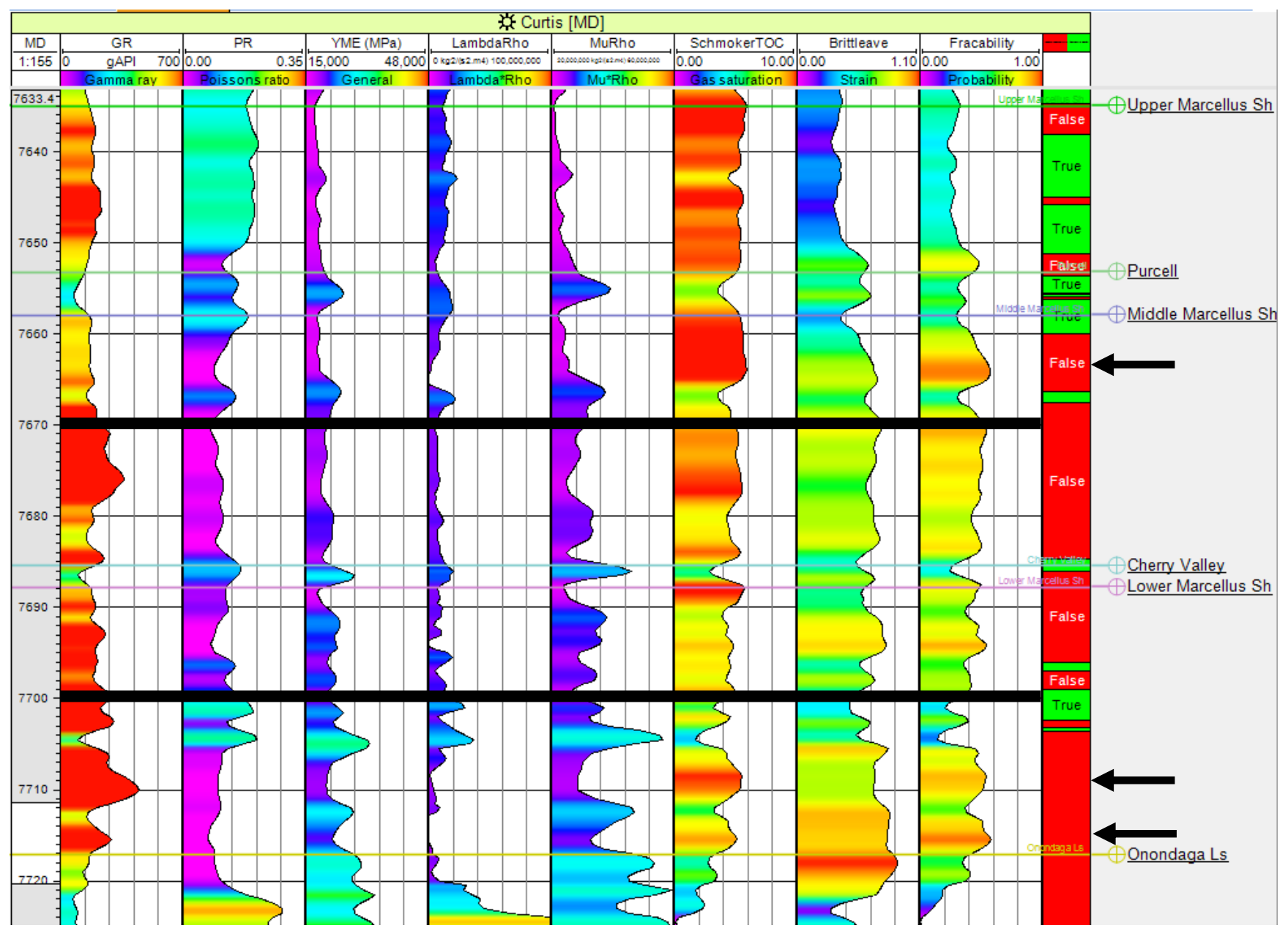

Figure 4-22. Fracability estimate compared to the modified lambda-rho/mu-rho cut-offs at the Curtis well. The black lines correspond to the top and base of the current producing interval. New potential targets, based on the fracability and lambda-rho/mu rho, are highlighted by the black arrows. 


\section{Chapter 5 \\ Petrophysics}

\subsection{Total Organic Carbon}

Total organic carbon (TOC) is the concentration of organic matter in a source rock, and is usually represented by weight percentage. TOC can be estimated using multiple methods. TOC was calculated in this study using the Schmoker (Charsky and Herron, 2013) and Passey (Passey et al, 1990) methods. The Schmoker method uses a standardized equation with the bulk density as the variable. The Passey method (also called $\Delta \operatorname{logR}$ ) uses the resistivity and sonic (or bulk density if sonic is not available) to calculate the separation between the two curves (the delta log R) in the organic rich shale, the Marcellus Shale. The scaling is done by overlying the two curves in an organic lean shale.

The Schmoker TOC calculation is estimated based on bulk density as follows:

$$
\mathrm{TOC}=\left(154.497 / \rho_{\mathrm{b}}\right)-57.261
$$

where $\rho_{\mathrm{b}}$ is the bulk density in $\mathrm{g} / \mathrm{cc}$ and the TOC is calculated in $\mathrm{wt} \%$. This equation assumes a constant mineral composition and porosity throughout the formation. Although the Marcellus is heterogeneous and "the method was developed and refined based on specific environments, it is frequently used for TOC estimation in a wide variety of shale formations" (Charsky and Herron, 2013). The Schmoker TOC calculation at the Armstrong \#1 well can be seen in figure 5-1.

The Passey estimate is calculated:

$$
\Delta \log \mathrm{R}=\log 10\left(\mathrm{R} / \mathrm{R}_{\text {baseline }}\right)+0.02 *\left(\Delta \mathrm{t}-\Delta \mathrm{t}_{\text {baseline }}\right)
$$

where $\mathrm{R}$ is the resistivity in ohm- $\mathrm{m}, \mathrm{R}_{\text {baseline }}$ is the resistivity in the organic-lean zone in ohm-m, $\Delta \mathrm{t}$ is the sonic in $\mu \mathrm{sec} / \mathrm{ft}, \Delta \mathrm{t}_{\text {baseline }}$ is the sonic in the organic-lean zone. The scaling factor of 0.02 
can be adjusted after the baseline zone is established (Passey, 1990). In this area, the baseline zone is the Mahantango Shale, since it is an organic-lean shale. The resistivity curve is overlain with the sonic curve scaled such that one decade of resistivity is equal to $50 \mu \mathrm{s} / \mathrm{ft}$ shown in figure 5-2. The $\Delta \log \mathrm{R}$ separation of the two curves is then related to the maturity of the formation to determine the TOC weight percent (wt $\%$ ) in the organic-rich zones by:

$$
\mathrm{TOC}=(\Delta \log \mathrm{R}) * 10^{(2.297-0.1688 * \mathrm{LOM})}
$$

where LOM is the level of organic maturity. The LOM can be determined from a variety of measurements including vitrinite reflectance or rock evaluation if the type of organic matter is known. The LOM is directly indicated by the vitrinite reflectance, the higher the vitrinite reflectance, the more thermally mature the formation and the higher the LOM (Passey, 1990). In formations with a LOM over 10.5, a value of 10.5 should be used (Charsky and Herron, 2013). The results of the Passey method can be seen in figure 5-2. The Passey method will indicate higher TOC when the resistivity and sonic are higher than their respective baselines in the inorganic shale. In a few places, the resistivity greatly spikes, which gives extremely high TOC readings, which are likely false estimates.

The results from the study of Charsky and Herron (2013) showed the Schmoker and Passey methods yielded similar results that were also consistent with TOC measurements taken from core data. The similarity between the different TOC calculations within the Marcellus can be seen in figure 5-3a. The Passey and Schmoker estimates are very similar at the Armstrong \#1 well, except where there is a large spike in resistivity, which causes a huge spike in the Passey TOC estimate. The similarity is highlighted by cross-plotting the two TOC estimates in Figure 5$3 \mathrm{~b}$ where the trendline has a correlation (also called $\mathrm{R}^{2}$ ) of 0.7 . This means the two estimates give comparable results. 

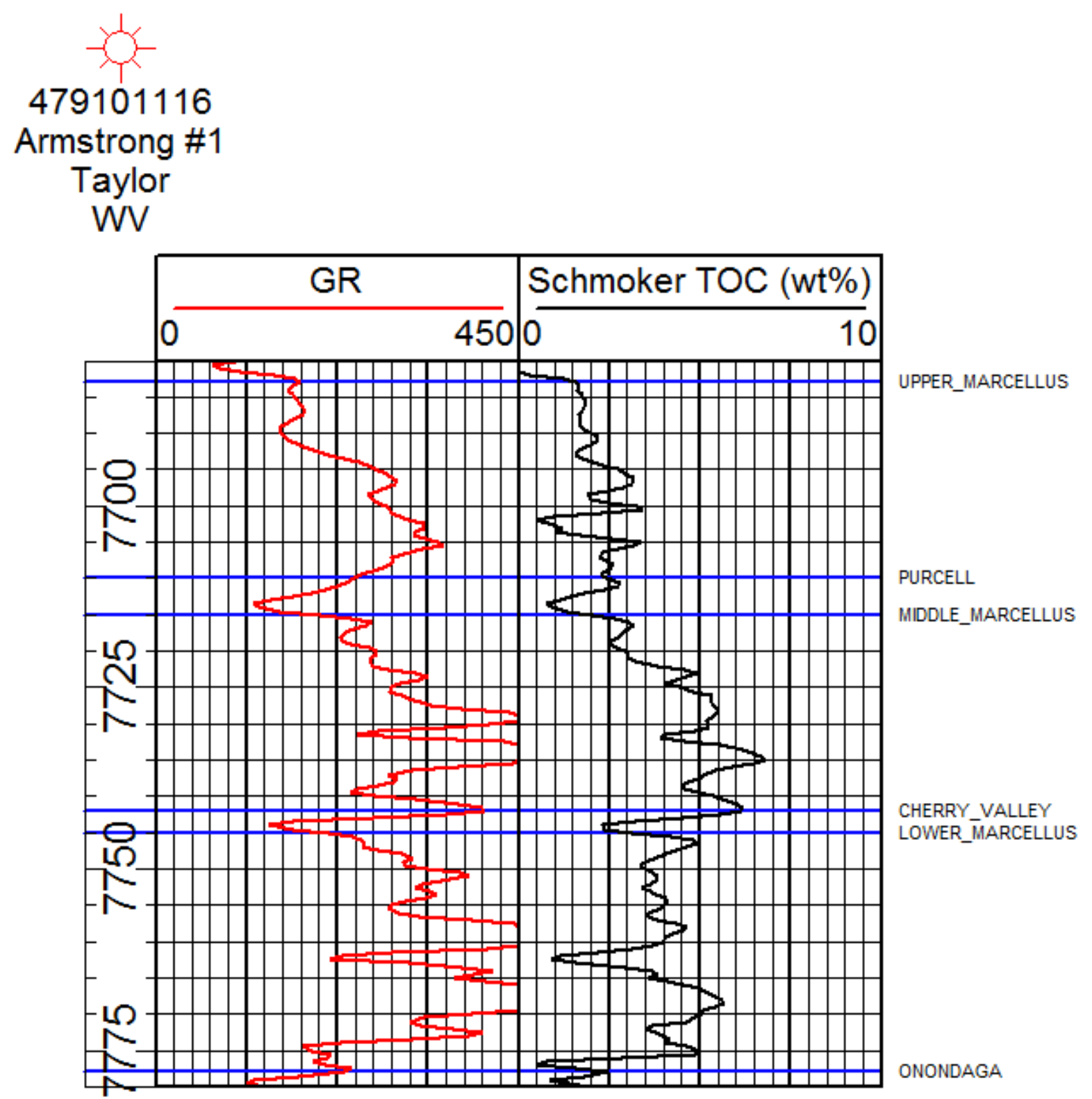

Figure 5-1. Schmoker TOC calculation through the Marcellus Shale at the Armstrong \#1 well plotted with gamma ray. 


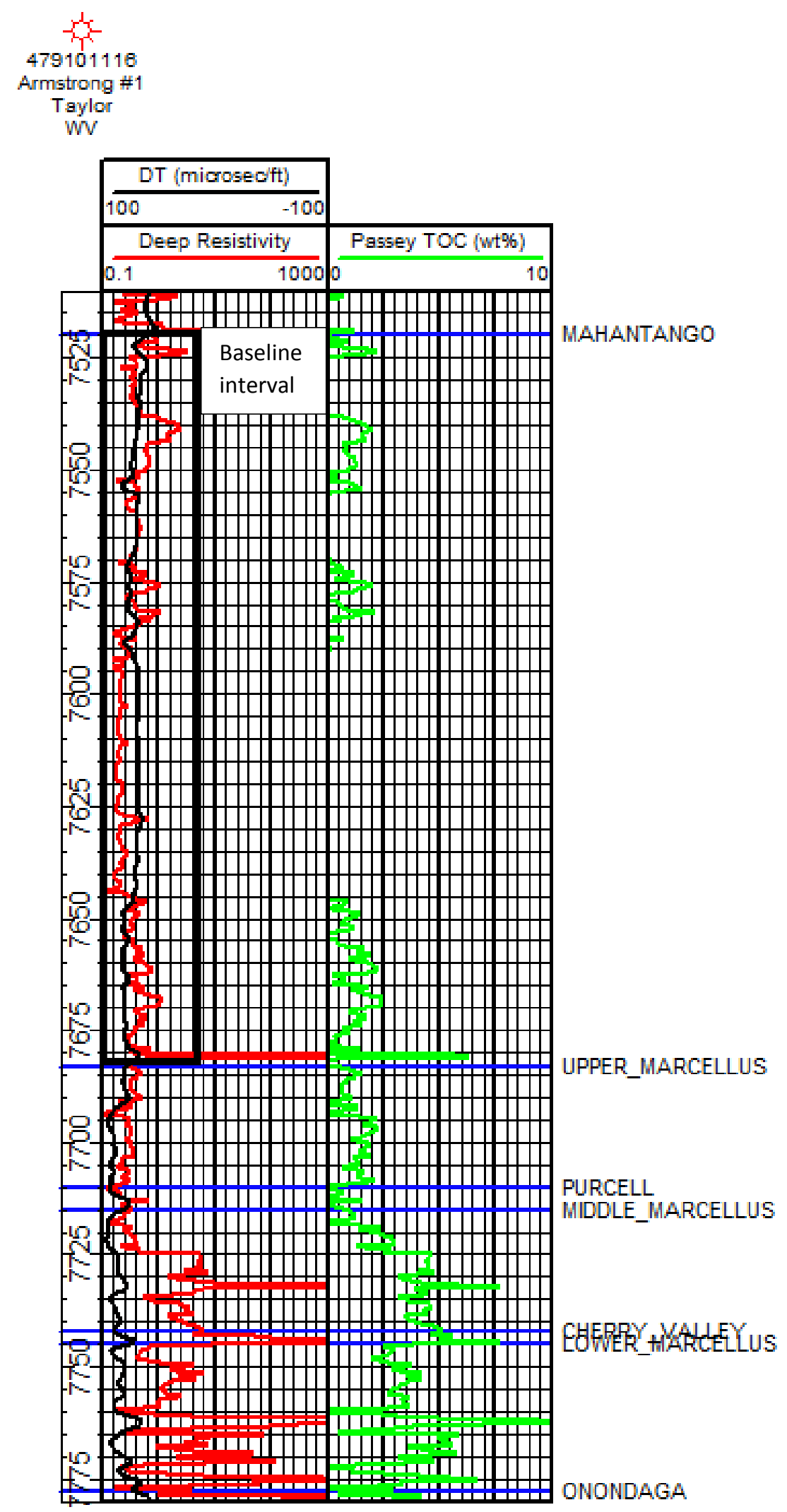

Figure 5-2. Overlying the sonic and resistivity curves through the Mahantango as a baseline for calculation of the Passey TOC estimate at the Armstrong \#1 well. 


\section{$-y$ \\ 479101116 \\ Armstrong \#1 \\ Taylor
WV}

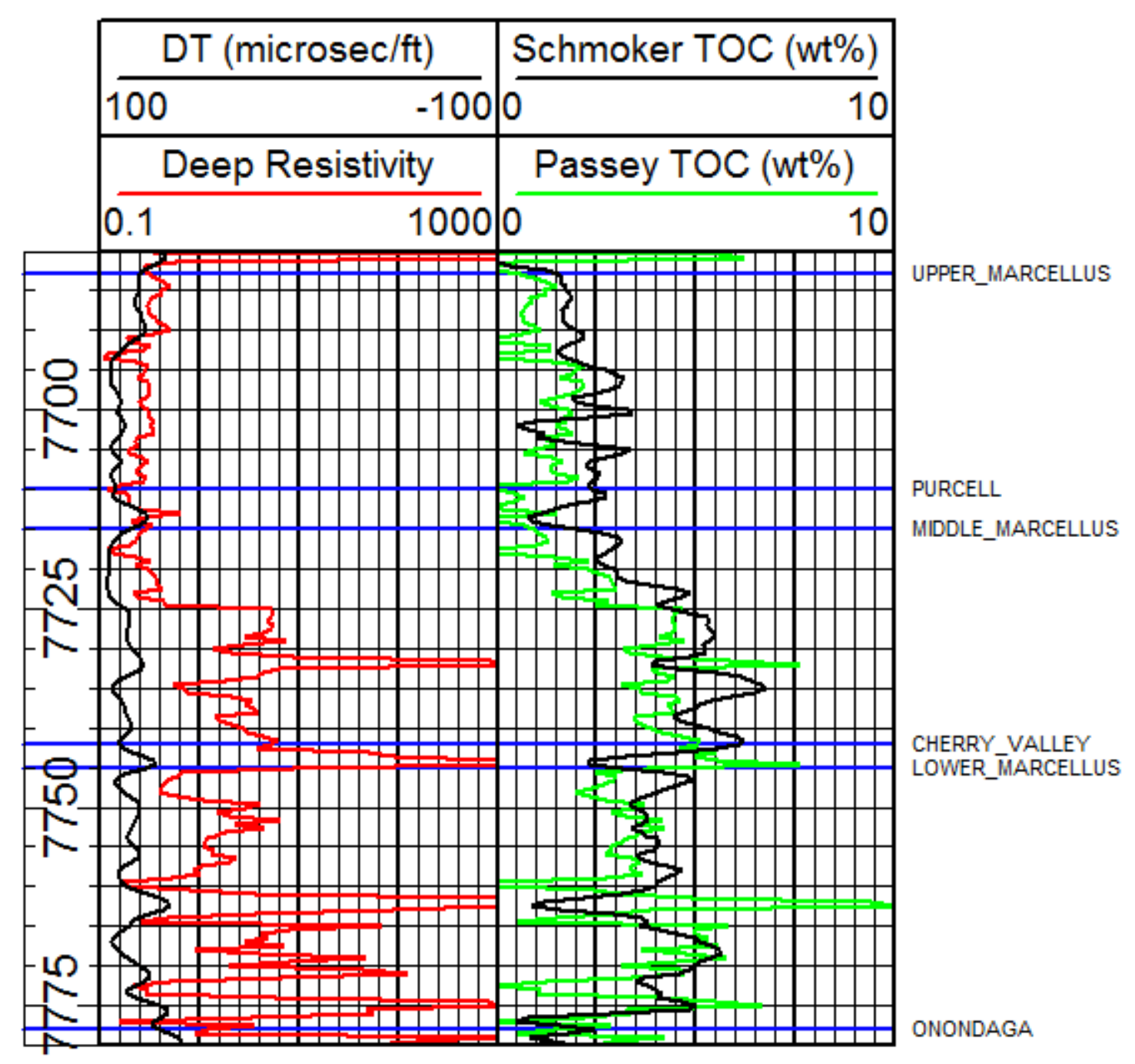

Figure 5-3a. Schmoker and Passey TOC calculations at the Armstrong \#1 well. 


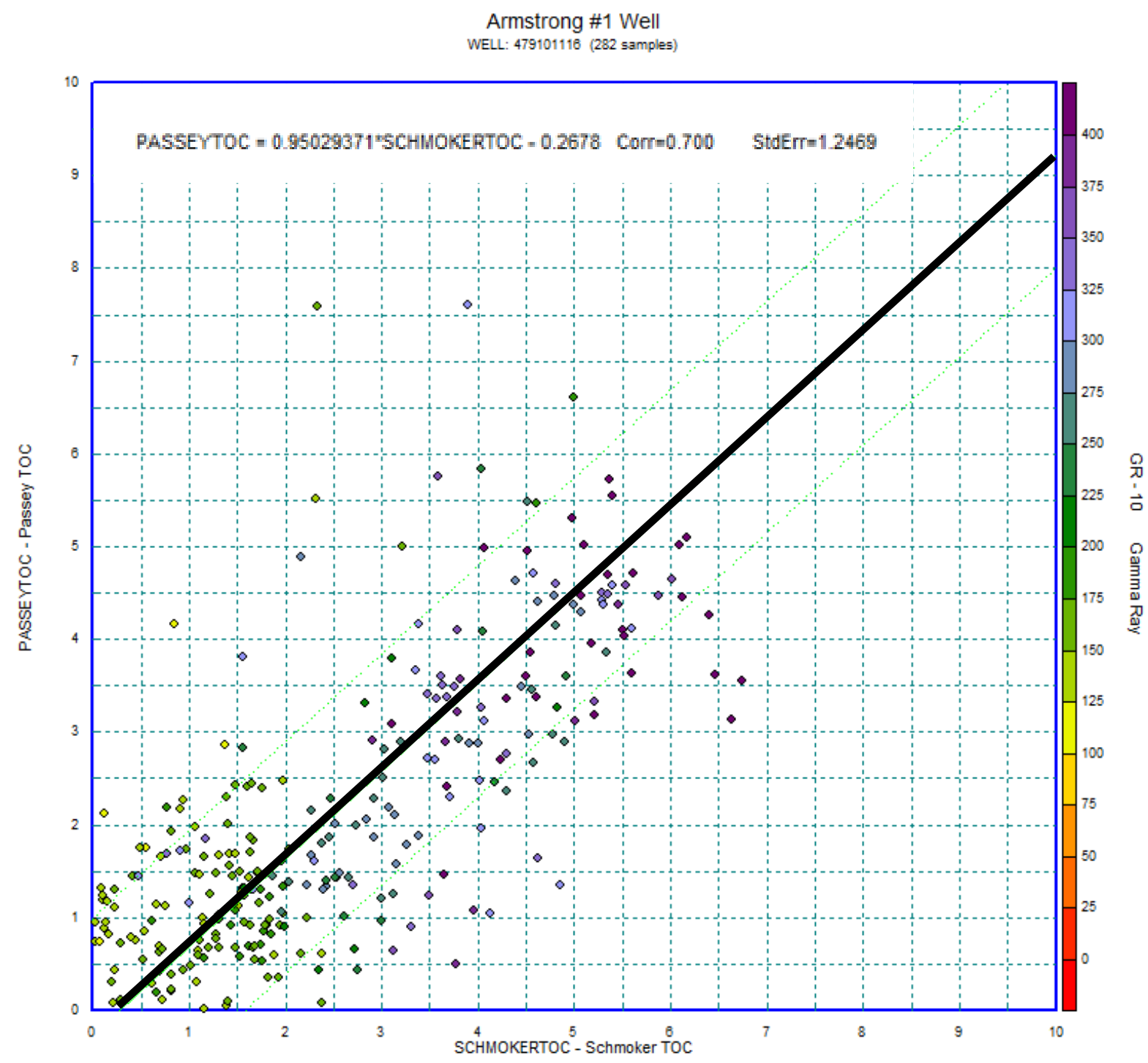

Figure 5-3b. Cross-plot of Schmoker and Passey TOC estimates colored by gamma ray indicating a mostly linear trend showing the correlations between the two methods.

\subsection{Mineralogy}

The photoelectric absorption index, or photoelectric factor $\left(\mathrm{P}_{\mathrm{e}}\right)$, is measured in units of barns per electron. $\mathrm{P}_{\mathrm{e}}$ is sensitive to the mineralogy because it is directly related to the atomic number $(Z)$ of the elements in the formation. Some commonly used reference $\mathrm{P}_{\mathrm{e}}$ values are quartz (1.81), dolomite (3.14), shale (3.42) and calcite (5.08 barns/electron). The larger photoelectric cross section per electron, the higher the $\mathrm{P}_{\mathrm{e}}$. In order to linearize its relation with 
composition, the $\mathrm{P}_{\mathrm{e}}$ must be converted to a volumetric photoelectric absorption index ( $\mathrm{U}$ in barns $/ \mathrm{cm}^{3}$ ), which is approximated:

$$
\mathrm{U}=\mathrm{P}_{\mathrm{e}} * \rho_{\mathrm{b}}
$$

where $\mathrm{P}_{\mathrm{e}}$ is the photoelectric factor and $\rho_{\mathrm{b}}$ is the bulk density (Doveton, 1994). A plot of $\mathrm{U}$ versus depth can be seen in figure 5-4. RHOmaa is the apparent matrix density calculated:

$$
\text { RHOmaa }=(\text { RHOB }- \text { PHIA }) /(1-\text { PHIA })
$$

where RHOB is the bulk density and PHIA is the average porosity, and Umaa is the volumetric photoelectric absorption coefficient of the matrix calculated as follows:

$$
\text { Umaa }=\text { U }- \text { PHIA / (1 - PHIA })
$$

where $\mathrm{U}$ is the volumetric photoelectric absorption index and PHIA is the average porosity.

When cross-plotted, the RHOmaa and Umaa give an indication of the mineralogy.

Typically, a triangle with three end members is overlain to show the mineralogical distribution/composition. The three end members plotted in Figure 5-3 were quartz, calcite, and illite. These end members were chosen to show the Marcellus interval composition based on the amount of silica, carbonate, and clay present. The RHOmaa/Umaa cross-plot shown in figure 5-5 is from the Tully Limestone through the Onondaga Limestone and has 3 end members of quartz, calcite, and illite. The Tully through Onondaga interval falls on the calcite and illite side, indicating not much silica is present. The clay contribution is coming from Mahantango Shales with decreasing amounts from the Upper and Middle Marcellus. The Lower Marcellus points are halfway between the calcite and illite end members as are the thin limey sections (Purcell and Cherry Valley) of the Marcellus Shale. The rest of the calcite is coming mainly from the Tully 
and Onondaga Limestones. The cluster of high Umaa values is indicative of iron from pyrite present in the formation (Boyce, 2010).

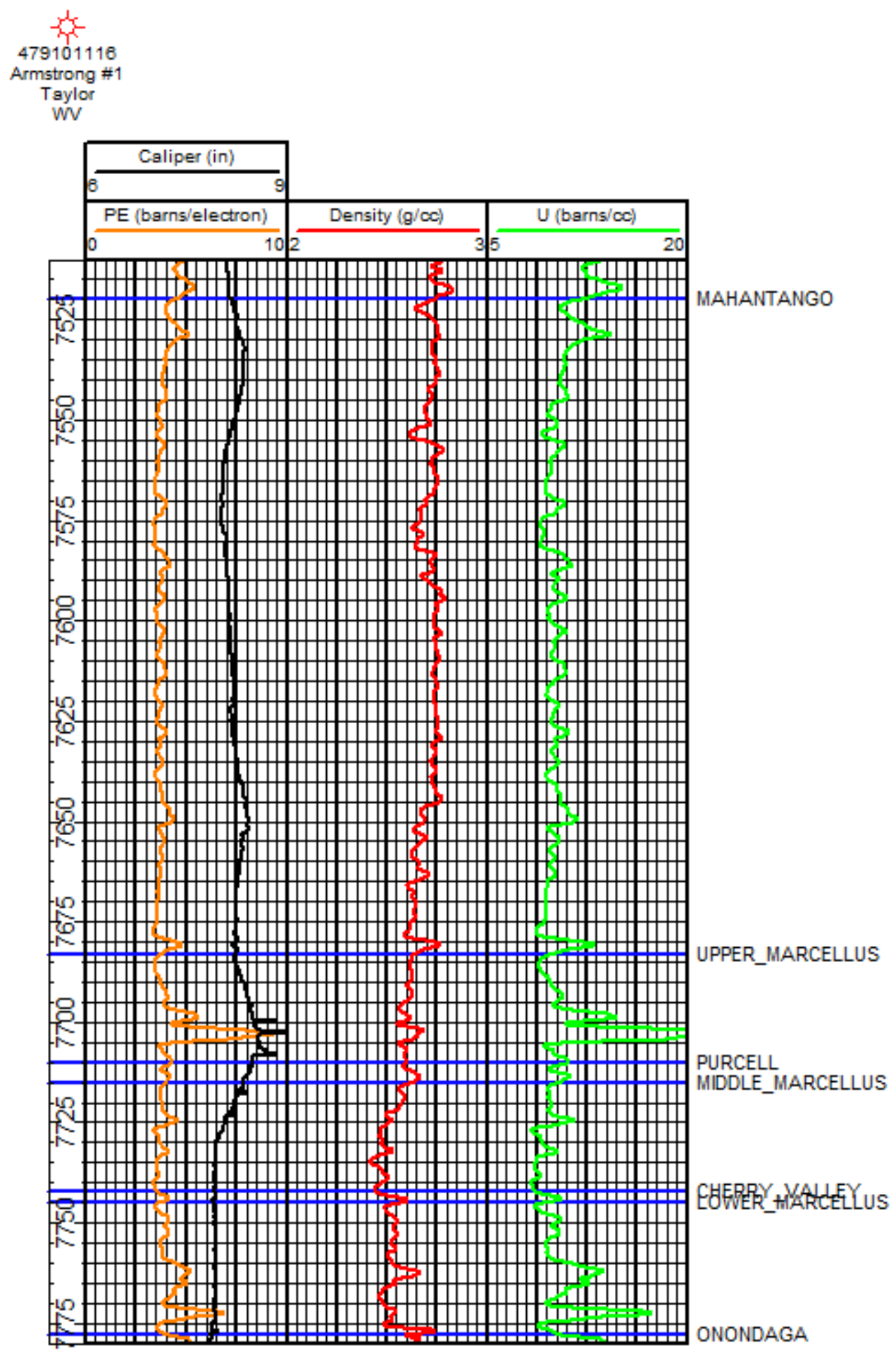

Figure 5-4. Photoelectric factor, density, and U plotted versus depth. 


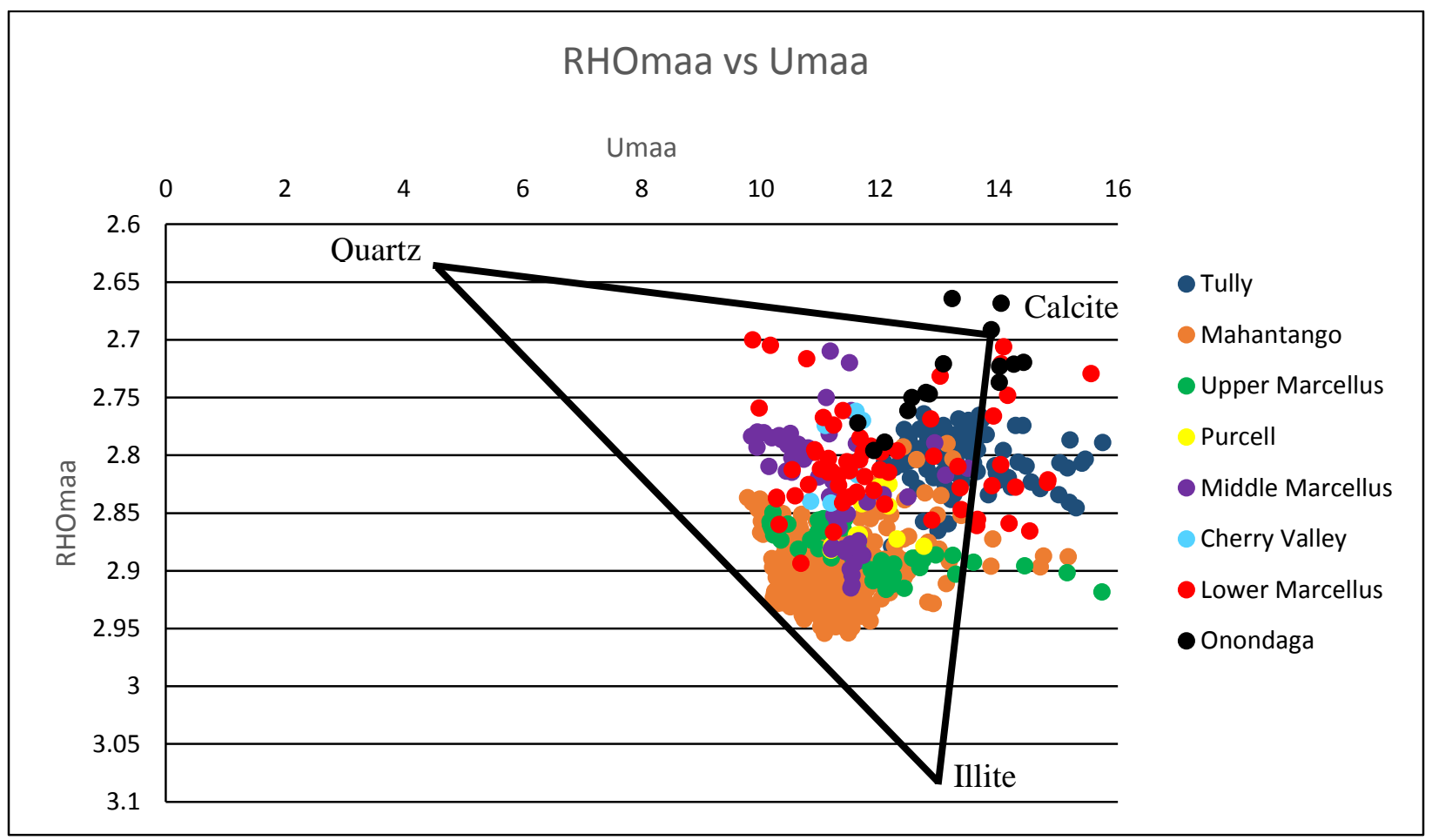

Figure 5-5. RHOmaa-Umaa from the Tully through Onondaga at the Armstrong \#1 well.

The Barnett Shale mineralogy was described by Jarvie (2003) as having a composition of 40\% quartz, $29 \%$ Illite, $13 \%$ calcite, $3 \%$ organic matter, and 2\% pyrite. Altamar and Marfurt (2014) found that the Lower Barnett trended more toward the quartz and the Upper Barnett trended toward the carbonate. More points in the Lower Barnett trend toward the clay (as illite) than in the Upper Barnett (Figure 5-6). These plots indicate there is quite a difference between the Marcellus and Barnett Shales based on the quartz, carbonate, and illite content present in these shales. Future studies can explore these mineralogical differences and how they affect the brittleness, TOC, lambda-rho, and mu-rho variation between the Barnett and Marcellus Shale. 


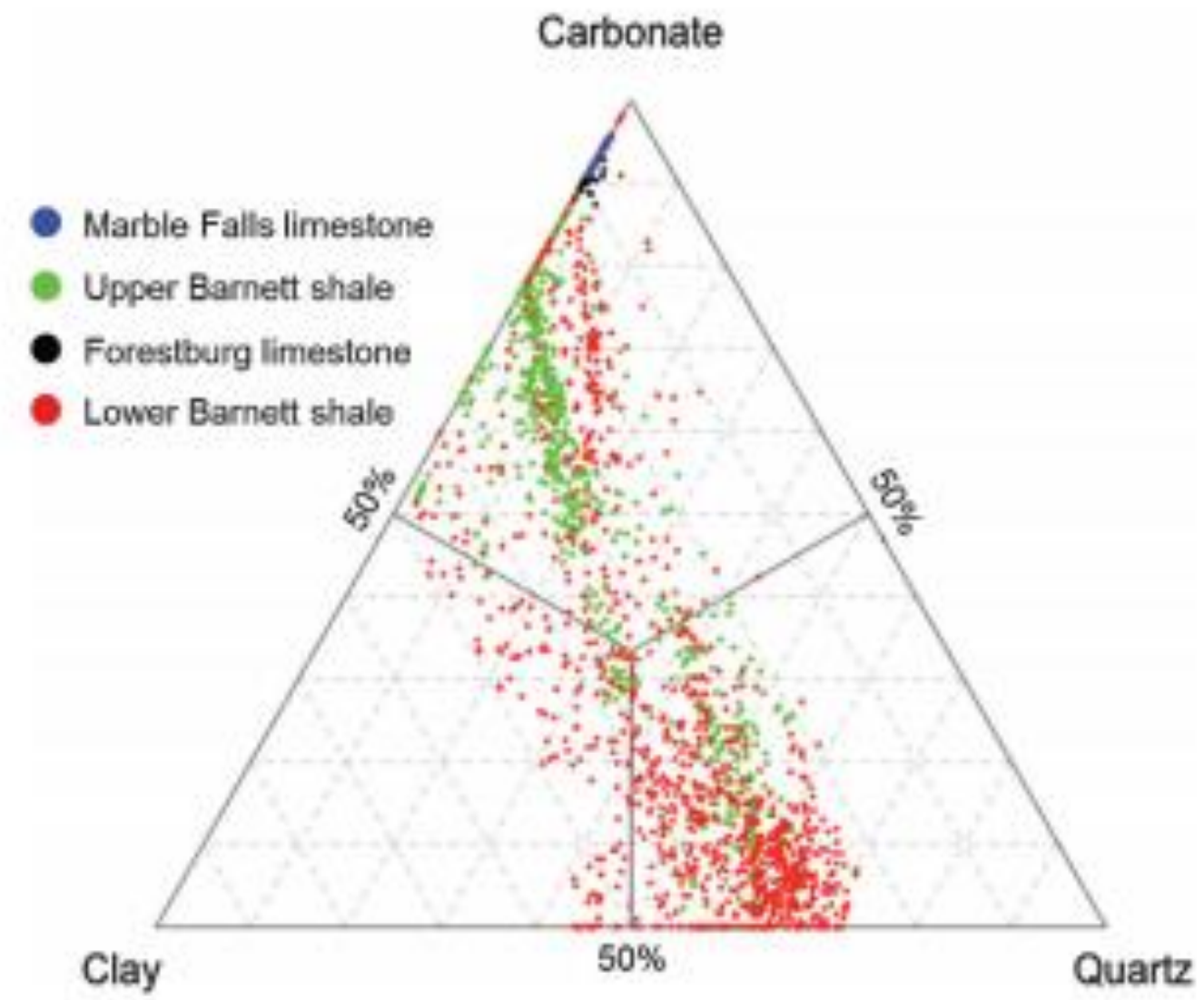

Figure 5-6. Ternary mineralogy distribution of the Marble Falls Limestone, Upper Barnett Shale, Forestburg Limestone, and Lower Barnett Shale (Altamar and Marfurt, 2014). 


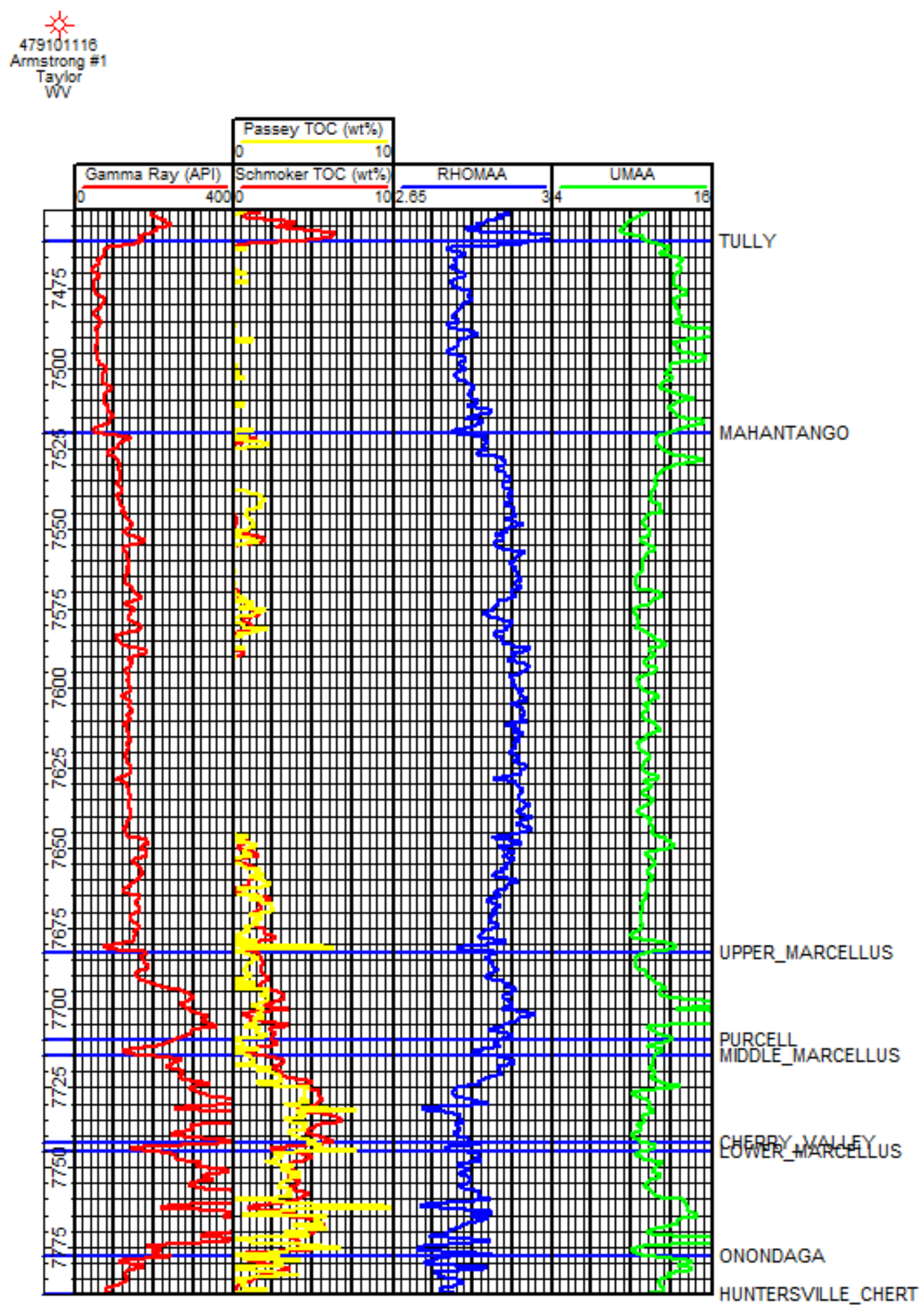

Figure 5-7. RHOmaa and Umaa plotted with Passey and Schmoker TOC estimates. 


\section{Chapter 6}

\section{Discussion and Conclusions}

This study demonstrates that the spectral blueing process significantly increases resolution and reveals additional details in the seismic response of the Marcellus Shale. Spectral blueing increased the resolution of the seismic volume in this study by approximately 14 feet, from 61 feet to 47 feet (see Chapter 3). One prominent features that was revealed in the Marcellus based on the spectral blueing volume was a second negative reflection that appeared between the Marcellus and Onondaga horizons in the southeastern part of multiple inlines. This is interpreted as part of the lower Marcellus. The isochore map, extracted from the spectral blueing volume, more accurately shows the thickening from the west to the east of the Marcellus across the study area and the variable thickness over the study area. Local cross strike structural discontinuities are also enhanced through spectral blueing.

Lambda-rho/Mu-rho can be used to identify potential high producing zones based on brittleness and TOC richness indicated by the logs. This study also suggests that lambda-rho/murho zones associated with high producing zones are likely defined by a different range of values than those identified by Alzate (2012) for the Barnett Shale. The Young's modulus fell at a lower range and the Poisson's ratio occurred over a wider range than the Alzate (2012) cut-offs, so the parameters for the Marcellus Shale must be adjusted to a more ideal range. This is reflected in Table 3 in Chapter 4. Relocation of optimal area in the lambda-rho/mu-rho space were inferred from log-based brittleness and TOC calculation. New targets stratigraphically outside of the initial target zones were highlighted at the end of Chapter 4. The relationship of lambda-rho and mu-rho to brittle and TOC rich zones can be can be applied to other wells and help improve the ability to identify favorable zones to target within the Marcellus. The current study provides 
some insights, but was limited to analysis of two wells. Use of a fracability estimate, in addition to lambda-rho/mu-rho, can be especially useful to pick target intervals, since one may identify targets the other has not. Future work based on a larger number of wells may help further refinement and resolution of optimal zones for landing and fracking.

Intervals within the Middle and Lower Marcellus both have the most potential to be producible and profitable targets, based on their high TOC and favorable brittleness. These targets were highlighted based on analysis of the relationship of mechanical and petrophysical responses in the well logs. For example, the calcite and clay content (as illite) highlighted in Chapter 5 is related to the Marcellus stratigraphy, and the higher calcite might be key due to the increased fracability, which would be an indicator to optimal targets in the Marcellus. This is supported by a negative correlation of Young's modulus with higher clay content. "Clay rich samples display ductile behavior and clay deficient samples show more brittle behavior" (Kumar et al. 2012). The more brittle intervals correspond with an increase in Umaa and a decrease in RHOmaa (figures 6-1 and 6-2). This indicates the most brittle zones are those that are higher in calcite, such as the Middle and Lower Marcellus. The highest TOC falls where the RHOmaa and Umaa are diverging, further indicating the highest TOC zones are within the Middle and Lower Marcellus (Figure 6-2). The higher calcite content indicating more brittle zones, combined with the high TOC make the zones within the Middle and Lower Marcellus very favorable to target. The recommended new target regions, at the Armstrong \#1 well and Curtis well, are shown in figures 6-3 and 6-4.

Integration of the petrophysical and mechanical properties produces better results and more informative targeting. The combination of petrophysical and mechanical properties with the seismic data enhances our understanding of a target formation in relation to its depth, lateral 
extent, internal variations, overall structure, mineralogy, organic content, and ultimately its potential as a producing interval.

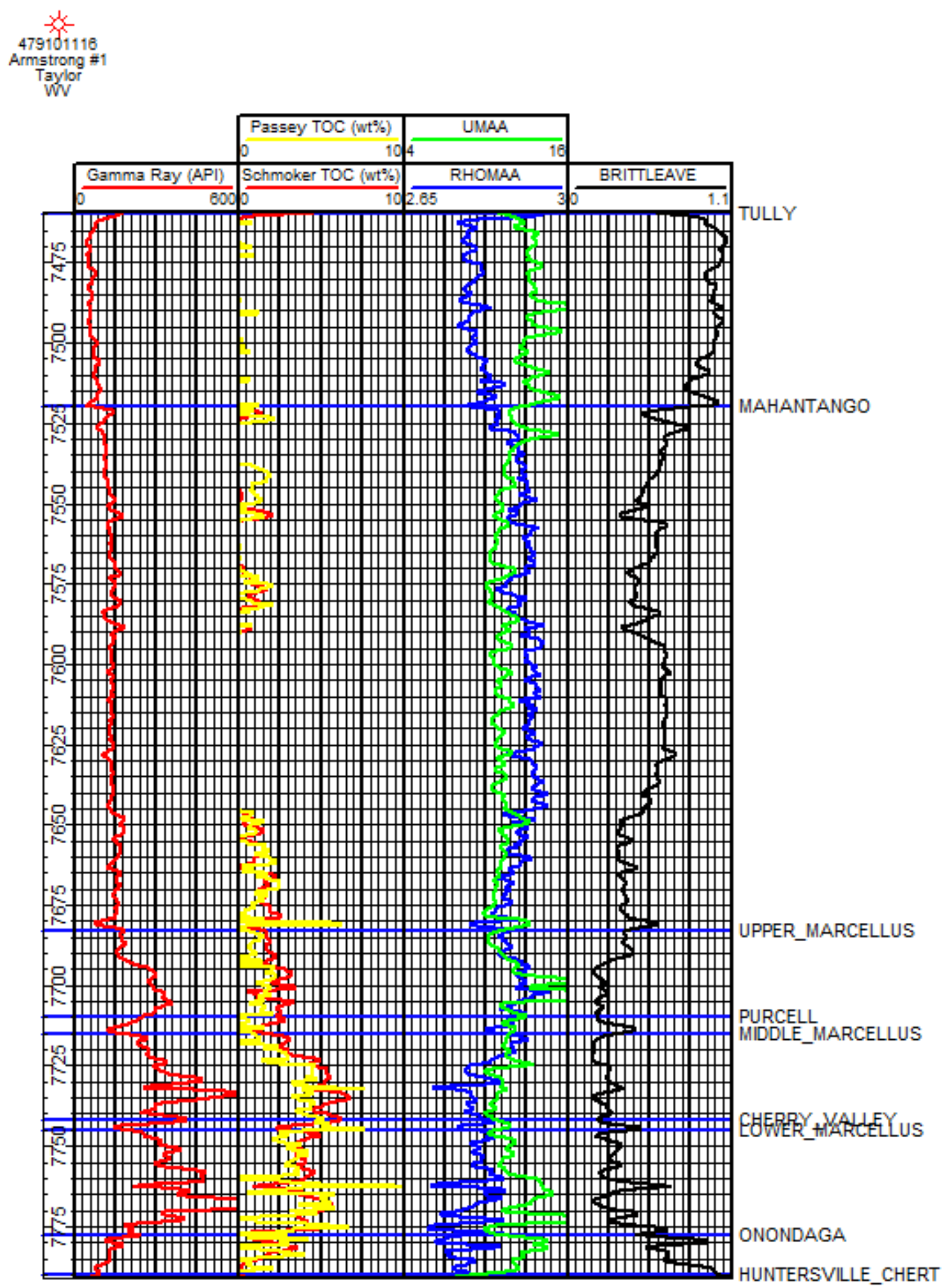

Figure 6-1. Tully through Huntersville Chert intervals showing how the TOC and brittleness change with RHOmaa and Umaa. 


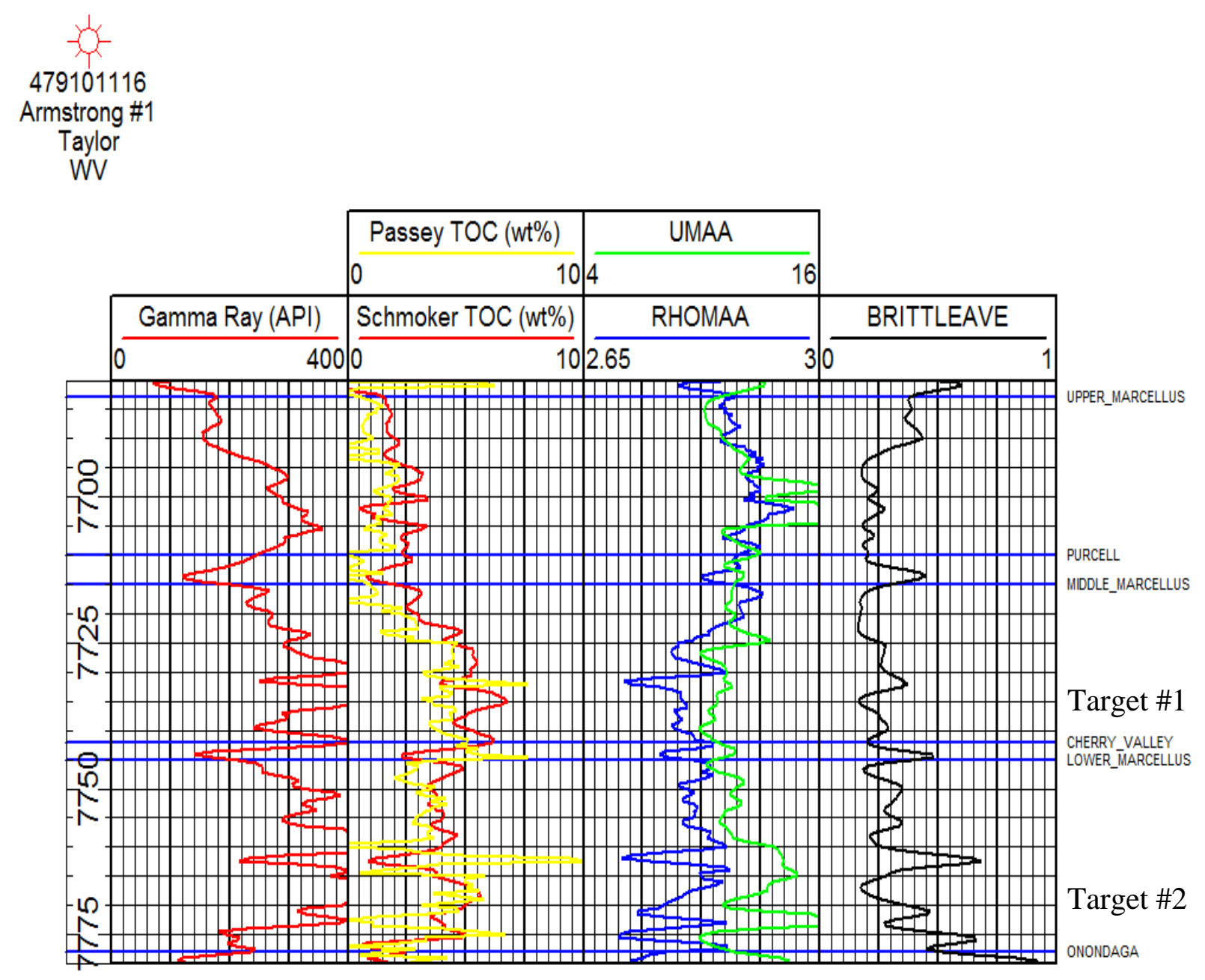

Figure 6-2. TOC comparison to RHOmaa/Umaa and brittleness at the Armstrong \#1 well. 


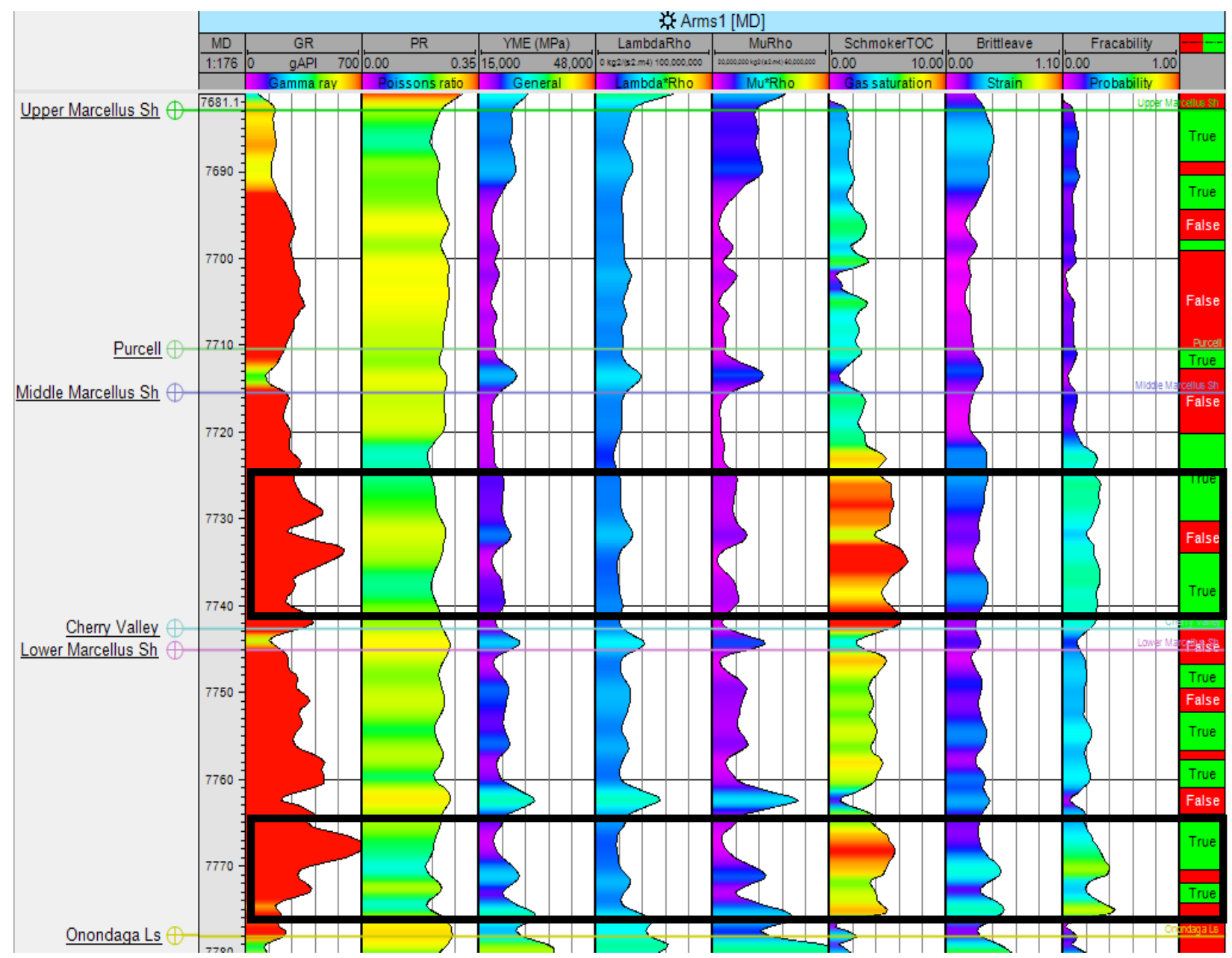

Figure 6-3. New target zones of the Armstrong \#1 well highlighted by the black boxes. 


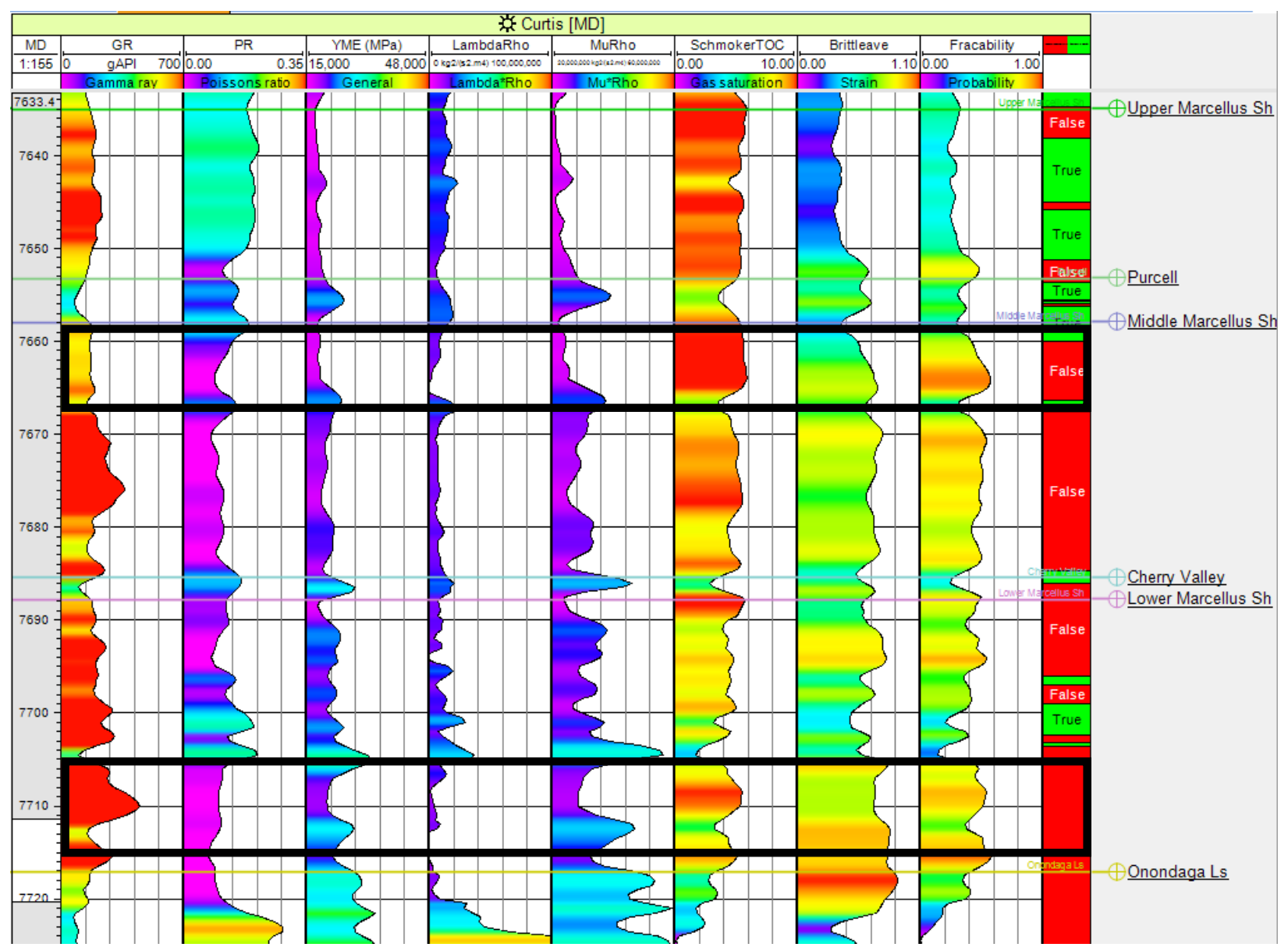

Figure 6-4. New target zones of the Curtis well highlighted by the black boxes. 


\section{Chapter 7}

\section{References}

Altamar, R. P. (2013). Brittleness Estimation from Seismic Measurements in Unconventional Reservoirs: Application to the Barnett Shale. Ph. D. Dissertation. University of Oklahoma: USA.

Altamar, R. P. and Marfurt K. (2014). Mineralogy-Based Brittleness Prediction from Surface Seismic Data: Application to the Barnett Shale. Interpretation 2(4), SQ1-SQ17 pp.

Alzate Buitrago, J. H. (2012). Integration of Surface Seismic, Microseismic, and Production Logs for Shale Gas Characterization: Methodology and Field Application. M. Sc. Thesis. University of Oklahoma: USA.

Alzate, J. H., and Devegowda, D (2013). Integration of surface seismic, microseismic, and production logs for shale gas characterization: Methodology and field application. Interpretation 1(2), SB37-SB49 pp.

Blache-Fraser, G. and Neep, J. (2004). Increasing Seismic Resolution Using Spectral Blueing and Colored Inversion: Cannonball Field, Trinidad. SEG Annual Meeting, 1794-1797 pp.

Boyce, M. L. (2010) Sub-Surface Stratigraphy and Petrophysical Analysis of the Middle Devonian Interval of the Central Appalachian Basin; West Virginia and Southwest Pennsylvania. Ph.D Dissertation. West Virginia University: USA.

Charsky, A. and Herron, S. (2013). Accurate, Direct Total Organic Carbon (TOC) Log from a New Advanced Geochemical Spectroscopy Tool: Comparison with Conventional Approaches for TOC Estimation. Search and Discovery Article \#41162.

Clark, W. B. (1918). The Geography of Maryland. Maryland Geological Survey. vol. 10. Baltimore: Johns Hopkins Press.

Doveton, J. H. (1994). Geological Log Interpretation: Reading the Rocks from Wireline Logs. SEPM Short Course Notes No. 29. 91-116 pp.

Engelder, T, Lash, G. G., Uzcategui, R. S. (2009). Joint sets that enhance production from Middle and Upper Devonian gas shales of the Appalachian Basin. AAPG Bulletin, 93(7), 857-889 pp.

Faill, R.T. (1997). A Geologic History of the North-Central Appalachians. Part 1. Orogenesis from the Mesoproterozoic through the Taconic Orogeny. American Journal of Science, 297, 551-619 pp.

Faill, R.T. (1997). A Geologic History of the North-Central Appalachians. Part 2. The Appalachian Basin from the Silurian through the Carboniferous. American Journal of Science, 297, 729-761 pp. 
Fox, A., et al. (2013). Geomechanical Principles for Unconventional Reservoirs. MicroSeismic Inc.

Grieser, B. and Bray, J. (2007). Identification of Production Potential in Unconventional Reservoir. SPE 106623 presented at the 2007 SPE Preduction and Operations Symposium.

Neal, D. W. (1979). Subsurface stratigraphy of the middle and upper Devonian clastic sequence in southern West Virginia and its relation to gas production. West Virginia Geological and Economic Survey.

Jarvie, D. M. (2003). Evaluation of unconventional natural gas prospects: The Barnett Shale fractured shale gas model: Presented at 21st International Meeting on Organic Geochemistry.

Kargbo, D. M., Wilhelm, R. G., \& Campbell, D. J. (2010). Natural gas plays in the Marcellus shale: Challenges and potential opportunities. Environmental Science \& Technology, 44(15), 5679-5684 pp.

Kumar, V. et al. (2012). Nano to Macro Mechanical Characterization of Shale. SPE Annual Technical Conference and Exhibition. Society of Petroleum Engineers.

Laubach, S. E. et al. (2009). Mechanical and Fracture Stratigraphy. AAPG Bulletin. The American Association of Petroleum Geologists, 93(11), 1413-1426 pp.

Passey, Q. R., et al. (1990). A Practical Model for Organic Richness from Porosity and Resistivity Logs. AAPG Bulletin, 74(12), 1777-1794 pp.

Rickman, R., et al (2008). "A Practical Use of Shale Petrophysics for Stimulation Design Optimization: All Shale Plays are not Clones of the Barnett Shale." SPE Annual Technical Conference and Exhibition. Society of Petroleum Engineers.

Soeder, D. J., and Kappel, W. M. (2009). Water resources and natural gas production from the Marcellus Shale. Reston, Virginia: US Department of the Interior, US Geological Survey.

Wang, G. (2012). Black Shale Lithofacies Prediction and Distribution Pattern Analysis of Middle Devonian Marcellus Shale in the Appalachian Basin, Northeastern U.S.A. Ph.D Dissertation. West Virginia University: USA.

Zhu, L. (2013). 3D Seismic Interpretation and Well Log Analysis of the Marcellus Shale of Appalachian Basin at Taylor County, West Virginia. M.Sc. Thesis. West Virginia University: USA. 